\title{
Age-related resistance to experimental autoimmune myasthenia gravis : immunological and neurobiological aspects
}

Citation for published version (APA):

Hoedemaekers, C. W. E. (1997). Age-related resistance to experimental autoimmune myasthenia gravis : immunological and neurobiological aspects. [Doctoral Thesis, Maastricht University]. Universiteit Maastricht. https://doi.org/10.26481/dis.19970926ch

Document status and date:

Published: 01/01/1997

DOI:

10.26481/dis.19970926ch

Document Version:

Publisher's PDF, also known as Version of record

Please check the document version of this publication:

- A submitted manuscript is the version of the article upon submission and before peer-review. There can be important differences between the submitted version and the official published version of record.

People interested in the research are advised to contact the author for the final version of the publication, or visit the DOI to the publisher's website.

- The final author version and the galley proof are versions of the publication after peer review.

- The final published version features the final layout of the paper including the volume, issue and page numbers.

Link to publication

\footnotetext{
General rights rights.

- You may freely distribute the URL identifying the publication in the public portal. please follow below link for the End User Agreement:

www.umlib.nl/taverne-license

Take down policy

If you believe that this document breaches copyright please contact us at:

repository@maastrichtuniversity.nl

providing details and we will investigate your claim.
}

Copyright and moral rights for the publications made accessible in the public portal are retained by the authors and/or other copyright owners and it is a condition of accessing publications that users recognise and abide by the legal requirements associated with these

- Users may download and print one copy of any publication from the public portal for the purpose of private study or research.

- You may not further distribute the material or use it for any profit-making activity or commercial gain

If the publication is distributed under the terms of Article $25 \mathrm{fa}$ of the Dutch Copyright Act, indicated by the "Taverne" license above, 
Age-related resistance to experimental autoimmune myasthenia gravis Immunological and neurobiological aspects 
The studies described in this thesis were financed by

Het Prinses Beatrix Fonds

l'Association Française contre les Myopathies

EC Bíomed (BMHI-CT93-1100)

Printed by

Unigraphic, Maastricht, The Netherlands

Illustration cover by

Willem Poos 


\section{Age-related resistance to experimental autoimmune myasthenia gravis}

Immunological and neurobiological aspects

\section{PROEFSCHRIFT}

ter verkrijging van de graad van doctor

aan de Universiteit Maastricht,

op gezag van de Rector Magnificus, Prof. Mr. M. J. Cohen,

volgens het besluit van het College van Decanen,

in het openbaar te verdedigen

op vrijdag 26 september 1997 om 16.00 uur

$$
\text { dloor }
$$

Cornelia Wilhelmina Elisabeth Hoedemaekers

geboren 20 februari 1968 te Maastricht 


\section{Promotor:}

Prof. Dr. P. J. C. var Breda Vriesman

\section{Ca-promotor:}

Dr. M. H. De Barts

\section{Beoordelingscommissie:}

Prof. Dr. I. Troost (woorziter)

Prof. Dr. J. W. Arends

Prof. Dr. W. van Eeden (Universiteit Urecht)

Prof. Dr. H. I. G. H. Oosterhuis (Riksuniversiteit Groningen) 
Par la persévérance dans la recherche, on finit par acquérir ce que j'appelle volontiers l'instinct de vérité

Louis Pastew

Voor mijn ouders 


\section{Contents}

List of abbreviations

Introduction

Chapter 1: Myasthenia gravis as a prototype autoimmune receptor disease

Chapter 2: Age- and sex-related resistance to experimental autoimmune myasth gravis (EAMG) in Brown Norway rats

Chapter 3: Macrophage infiltration at the neuromuscular junction does not cont to AChR loss and age-related resistance to EAMG

Chapter 4: Age-related susceptibility to experimental autoimmune myasthenia 1 immunological and electrophysiological aspects

Chapter 5: Role of the target organ in determining susceptibility to experimenta autoimmune myasthenia gravis

Summary and general discussion

Samenvatting en algemene discussie

Publications

Dankwoord

Curriculum Vitae 


\section{Abbreviations}

\begin{tabular}{|c|c|}
\hline$\alpha-B T$ & $\alpha$-Bungarotoxin \\
\hline $\mathrm{AChR}$ & Acetylcholine Receptor \\
\hline ARIA & Acetylcholine Receptor Inducing Activity \\
\hline $\mathrm{BN}$ & Brown Norway \\
\hline CFA & Complete Freund's Adjuvant \\
\hline CGRP & Calcitonin Gene Related Peptide \\
\hline $\mathrm{EAMG}$ & Experimental Autoimmune Myasthenia Gravis \\
\hline ELISA & Enzyme Linked Immuno Sorbent Assay \\
\hline HRP & Horse Radish Peroxidase \\
\hline IFA & Incomplete Freund's Adjurvant \\
\hline MAb & Monoclonal Antibody \\
\hline $\mathrm{MAC}$ & Membrane Attack Complex \\
\hline MIR & Main Immunogenic Region \\
\hline $\mathrm{MG}$ & Myasthenia Gravis \\
\hline $\mathrm{NMJ}$ & Neuromuscular Junction \\
\hline PBS & Phosphate Buffered Saline \\
\hline PCR & Polymerase Chain Reaction \\
\hline $\mathrm{rAChR}$ & Rat Acetylcholine Receptor \\
\hline RTA & Radio Immuno Assay \\
\hline $\mathbb{R T}$ & Reverse Transcription \\
\hline SFEMG & Single Fiber Electromyography \\
\hline tAChR & Torpedo Acetylcholine Receptor \\
\hline
\end{tabular}




\section{Introduction}

The immune system defends the body by recognizing, eliminating or destroying foreign antigens. At the same time, the immune system maintains a state of non-responsiveness against self-antigens. Tolerance for self is established by positive and negative selection in the thymus and by peripheral tolerizing mechanisms. When tolerance for self is lost, autoimmune disease develops. Severity and course of autoimmune diseases are influenced by several factors, including genetic predisposition, sex hormones, environment and age. Several immunological changes occur in senescence. $T$ cell and antibody responses to foreign and autoantigens decrease, whereas the spontaneous occurrence of $T$ cell autoreactivity and circulating autoantibodies increase with aging. This increased autoimmune reactivity, however, is rarely accompanied by overt disease.

Myasthenia gravis (MG) is an organ specific autoimmune disease in which autoantibodies against nicotinic acetylcholine receptors (AChR) at the postsynaptic membrane cause loss of functional $\mathrm{AChR}$ and disturbed neuromuscular transmission. Experimental autoimmune myasthenia gravis ( $E A M G$ ) is an animal model for the disease MG. It can be induced by active immunization with $\mathrm{AChR}$ or by passive transfer of anti-AChR antibodies. Similar to other autoimmune diseases, susceptibility to MG and EAMG are influenced by genetic factors, sex hormones and age. It has been shown previously that aged rats are resistant to induction of EAMG. Aim of the present study was to investigate the mechanisms underlying the resistance to $\mathrm{EAMG}$ in aged rats.

In Chapter 1 the current concepts of the structure and function of the $A C h \mathbb{R}$, and the immunopathological mechanisms in MG and its experimental model EAMG are reviewed. Resistance to EAMG may be caused by age-related defects in the immune attack towards the neuromuscular junction (NMJ) in aged rats. Possible differences in the immune attack were examined in Chapters 2,3 and 4. 
In Chapter 2 the influence of age and sex on the induction of chronic EAMG was analyzed. Possible differences in ant:-AChR antibody titers, isotype distribution, fine specificity or complement activation were investigated.

In young susceptible rats, induction of passive transfer EAMG resulted in macrophage infiltration at the NMT. Infiltrating macrophages were absent at the endplates of resistant aged rats. In Chapter 3 it was investigated whether age-related resistance to passive transfer EAMG was determined by the absence of infiltrating macrophages at the NMJs in aged rats. In addition the contribution of macrophages to induction of AChR loss in the effector phase of EAMG was examined. In Chapter 4 several factors were analyzed that may determine clinical severity of disease in EAMG. It was investigated whether differences in clinical severity of disease between young and aged rats of 2 different strains correlated with differences in AChR loss, anti-AChR antibody titers, or with the ability of anti-AChR antibodies to interfere with $A C h R$ function. Using single fiber electromyography (SFEMG) the influence of aging and EAMG induction on neuromuscular transmission properties in young and aged rats was studied.

Resistance to induction of EAMG in aged rats may not only be related to defects in the immune response towards the $\mathrm{AChR}$, but may be caused by the existence of more efficient AChR neosynthesis to compensate for AChR loss in aged rats. In susceptible rats AChR loss and subsequent neuromuscular transmission defects trigger a cascade of events, resulting in increased levels of mRNA coding for the different $A C h R$ subunits. In Chapter $\mathbf{5}$ possible differences in the AChR gene expression between young and aged rats were studied. Alternatively, the postsynaptic membrane in aged rats may be more resistant against antibodymediated AChR degradation compared to young rats. Therefore, the in vivo AChR degradation rates were measured in young and aged rats before and after induction of EAMG. Furthermore, possible differences in proteins known to be involved in anchoring of the $A C h R$ in the postsynaptic membrane were analyzed. 


\title{
Chapter 1
}

\section{Myasthenia gravis as a prototype autoimmune receptor disease}

\author{
A. Hoedemaekers, P. van Breda Vriesman and M. De Baets \\ Department of Immunology, Maastricht University, P.O. Box 616,6200 MD Maastricht, \\ The Netherlands
}

Published (in part) in Immunol. Res. (in press)

\section{Summary}

Myasthenia gravis (MG) is an autoimmune disease mediated by autoantibodies against nicotinic acetylcholine receptors (AChR) at the neuromuscular junction (NMJ). Binding of autoarntibodies to $\mathrm{AChR}$ in the postsynaptic membrane resulls in loss of functional $\mathrm{AChR}$. The pathogenic mechanisms responsible for loss of AChR include: crosslinking of AChR by antibodies, resulting in increased internalization; activation of the complement system resulting in focal lysis of the postsynaptic membrane; direct interference of a small subset of anti-AChR antibodies with binding of acetylcholine to the AChR or with ionchannel function. Experimental autoimmune myasthenia gravis (EAMG) is an animal model for the disease MG. It can be induced by active immunization with purified $A C h R$ or by passive transfer of anti AChR antibodies. Susceptibility to MG and EAMG is determined by several factors including genetic factors, sex hormones and age. In this chapter current concepts of the structure and function of the $A C h R$, and the irmmunopathological mechanisms in MG and EAMG are reviewed. 


\section{STRUCTURE AND FUNCTION OF THE NEUROMUSCULAR JUNCTION}

\section{Histology of the NMJ}

The NMJ plays a central role in the transmission of electrical impulses from nerve to muscle (rewiewed in (1) and (2)). Striated skeletal muscle is innervated by axons of motor neurons located in the ventral horn of the spinal cord or in motor nuclei of some of the cranial nerves. Intramuscular nerves branch into small fibers and lose their perineural and myelin sheaths near the endplates. Thereafter the preterminal nerve fibers divide into small branches to form the terminal spray.

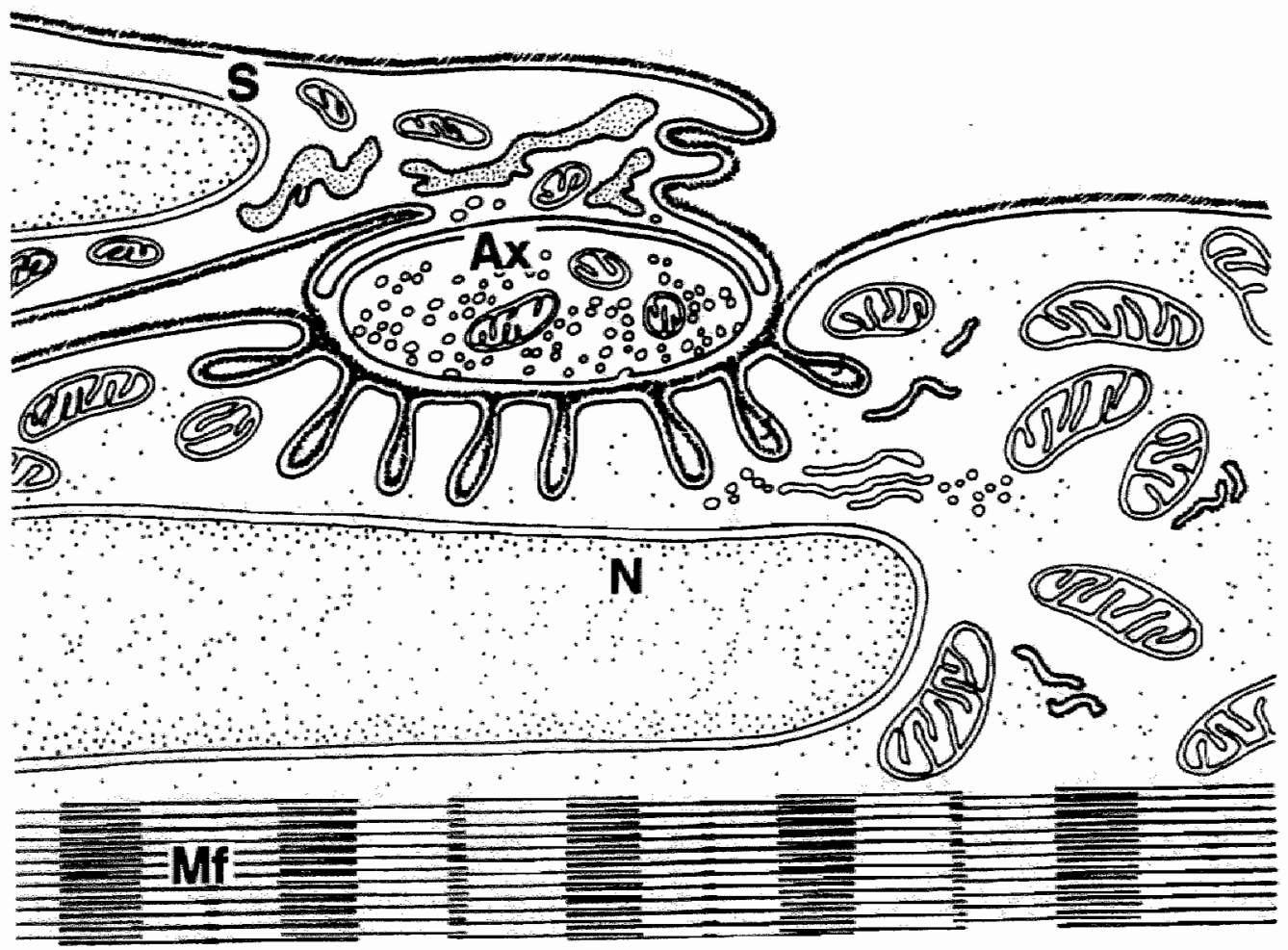

Schematic drawing of a NMJ. A Schwann cell (S) covers the axonal (Ax) ending. The Schwann cell basal lamina fuses with that of the muscle fiber and extents into the symaptic cleft and the junctional folds $(\mathfrak{D})$. Nuclei $(N)$, mitachondria, free ribosomes and rough endoplasmic reticulum are found in subsynaptic cytoplasm. Myofilaments (Mf) are indicated at the bottom of the drawing. (From: Cell and tissue biology. A textbook of histology. Ed. L. Weiss. 6th Edition 1988. Urban and Schwartzberg, Inc Baltimore, USA) 
The presynaptic axonal terminal is an oval shaped structure of $3-4 \mu \mathrm{m}^{2}$ containing numerous mitochondria, endoplasmic reticulum, neurofilaments, microtubili and synaptic vesicles that are filled with the neurotransmitter acetylcholine. These synaptic vesicles are clustered close to dense cytoplasmic bands, called active zones. The motor nerve endings also contain large dense-core vesicles that contain neuropeptides such as calcitonin gene-related peptide (CGRP). The mitochondria present in the presynaptic nerve terminal supply energy that is needed for exocytosis of the neurotransmitter acetylcholine. Released acetylcholine crosses the synaptic cleft and binds to receptors located on the top of the postsynaptic junctional folds, the AChR.

At the $\mathrm{NMJ}$ s axons contact and invaginate the muscle sarcolemma membrane. The surface area of the NMJ is further increased by formation of secondary junctional folds in the muscle sarcolemma. AChR are clustered at high density on the tops of these folds. In proximity of the NMJ, the axon is demyelinated and covered by a basal lamina, which extends into the synaptic cleft, separating the nerve fiber from the muscle fiber.

\section{Development of the NMJ}

Development of the NMJ is the result of a cross-talk between nerve and muscle. The NMJ starts to develop in humans between week 6-10 and in rats and mice between day 14-16 of embryonic life but maturation continues until after birth. The morphological differentiation of the presynaptic terminal depends on the presence of the postsynaptic muscle cell. In addition, the presynaptic axon exerts an influence on the postsynaptic membrane through the generation of electrical activity and the release of neurotrophic factors (reviewed in (3)).

As the axon approaches the developing myofibers, the sarcolemma at the postsynaptic side thickens. The axon terminals already contain some vesicles, however with no particular accumulation at points of neuromuscular contact. Postsynaptic molecules such as AChR, NCAM and N-cadherin start to concentrate at the site of contact. Subsequently, synaptic vesicles cluster at active zones, mitochondria appear and the junctional infoldings gradually develop. Between the developing pre-and post-synaptic site a basal lamina forms in the synaptic cleft. During further maturation, the synapse gradually enlarges and infoldings become deeper, 
thereby increasing the surface of the postsynaptic membrane (reviewed in (4)). Initially, endplate sites are innervated by multiple axons. During early postnatal life however, activity results in elimination from each NMJ of all but one axon (reviewed in (5)).

\section{Structure and function of the $\mathrm{AChR}$}

The AChR is the dominant component of the postsynaptic membrane. It is a transmembrane glycoprotein composed of 4 different subunits. In embryonic muscle, the $A C h R$ is composed of $\alpha-\beta-\gamma$, and $\delta$-subunits. In adult, innervated tissue, the $\gamma$-subunit is replaced by a homologous e-subunit to yield an $\alpha_{2} \beta \varepsilon \delta$ stochiometry (6)، Replacement of the $\gamma$-subunit by an $\varepsilon$-subunit is accompanied by a decrease in channel open time and longer half-life (7-11).

The different subunits form a pentameric structure around a central ionchannel (12). The AChR has a cylindrical shape and a length of about $120 \AA$, with about $65 \AA$ extending on the extracellular surface and about $15 \AA$ extending on the cytoplasmic surface. Each subunit has 4 (M1-M4) transmembrane segments (13). The first 3 transmembrane segments follow a large extracellular $\mathbb{N}$-terminal domain and are critical for the formation of the ionchanmel structure (14-16). These transmembrane segments are followed by a large cytoplasmic domain, a fourth transmembrane domain (M4) and a short extracellular C-terminal tail (17).

The genes coding for the AChR show extensive homology between the subunits and between species. The $\alpha$-subunit contains both the acetylcholine/ $\alpha$-Bungarotoxin $(\alpha-B T)$ binding site (residues $\alpha 185-196$ or $\alpha 181-200$ ) and the Main Immunogenic Region (MIR) (residues $\alpha 67$ 76) against which most of the autoantibodies in myasthenia gravis (MG) are directed (18-20). The $\alpha$-subunit of the AChR exists as two isoforms in Xenopus (21) and in humans (22). These isoforms are derived from alternate splicing of a P3A exon coding for 25 amino acids. Expression of the AChR as a P3A 4 homodimer in Xenopus oocytes results in changes in singlechannel conductances and does not form a functional AChR lonchannel (23). The P3A+ exon is not found in marmmals (22). The human $\beta$-subunit also consists as two isoforms (24), differing by 9 bases in their $5^{\prime}$ coding sequence, probably as a result of the use of different exon/intron splice sites in the $\beta$-subunit gene. 

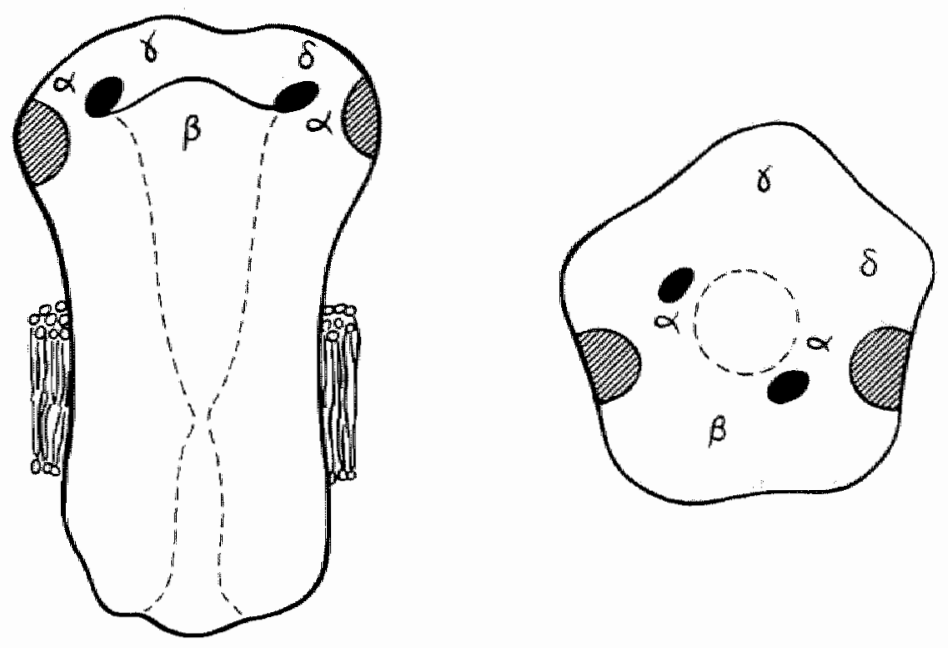

$\alpha$ - Bungarotoxin / ACh binding site

Main immunogenic region

Schematic model of the AChR showing the transmembrane nature of the receptor subunits and positionof the acetylcholine/ $\alpha-\mathrm{BT}$ binding site and the MIR. (From: The molecular pathology of autoimmune diseases. Eds C. Bona. K. Siminowitch, M. Zanetti and A. Theophilopolous. 1993, Harwood Academic Publishers GmbH, Chur, Switserland)

\section{Neuromuscular signal transmission}

Depolarization of the nerve ending by an action potential results in opening of voltagedependent $\mathrm{Ca}^{2+}$ channels. Influx of $\mathrm{Ca}^{2+}$ ions through the $\mathrm{Ca}^{2+}$ channels leads to exocytosis of acetylcholine from acetylcholine-containing vesicles into the synaptic cleft. Under normal circumstances more acetylcholine is released than is needed for neuromuscular transmission. This surplus of acetylcholine release is the safety margin of neuromuscular transmission.

Each AChR moleculle has 2 acetylcholine binding sites located on the $\alpha$-subunits. Binding of acetylcholine to both acetylcholine binding sites, results in opening of the AChR ionchannel. Subsequently ions (mostly $\mathrm{Na}^{+}$) enter and generate an endplate potential in the postsynaptic membrane, leading to contraction of the muscle. After contraction, the muscle rapidly relaxes as a result of inactivation of the $\mathrm{Na}^{+}$channels. Subsequently, $\mathrm{K}^{+}$channels open 
to restore the membrane potential. Any acetylcholine which has not bound to the AChR is rapidy hydrolized by acetylcholinesterase (AChE) present in the basal lamina in the synaptic cleft to terminate the signal transmission (reviewed in (1) and (2)).

\section{Anchoring of AChR in the postsynaptic membrane}

During development of the NMJ, AChR accumulate at the crests of the postsynaptic junctional folds at a density of approximately $10.000 / \mu \mathrm{m}^{2}$, whereas extrasynaptically the density of $\mathrm{AChR}$ decreases to less than $10 / \mu \mathrm{m}^{2}(25,26)$. Several proteins of the basal lamina and the postsynaptic cytoskeleton are involved in maintaining AChR at this high density at the symapse.

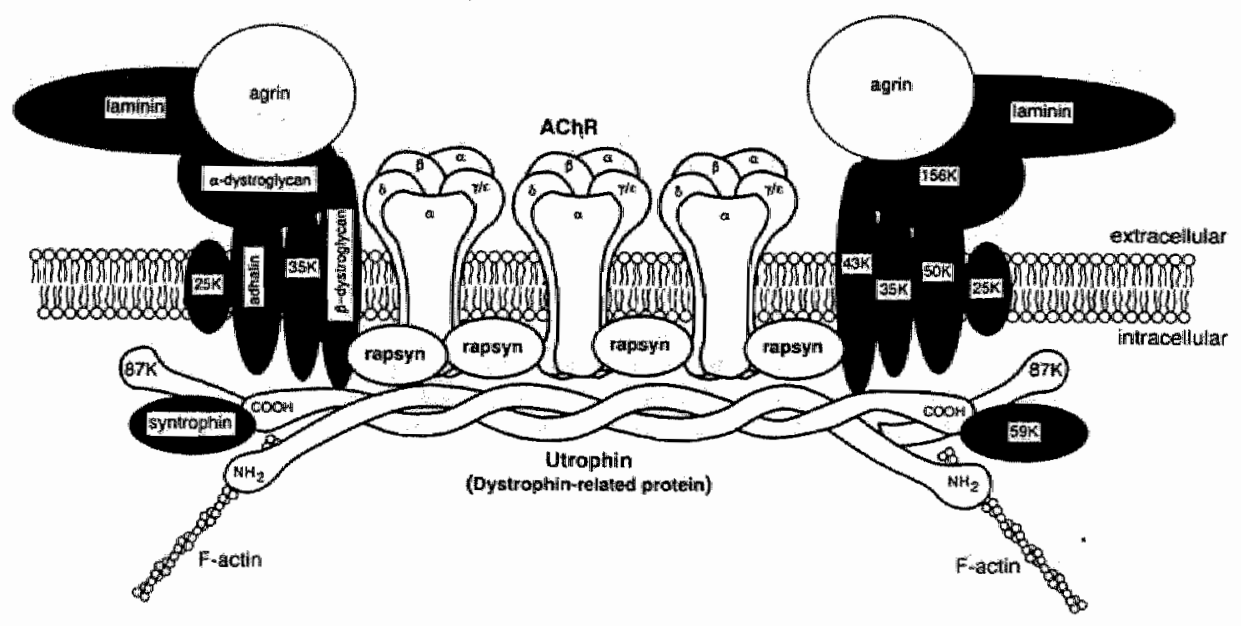

Molecular organization of $\mathrm{AChR}$ in the postsynaptic membrane. AChR are anchored in the postsynaptic membrane by a crossilinking network containing proteins of the basal lamina and the cytoskeleton. (From: E. Apel and J. Merlie. Assembly of the postsynaptic apparatus. Curr. Opin. Neurobiol. 1995, 5: 62-67)

The components of the synaptic basal lamina are synthetized by both the presynaptic nerve terminal and the postsynaptic myocyte, and are known to play an important role in AChR clustering. Synaptic and extrasynaptic basal lamina are ultrastructurally similar and have a comparable overall composition of proteins and carbohydrates. However, the synaptic basal lamina contains several synapse specific molecules (reviewed in (27)). Agrin is a basal laminaassociated protein able to induce $\mathrm{AChR}$ clustering in cultured myotubes $(28,29)$. Agrin is 
synthetized by both the motor neuron and the muscle cell; the motor neuron derived isoform, however, has the highest clustering capacity (30). Laminins are the major non-collagenous glycoproteins of most basal laminas throughout the body. S-laminin is synapse specific and has been shown to affect synapse formation in vitro (31). Furthermore, in s-laminin knockout mice the development of the NMJs is abnormal with protrusion of Schwann cell processes in the synaptic cleft and paucity of junctional infolds (32). The basal lamina also contains growth factors such as basic fibroblast growth factors (bFGF) and AChR inducing activity [ARIA (chicken)/neu differentiation factor (rat) /heregulin (human)] that are involved in AChR clustering $(29,33)$.

The postsynaptic cytoskeleton plays an important role in AChR anchoring by formation of a crosslinking network. A cytoskeletal protein of $43 \mathrm{kDa}$ (rapsyn/43K protein) and the $\mathrm{AChR}$ are present in approximately equimolar concentration in the postsynaptic membrane (34). It is in close association with the AChR $\beta$-subunit and prevents lateral and rotational mobility of the receptor in the postsynaptic membrane. Rapsyn is probably linked to the actin cytoskeleton through $58 \mathrm{~K}$ protein and $\beta$-spectrin. (35-38). Dystrophin-related protein (DRP)/utrophin is another protein that is highly concentrated at the endplates (39). It is also closely associated with the $\mathrm{AChR}$ in the postsynaptic membrane and clusters $\mathrm{AChR}$ by interaction with other proteins of the dystrophin family or $58 \mathrm{~K}$ protein. In addition, several other proteins have been identified that may play a role in the organization of the postsynaptic membrane (reviewed in (40)).

\section{Transcription and compartimentalization of the $\mathrm{AChR}$ genes}

Under the inffuence of the motor nerve, structure and function of the AChR show developmental changes. The switch from embryonic to adult type AChR is regulated by innervation. Furthermore, innervation controls the accumulation of the AChR at the synapse (reviewed in $(41,42)$ ). Initially, $\alpha-\beta-, \gamma$ and $\delta$ - subunit mRNAs are evenly distributed throughout the muscle fiber (43-45). Upon innervation of the myotubes, $\alpha-\beta-\gamma$ - and $\delta$ - subunit mRNAs become progressively restricted to subsynaptic nuclei. These nuclei are located under the postsynaptic membrane (fundamental nuclei) and morphologically distinguisable from other 
nuclei in the multinucleated muscle fibers by the hypertrophied nucleus. From the onset, the $\varepsilon-$ subunit gene is transcribed in subsynaptic nuclei only. The mRNA coding for the embryonic $\gamma$ subunit is not detectable in adult innervated muscle. This compartimentalized expression can, to some extend, be attributed to a restricted diffusion of mRNA as a general property of muscle fibers $(46,47)$. Moreover, the compartimentalized expression of AChR genes is under the control of both electrical activity and neurotrophic factors.

Electrical activity plays a central role in the repression of extrajunctional $A C h R$ expression during development and in the maintenance of this repressed state in adult muscle. At the synapse; the enhanced transcription of $A C h R$ genes in the subsynaptic nuclei is under the control of neural factors, such as CGRP (48) and ARIA (homologous to rat new-differentiation factor and human heregulin) (49). CGRP is stored in dense-core vesicles in the motor nerve endings and increases the synthesis of AChR in myotube cultures via CAMP as a second messenger (48). ARIA also increases AChR gene expression in myotube cultures and in vivo (50). It has been shown that ARIA increases the levels of AChR $\alpha$-subunit mRNA by phosphorylation of ErbB3 and ErbB2/neu. In adult rat muscle this ErbB3 expression is restricted to the endplate region, suggesting its involvement in the synapse-specific action of $\operatorname{ARIA~(51)}$

The regulation of $\mathrm{AChR}$ gene expression by electrical activity and neural factors is determined through DNA regulatory sequences in cis and by transacting nuclear factors that bind to them. In the promotor regions of the $\alpha-, \beta-, \gamma$ and $\delta$ - subunit genes of various species CANNTG consensus sequences ( $\mathrm{E}$-boxes) have been identified. It has been shown that these $\mathrm{E}$ boxes directly participate in the muscle-specific and electrical activity dependent regulation of AChR $\alpha$-subunit gene expression (52). These E-boxes are binding sites for myogenic factors of the MyoD family (53). The proteins of the MyoD family contain a conserved basic helix-loophelix (HLH) domain and a basic homology region (DNA binding region) (reviewed in (54)). Four members of this family are identified: MyoD, myogenin, myf5 and MRF4. Each of these factors is able to convert non-muscle cell types in to muscle cells. Experiments using knockout mice have demonstrated that MyoD and myf5 play a role in early myogenesis, while myogenin and MRF4 are important factors for the differentiation from myoblasts into muscle fibers (54- 
56). In addition to E-boxes, other DNA elements have been identified in both the $\varepsilon-s u b u n i t$ (Nbox) $(57,58)$ and $\delta$-subunit promotor (59) which determine synaptic expression.

\section{Aging and the NMJ}

Aging results in gradual changes in structure and function of the NMJ. On the presynaptic side, the number of preterminal axons entering an endplate and the length of the endplate increase (60). In addition, agglutination of synaptic vesicles is observed (61) and the synaptic vesicle density decreases (62). The shape of the nerve terminal becomes more irregular and Schwann cell processes sometimes intrude into the synaptic cleft (63). The width of the synaptic cleft tends to decrease with aging (64).

On the postsynaptic side, the size of the AChR conglomerates decreases and AChR are found in the extrajunctional areas of some aged human muscle fibers (60). This extrajunctional expression of $\mathrm{AChR}$ could be a result of less muscle activity in aged subjects. Furthermore, the postsynaptic membrane length enlarges, while the junctional folds degenerate. In addition, an age-related increase in the junctional size and the total number of AChR has been demonstrated in rats, with a plateau being reached between 150-200 days (65). Part of the changes observed with aging might be the result of a slow proces of denervation and subsequent reinnervation.

Skelletal muscle fibers are also known to change with increasing age. In mice, aging resulted in a reduction in muscular mass and muscle fiber size (66). Furthermore, the number of type II (fast) fibers decrease with a parallel increase in type I (slow) fibers. Concommittant with these morphological changes, the levels of the myogenic regulatory factors MyoD, myogenin. and myf5 were found to increase in aged mice, while the amount of MRF4 remained constant (66). The muscle-specific genes such as the AChR $\alpha$-subunit and muscle creatine kinase (MCK) were also upregulated with aging, although to a lesser extent. In contrast, in rats levels of MyoD and myogenin remained unchanged with aging as measured by northern blotting, whereas a decrease in the amount of MRF4 was detected in aged rats (Hoedemaekers et al, unpublished results). Changes in gene expression might act as compensatory mechanism in maintaining the muscle phenotype in old muscle. 


\section{MYASTHENIA GRAVIS}

\section{Historical introduction}

The first description of patients with MG-like symptoms was given in 1672 by Thomas Willis in his book "De Anima Brutorum" (reviewed in (67)). This English physician reported several patients which suffered from a fluctuating weakness which he called "paralytica spuria non habitualis". In 1868 the French clinician Hêrard in the Hôpital Lariboisière in Paris made a more convincing description of a patient with $\mathrm{MG}$ under the title "De la paralysie glossolabiolaryngée". The name myasthenia gravis pseudoparalytica was introduced a few years later by Jolliy (1895). He described electromyographic abnormalities during repetitive nerve stimulation and also suggested the use of the anticholinesterase drug physostigmine. Physostigmine and the less toxic prostigmin were first used in patients by the English physician Mary Walker in 1934. The fact that these anticholinesterase drugs (temporarily) releaved the symptoms strongly suggested that the defect in MG was located at the level of the NMJ. However, it was not clear yet whether the disturbance in neuromuscular transmission was located either synaptically or extrasynaptically. This was elucidated in the beginning of the 1970 s when it was shown that the postsynaptic membrane is destructed and the number of AChR is reduced in muscle biopsies of MG patients (68).

The autoimmune nature of the disease $\mathrm{MG}$ was first suggested by Simpson and Nastuk in 1960. Simpson noticed the frequent occurence of concomitant diseases with an autoimmune nature and also the high frequency of thymic abnormalities in MG patients (69). Nastuk first showed that seria of MG patients contain components that can damage nerve/muscle tissue (70). In addition it was shown that serum complement levels were lower during clinical excacerbations of the disease (71).

The first experimental evidence for the autoimmune nature of MG was fortuitously demonstrated by immunization of rabbits with AChR isolated from electric eel resulted in loss of AChR and muscular weakness that resembled human MG (72). The experimental model for $\mathrm{MG}$ has greatly contributed to the understanding of the pathogenetic mechanisms underlying the autoimmune disease $\mathrm{MG}$ (73). 
MG has been shown to fully fit the criteria for antibody mediated autoimmune diseases as they are proposed by Drachman (74). 1. In the majority of the MG patients circulating antibodies against $\mathrm{AChR}$ are detectable (75). 2. Anti-AChR antibody binding to the AChR in the postsynaptic membrane has been demonstrated in muscle biopsies (68). 3. Passive transfer of serum from MG patients into mice results in clinical symptoms in these animals that resemble human $M G$ (76). 4. Rabbits that are immunized with purified $A C h R$ develop muscular weakness and typical electromyographic decremental responses on repetitive nerve stimulation (72). 5. Reduction of anti-AChR antibody titers by plasmapheresis or immunosuppression results in clinical improvement (77-79).

\section{Clinical aspects}

The prevalence of MG in recent studies ranges between 60-70 per million with an annual incidence of 2.5-9.8 per million (80). The incidence of generalized MG is highest in women in the childbearing age, whereas ocular MG has a higher incidence in men over the age of 40 .

The symptoms in MG include muscular weakness and excessive fatigue. Muscular weakness is typically aggravated by exercise. At onset muscular weakness frequently begins in the ocular muscles, causing ptosis and diplopia. In approximately $15 \%$ of the MG patients muscular weakness remains restricted to ocular muscles (ocular MG). In the majority of the MG patients the disease becomes generalized; in addition to ocular muscles, bulbar, trunk and limb muscles are also affected, with the proximal muscle groups more affected than distal ones. When respiratory muscles are affected, a myasthenic crisis may develop that neccesitates artificial respiration. The clinical severity of MG is usually graded according to the revised Osserman classification: $(81,82)$. 


\begin{tabular}{|c|c|}
\hline SCORE & SYMPTOMS AND SIGNS \\
\hline I & Purely ocular \\
\hline IIA & Mild generalized (ocular and extremities, no prominent bulbar signs) \\
\hline $\mathrm{IIB}$ & $\begin{array}{l}\text { Moderate generalized (ocular and/or bulbar signs, variable limb muscle } \\
\text { involvement, no crisis) }\end{array}$ \\
\hline IIII & $\begin{array}{l}\text { Acute fulminating generalized signs with prominent bulbar involvement } \\
\text { and respiratory crisis }\end{array}$ \\
\hline IV & $\begin{array}{l}\text { Late severe generalized and prominent bulbar signs and respiratory } \\
\text { crisis }\end{array}$ \\
\hline
\end{tabular}

Only motor functions are impaired in MG; sensation, reflexes, coordination and other neural functions remain normal.

\section{Immunopathogenesis of MG}

The clinical signs and symptoms in $\mathrm{MG}$ result from loss of functional $\mathrm{AChR}$ which in turn leads to disturbed neuromuscular transmission. The main pathogenic mechanisms in MG are crosslinking of $\mathrm{AChR}$ by antibodies, leading to increased degradation rates, complement mediated focal lysis of the post-synaptic membrane, and interference by antibodies with ligand binding and ionchannel function. The loss of functional AChR in MG is entirely antibody mediated (reviewed in (83)). Anti-AChR antibodies are detectable in approximately 85-90\% of the MG patients. In ocular MG, anti-AChR antibody titers are lower compared to $\mathrm{MG}$ patients with generalized disease. Although anti-AChR antibody titers do not correlate with age, sex, steroid therapy or duration of symptoms (75), reduction of anti-AChR antibody titers in individual patients is accompanied by clinical improvement (77-79).

Using monoclonal anti-AChR antibodies with known specificity, it has been shown that the majority of the anti-AChR antibodies are directed against the MIR on the extracellular part of the AChR $\alpha$-subunit (84). This MIR however, does not seem to be one single epitope but rather a group of closely overlapping epitopes. Furthermore, no correlation between the titer of 
anti-MIR antibodies and clinical severity of disease was found (84). Besides the AChR $\alpha$ subunit, regions on the $\beta$ - and $\gamma$ subunit near the MIR were found to be highly immmnogenic, whereas antibodies directed against the acetylcholine binding site represented only a small proportion of the total anti-AChR antibody response. In addition to the heterogeneity in the antiAChR antibody fine specificity, the isotype distribution and heavy-and light-chain composition were also found to be heterogeneous among MG patients, and show no association with clinical severity of disease (85).

No anti-AChR antibodies are detectable in approximately $10-15 \%$ of the MG patients when measured by radioimmunoassay (using assays with a sensitivity $>2 \mathrm{nM}$ ). However, these patients have similar severity of muscular weakness compared to seropositive MG patients (86). Miniature end-plate potential (mepp) amplitudes and endplate ${ }^{125}$ I- $\alpha$-BT binding were significantly reduced in intercostal muscle biopsies from these seronegative $\mathrm{MG}$ patients. Furthermore, these patients respond well to immunosuppressive therapy. Passive transfer of seronegative immunoglobulin into mice resulted in defective neuromuscular transmission. However, the reduction in number of AChR was small and the immunoglobulin injected did not bind to AChR extracted from muscle (87). Altogether, these results suggest that seronegative MG may be caused by low affinity (IgM) anti-AChR antibodies, by antibodies against other membrane proteins in the synapse or by a non-immunoglobulin (immune related) factor (86).

In addition to anti-AChR antibodies, MG patients have circulating antibodies against other muscle components such as actin, myosin, $\alpha$-actinin and titin (88) Skeletal muscle antibodies are closely associated with the presence of thymomas in MG patients. When tested by immunofluorescence a cross-striational pattern is observed. These skeletal muscle antibodies may be a paraneoplastic phenomenon in $\mathrm{MG}$ patients with thymoma.

\section{$\mathrm{T}$ cell responses in $\mathrm{MG}$}

Although the effector phase in $\mathrm{MG}$ is entirely antibody mediated, the anti- $\mathrm{AChR}$ antibody production by $\mathrm{B}$ cells is $\mathrm{T}$ cell dependent. $\mathrm{CD} 4+\mathrm{T}$ cells in thymus and peripheral blood lymphocytes (PBL) from MG patients give help to MHC compatible B cells to enhance the anti-AChR antibody production. These $\mathrm{T}$ cells recognize efficiently both native and 
denatured $A C h R$ subunits and small peptides, whereas most $B$ cell epitopes are conformational dependent epitopes (89-91).

The majority of the $T$ cells are directed against the AChR $\alpha$-subunit, but there is a large heterogeneity in aritgenic sites on this subunit, with no single immunodominant epitope (92. 94). This strong heterogeneity may, to some extent, be the result of differences in MHC haplotypes, since CD4+ T cells recognize peptides only in the context of MHC class II molecules (reviewed in (95)). The proliferative response of PBL or thymus derived $\mathrm{T}$ cells to a panel of synthetic peptides show a strong correlation with the clinical severity of disease and the anti-AChR antibody titers (96). However, AChR specific T cells are also present in the thymus. and PBL from healthy controls, suggesting a peripheral immune regulatory system for maintaining a state of tolerance $(97,98)$. Analysis of the $T$ cel cytokine production showed that AChR stimulated iT cells produce IL-4, IFN $\gamma$ and $\mathrm{L}-2$, indicating that both Th1/Th2 or Tho subpopulations are involved in MG (99).

\section{Thymic abnormalities}

The (MG) thymus contains all the components necessary to induce an immune response towards the AChR: AChR specific $\mathrm{T}$ and $\mathrm{B}$ cells, antigen presenting cells and the antigen. Thymic abnormalities are found in approximately $75 \%$ of the $\mathrm{MG}$ patients. Thymic hyperplasia (lymphoid follicles in the medullary area) is found in $85 \%$ of these patients, especially under the age of 40 , whereas thymomas (lympho-epithelial tumors, composed of a varying proportion of neoplastic epithelium and non-neoplastic lymphocytes) are found in $15 \%$ of the patients, most frequently in the 5 th and 6 th decade $(100,101)$.

$\mathrm{T}$ cells from hyperplastic thymuses and thymomas give higher and more consistent responses to $A C h R$ than parallel cultures of autologous $\mathrm{PBL}$, suggesting a preferential localization of AChR-reactive $T$ cells in the thymus (102). Moreover, thymectomy results in a amelioration of muscular weakness and a progressive decrease in anti-AChR antibody titers (79).

In addition to autoreactive $T$ cells, the normal and $M G$ thymus also expresses autoantigen. The thymus contains myoid cells, which have the immunohistochemical features of 
striated muscle cells. Most of these cells can bind $\alpha-\mathrm{BT}$, and are stained with antibodies directed to the cytoplasmic site of the $A C h R$, but only a minority of these cells can bind antibodies directed to the MIR, indicating that they contain AChR-related determinants, but probably not complete AChR (103). Furthermore it has been shown that thymic epithelial cells express the adult type AChR mRNA and protein, while AChR protein expression is undetectable in thymocytes (104). However, no qualitative or quantitative differences in $\mathrm{AChR}$ expression between thymuses from healthy controls and MG patients were detectable, indicating that thymic expression of $A C h R / A C h R$-like epitopes alone is not sufficient to induce an autoimmune response towards the $A C h \mathbb{R}$.

\section{Destruction of the NMJ in MG}

The antibody mediated autoimmune attack in $\mathrm{MG}$ results in loss of $\mathrm{AChR}$ and focal destruction of the postsynaptic membrane. In muscle biopsies of MG patients a simplification of the postsynaptic membrane and widening of the synaptic space is observed by electron microscopy (105). The number of $A C h R$ per NMJ were found to be significantly lower in $\mathrm{MG}$ patients when compared to normal controls $(106,107)$.

Immunohistochemical analysis of the NMJs showed depositions of $\mathrm{IgG}$, complement components $\mathrm{C} 3$ and membrane attack complex (MAC) at the postsynaptic membrane and in debris in the synaptic space (108,109). Complement activation at the level of the endplate results in focal lysis of the postsynaptic membrane and in synthesis of pro-inflammatory mediators. Despite the presence of chemotactic factors, no cellular infiltrates are observed at the endplates in $M G$, indicating that inflammatory cells do not play a primary role in the pathogenesis of MG. Although mononuclear cells are detectable throughout the muscle in the majority of MG patients, only a small percentage of endplates are infiltrated by activated macrophages $(109,110)$.

Intercellular recording revealed diminished amplitudes of miniature endplate potentials and currents, indicating a disturbance in neuromuscular transmission (110). The reduction of the amplitude of the miniature endplate potentials is accompanied by an increase in acetylcholine quanta to compensate the disturbed neuromuscular transmission (111). 


\section{Diagnosis}

Clinical history and physical examination lead to the diagnosis MG. For the diagnosis MG the patient's symptoms and signs must be caused by muscle weakness and influenced by exertion and rest, and in the course of the disease at least one muscle group innervated by a cranial motor nerve should be involved (2). Additionall tests can be used to confirm the diagnosis.

The Tensilon test has a sensitivity and specificity of approximately 0.90-0.95. This anticholinesterase drug inhibits the enzyme cholinesterase, resulting in enhanced muscle strength in MG patients $(112,113)$.

The presence of anti-AChR antibodies is highly specific for $\mathrm{MG}$, however only $85 \%$ of the patients with generalized MG and approximately $50 \%$ of the patients with pure ocular MG have significant anti-AChR antibody titers $(75,114)$. MG patients with no detectable anti-AChR antibodies in the immunoprecipitation assay using embryonic type $\mathrm{AChR}$ may have antibodies specific for the adult type AChR (115). In addition, it has been shown that the sera of approximately $50 \%$ of the seronegative $\mathrm{MG}$ patients are able to inhibit the carbachol-induced $22 \mathrm{Na}+$ flux into the rhabomyosarcoma TE671 cell line expressing the human AChR $(86,116)$.

The antibody-mediated autoimmune attack in MG results in an insufficient neuromuscular transmission. A commonly used test for the diagnosis of $M G$ is the repetitive nerve stimulation test. Repetitive stimulation of the same muscle results in decrement of the muscle action potential in MG with more than 10\%. Single tiber electromyography (SFEMG) is a more sensitive electrophysiological test for $\mathrm{MG}(117,118)$. With this technique neuromuscular transmission disturbances can be detected before impulse blocking (before decrement and clinical symptoms) occurs (119,120). SFEMG recordings were abormal in $85 \%$ of patients with generalized MG and in $60 \%$ of the patients with ocular MG (120).

Of the prementioned tests, SFEMG is the most sensitive diagnostic test compared to anti-AChR antibody determination. Tensilon test and repetitive nerve stimulation, whereas anti-AChR antibody measurement is the most specific diagnostic test $(75,80,121)$ 


\section{Therapeutic strategies}

The therapeutic strategies in MG include improvement of neuromuscular transmission by anticholinesterase drugs, and reduction of the immune attack towards the NMJ by thymectomy, immunosuppressive drugs, plasmapheresis or intravenous administration of IgG.

The enzyme acetylcholinesterase (AChE) which is present in the basal lamina of the postsynaptic membrane quickly hydrolizes the acetylcholine that is released from the presynaptic membrane. Inhibition of AChE results in a longer action of acetylcholine and alleviates the muscular weakness in MG.

Corticosteroids are widely used as immunosuppressants in MG. Corticosteroids reduce the anti-AChR antibody levels and the reactivity of peripheral blood lymphocytes against $\mathrm{AChR}$ $(122,123)$. Furthermore, corticosteroids have been shown to induce $\mathrm{AChR}$ on cultured human myoblasts in vitro (124). Azathioprine or cyclosporin A when added to the immunosuppressive treatment have a steroid-sparing effect $(125,126)$. Analysis of large groups of patients shows that immunosuppressive treatment is effective $(127,128)$.

Thymectomy generally results in a strong and gradual decrease in anti- $\mathrm{AChR}$ antibodies concomitant with clinical improvement (79).

In cases of very severe MG, plasmapheresis or intravenous administration of IgG can be indicated. During plasmapheresis, circulating anti-AChR antibodies are removed, leading to a rapid decline in anti-AChR antibody titers and improvement of clinical symptoms within 24-72 hours $(129,130)$.

\section{MG in aged patients}

In MG the relative incidence shows a bimodal distribution, with a first peak between 20-29 years of age affecting mostly women, and a second peak between $70-79$ years of age with a male: female ratio varying from $1: 1$ to $3: 2(80,82,131,132)$. Based on these age-specific incidence rates, younger women are generally more susceptible than younger men, whereas similar rates are found in older men and post-menopousal women. This indicates that sex hormones may play an immunomodulatory role in $\mathrm{MG}$, similar to epidemiological evidence in other autoimmune diseases (reviewed in (133)). Few studies report on the course and severity of 
MG in the elderly. A retrospective study of 165 patients revealed significantly more often progression from ocular MG to severe disease in patients with late onset MG (age at onset $>50$ years) compared to early onset MG. However, this may have been related to the fact that fewer of the older patients underwent thymectomy (134). In MG patients the incidence of thymoma increased with aging $(134,135)$. Longitudinal analysis of MG patients in Denmark showed a decrease in the mean annual incidence rate of MG in individuals of 80 years and older and lower mortality rates in aged compared to young MG patients (131). Furthermore, low dose steroid therapy has been reported more effective in aged than in young MG patients $(136,137)$.

Analysis of a group of Dutch MG patients, without immunosuppressive therapy confirmed that the distribution of MG is age- and sex-related. Most patients were found in the female group between 20-60 years of age (Figure 1A/B), (Hoedemaekers and Kuks, unpublished data). Severity of disease at onset did not change significantly with aging in male nor female patients. The anti-AChR antibody titers were similar in young and aged male patients. In female patients, however, a change in anti-AChR antibody titers was found with aging, since very high anti-AChR antibody titers were only found in patients under 50 years of age (Figure $2 \mathrm{~A} / \mathrm{B}$ ). No correlation was found between severity of disease and anti- $\mathrm{AChR}$ antibody titers. However, these results should be interpreted with caution, since this group of MG patients was not selected randomly. Furthermore, severity of disease was only determined at the onset of disease and may have changed during course of the disease. However, very high anti-AChR antibody titers were predominantly found in female patients under the age of 50 years, suggesting an effect of aging on anti-AChR antibody titers. 


\section{Figure 1}

A

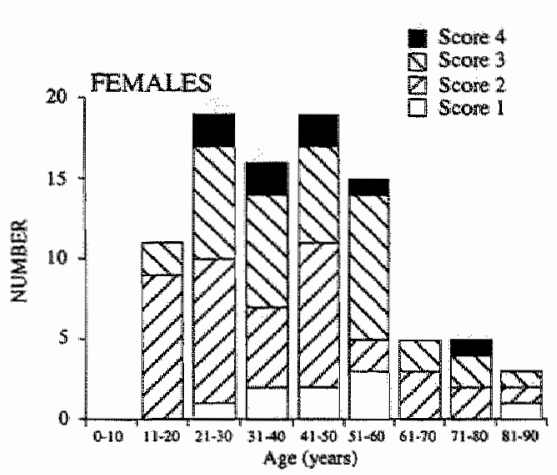

B

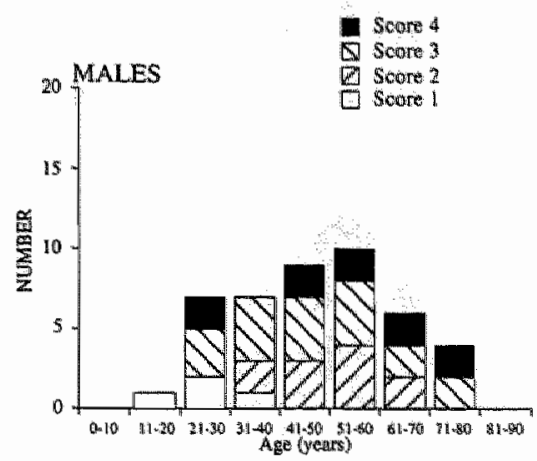

Age and severity of disease at onset of a group of Dutch MG patients. Severity of disease was classified on a scale ranging from 0 (no complaints, no signs after exertion or at special testing) to 5 (severe disability needing respiratory support) according to Oasterhuis (Oosterhuis $\mathrm{H}$, Myasthenia gravis, Churchill Livingstone, Edinburgh, 1984)

Figure 2

A

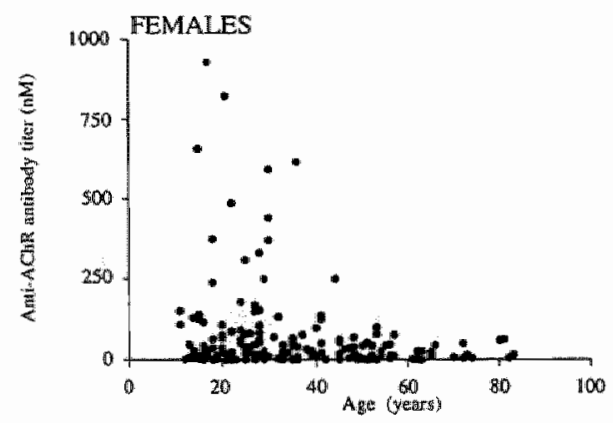

B

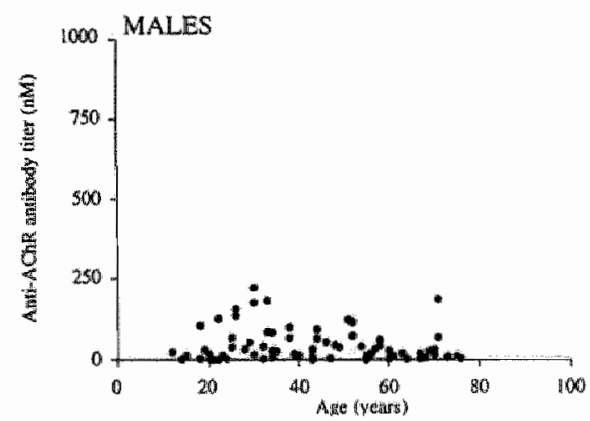

Correlation between age of the MG patients and anti-AChR titers at onset. Anti-AChR antibody titers are exprestged as nmoles/titer. 


\section{EXPERIMENTAL AUTOIMMUNE MYASTHENIA GRAVIS}

\section{Induction of EAMG}

In 1973 Patrick and Lindstrom observed that precipitating antibodies against the $\mathrm{AChr}$ coincided with flaccid paralysis in rabbits which had been immunized with purified AChR (72). Based on the observations in rabbits, a reproducible (chronic) model was developed in rats and guinea pigs that has many similarities to human MG (73). In 1975 Toyka was the first to inject serum from $M G$ patients into recipient mice. Such passive transfer of sera from $M G$ patients or from EAMG rats into mice and rats resulted in muscular weakness, electrophysiological abnormalities and reduced numbers of $\mathrm{AChR}$, thus indicating that the effector phase in $\mathrm{MG}$ and EAMG is entirely antibody mediated $(76,138)$. EAMG is a useful animal model for the disease MG; it is, however, a self-limiting disease with no associated thymic abnormalities and no spontaneous animal model exists except for sporadic cases in dogs and cats $(138,139)$.

\section{Induction of chronic EAMG}

Chronic EAMG can be induced by immunization with $\mathrm{AChR}$ from several animal species or from cell lines expressing AChR, emulsified in Complete Freund's Adjuvant (CFA) (140-142). Most commonly AChR is used purified from the electric organs of electric eel or ray (141). Clinical signs of disease develop 4-6 weeks after immunization and include muscular weakness, hunched back and tremor. As a result of swallowing disorders, malnutrition and dehydration animals loose weight. When Bordetella Pertussis is added in addition to CFA, the disease has a biphasic course with an acute transient phase 7-12 days after immunization, followed by a chronic phase 4-6 weeks after immunization (73).

Chronic EAMG can also be induced by immunization with individual subunits and synthetic peptides. Each of the individual subunits isolated from Torpedo AChR shows weak myasthenogenic activity when injected repeatedly in high doses in CFA (143). Repeated immunization of Lewis rats with a peptide corresponding to $\mathrm{AChR} \alpha$-subunit extracellular residues $125-147$ resulted in mild clinical and electrophysiological signs of disease. In addition, $T$ cell responses, antibodies reactive with native AChR (144), and morphological changes at the 
NMI were observed (145). Immunization with the Torpedo AChR $\alpha$-subunit 183-200 peptide resulted in the generation of blocking antibodies, interfering with binding of acetylcholine to the AChR (146). Immunization with recombinant human AChR $\alpha$-subunit 1-200 fusion protein resulted in severe EAMG with high anti-AChR antibody titers and approximately $50 \% \mathrm{AChR}$ loss (147). However, no EAMG developed in other experiments using synthetic peptides with overlapping sequences, most likely as a result of the fact that $T$ cells are able to recognize (denatured) epitopes different from the (conformational dependent) epitopes recognized by antibodies (reviewed in (18)).

EAMG-like features also develop in transgenic mice in which the IFN- $\gamma$ gene has been inserted in the $\mathrm{AChR} \varepsilon$-promotor, resulting in synaptic IFN- $\gamma$ expression at the postsynaptic membrane. Autoantibodies were detectable at the endplates, but no serum anti-AChR antibodies were found in these mice (148). The IFN- $\gamma$ induced autoimmune response in these transgenic mice is most likely directed against a non-AChR protein of $87 \mathrm{kDa}$.

\section{Induction of passive transfer EAMG}

Passive transfer of polyclonal or monoclonal anti-AChR antibodies results within 24-48 hours in muscular weakness and weight loss similar to that in the chronic EAMG model $(76,138,149,150)$.

Injection of monoclonal antibodies directed to the MIR has been shown very effective in inducing EAMG, whereas antibodies directed to the $\beta$-subunit or the cytoplasmic site of the AChR were ineffective (151). A chronic form of passive transfer EAMG can be induced by repeated injections with low dose monoclonal anti-AChR antibodies, resulting in chronic EAMG with extensive destruction of the postsynaptic membrane. However, no clinical or electrophysiological abnormalities develloped (152).

\section{Susceptibility for EAMG}

Several species, including rabbits, guinea pigs, monkeys, rats and mice have been shown to be susceptible for induction of chronic EAMG $(72,73,153,154)$. Within one species, susceptibilty for EAMG has been shown to vary between different strains. In rats, the Wistar 
Munich strain is highly susceptible, and the Wistar Furth strain highly resistant, while Lewis and Brown Norway strains are intermediate susceptible to induction of EAMG (155). Susceptibility for EAMG in inbred strains of mice and rats is primarily controlled by MHC class II genes (155-158). In addition, the presence of certain non-MHC class II genes, such as IgH, C5 and TCR genes may also influence the susceptibility for EAMG (reviewed in (159)).

Differences in susceptibility for EAMG may also be related to differences in the avallable antibody repertoire (160). Anti-mouse monoclonal antibody clones obtained from the highly susceptible C57bl/6 strain were more frequently directed against the MIR or $\alpha-B T$ binding site, whereas monoclonal antibodies obtained from $\mathrm{Balb} / \mathrm{c}$ mice with low susceptibility for EAMG were more frequently directed against non-pathogenic epitopes on the AChR (161). However, these differences were not reflected in the anti-AChR antibody specificities found in sera from susceptible C57bI/6 and resistant Balb/c mice.

Susceptibility for EAMG is also sex-related in BN and Lewis rats. Injection of anti-MIR monoclonal antibodies in young female rats resulted in severe muscular weakness and AChR loss, whereas no clinical signs of disease nor AChR loss was found in young male rats from the same strain (162). Immunohistochemical analysis of muscle biopsies from these rats showed depositions of MAC in both male and female rats. Infiltrating macrophages, however, were only found at the endplates of susceptible female rats, most likely secondary to tissue necrosis in these rats (Hoedemaekers et al, unpublished results, (163). Sex hormones have been shown to play an immunomodulatory tole in human disease and in several spontaneous and induced animal models (164-166). Treatment of female rats with the weakly virilizing anabolic steroid nandrolon in chronic EAMG resulted in protection from severe clinical symptoms and diminished AChR loss. However, in passive transfer EAMG a deleterious effect was seen, probably because of an increased complement synthesis (167).

\section{Pathogenic mechanisms}

In both $\mathrm{MG}$ and $\mathrm{EAMG}$ antibodies against $\mathrm{AChR}$ cause loss of $\mathrm{AChR}$. Anti-AChR antibodies cross-link $\mathrm{AChR}$, thereby increasing the $\mathrm{AChR}$ internalization rate, called antigenic modulation (168). The capacity of MG sera to induce antigenic modulation in vitro correlated 
with the anti-AChR antibody titers (169). Anti-AChR antibodies directed against the MIR are very efficient in inducing antigenic modulation $(169,170)$. The in vivo role of $\mathrm{AChR}$ crosslinking in inducing $A C h R$ loss, was determined by passive transfer of anti-MIR F(ab)2 and Fab fragments into rats (171). Compared to the intact anti-MIR monoclonal antibody anti-MIR F(ab)2 was less effective but still capable to induce EAMG, whereas anti-MIR Fab was totally ineffective.

Anti-AChR antibodies activate the complement system, resulting in focal lysis of the postsynaptic membrane and simplification of the postsynaptic folds (172). The relative contribution of complement in inducing AChR loss in vivo was determined in complement depleted rats and mice. Rats depleted from complement component C3 by cobra venom factor were found to be resistant to induction of passive transfer and the Bordetella Pertussis induced acute phase of chronic EAMG, despite the observation that $60 \%$ of the $\mathrm{AChR}$ in these rats were complexed with antibody (173). In vivo inhibition of MAC formation with a Fab antibody to complement component $\mathrm{C} 6$ also resulted in resistance against clinical signs of disease and $\mathrm{AChR}$ loss in passive transfer EAMG (174). C5 deficient B10.D2/OSN mice were resistant against induction of chronic EAMG, whereas the congenic B10.D2/nSN mice were susceptible (175). In contrast, it has been shown that induction of passive transfer EAMG in 4-6 week old decomplemented rats resulted in mild $A C h R$ loss (171). The contradiction in these experiments may have been related to differences in anti-AChR antibodies used to induce EAMG. These experiments indicate that although antigenic modulation alone is sufficient to induce AChR degradation in EAMG, activation of the complement system strongly enhances AChR loss.

The majority of the anti-AChR antibodies in EAMG is directed against the MIR on the $\alpha$-subunit of the AChR. A small subset of the anti-AChR antibody response in MG and EAMG is directed against the $\alpha-\mathrm{BT} /$ acetylcholine binding site on the $\mathrm{AChR} \alpha$-subunit or against epitopes on the $\mathrm{AChR}$ ionchannel $(161,176)$. These antibodies do not accelerate $\mathrm{AChR}$ degradation but are able to inhibit $\mathrm{AChR}$ function directly and are pathogenic in hatched chicken (177). Similarly, injection of $\alpha$-BT has been used to induce a pharmacological EAMGlike disease model with electrophysiological changes in neuromuscular transmission properties similar to those in MG and EAMG (178). The anti- $\alpha$-BT/acetylcholine binding site antibodies 
probably play an important role when the number of $\mathrm{AChR}$ is already reduced by antigenic modulation.

\section{T cell responses in EAMG}

The anti-AChR antibody production in chronic EAMG was found to be T-cell dependent $(89,179)$. Treatment with antibodies directed against CD4+ T cells resulted in suppression of EAMG in mice (180) In addition, MHC class II gene disrupted C57BL6 mutant mice which are CD4+ T cell deficient were resistant against induction of EAMG, while will-type C57BL6 mice were susceptible (181). CD8+ T cells are also involved in the pathogenesis of the disease. Depletion of CD8 + T cells suppressed EAMG in Lewis rats (182) and CD8-/- C57BL6 mutant mice were resistant against unduction of EAMG (183).

Analysis of the TCR VB usage by a panel of monoclonal antibodies has shown that the in wivo and in vitro $\mathrm{T}$ cell response to $\mathrm{AChR}$ in $\mathrm{EAMG}$ susceptible C57BL6 mice is restricted to few VB TCR, mostly belonging to the VB8 or VB6 subfamilies $(184,185)$. RNAse protection assays of $T$ cell lines demonstrated that the anti-AChR response in Lewis rats was dominated by TCR V $\beta 15$ (186).

\section{AChR gene expression in EAMG}

The $A C h R$ is the major target at which the immune response in $M G$ and EAMG is directed and can intluence both susceptibility and clinical course of disease. The involvement of AChR genes in determining susceptibility for MG was shown population study and familybased analysis. Using probes specific for 2 stable polymorphic nucleotide repeats in the $A C h R$ $\alpha$-subunit gene, it has been shown that certain AChR $\alpha$-subunit gene haplotypes are associated with a higher susceptibility for MG (187). Furthermore, a higher frequency of microsatellite variants was found in $\mathrm{MG}$ patients compared to controls.

AChR loss in EAMG resulted in increased expression of $A C h R \quad \alpha-\varepsilon$-, and $\delta$-subunit genes, accompanied by increased levels of MRF4, MyoD and myogenin mRNA (188-192). Other musle specific genes such as MCK, $\alpha$-actin or dystrophin were unaffected by EAMG induction (191). This increased expression of AChR genes is most likely the result of a 
disturbed neuromuscular transmission, since it is known that the expression of AChR subunit and MyoD family genes is controlled by electrical activity (reviewed in (42). In wivo AChR neosynthesis experiments in susceptible BN rats demonstrated that the increased AChR subunit mRNA synthesis also resulted in translation into $A C h R$ protein (Hoedemaekers et al, unpublished results).

$A C h R$-subunit mRNA concentrations were measured in muscle biopsies from $\mathrm{MG}$ patients by quantitative RT-PCR (193). In severely affected MG patients the amounts of AChR $\alpha$-subunit mRNA was increased, whereas no increase was found in moderately ill MG patients, independently of the anti-AChR antibody titers. This suggests that $A C h R$-subunit mRNA synthesis is only triggered above a certain degree of AChR loss.

\section{Experimental therapies in EAMG}

Optimal therapy in MG would be to specifically eliminate the autoimmune response against the $\mathrm{AChR}$, without otherwise affecting the immune system. Several therapeutic strategies have been designed based on knowlegde of the pathogenic mechanisms leading to AChR loss in MG. In this respect, EAMG is a good model to evaluate new therapeutic measures.

Inhibition of experimental autoimmune diseases by co-immunization with peptides unrelated to the autoantigen which bind to the same MHC molecule has been shown to be successful in several autoimmune animal models (194-196). Co-immunization of peptide OVA323-339 in EAMG susceptible Lewis rats resulted in complete disease inhibition (197). This suppression of the T cell response may result from a (partiall) MHC blockade, since peptide OVA323-339 is a strong RT1.BI binding competitor peptide. In addition, a shift from Th1 lowards a more Th2 dominated Ig isotype was found in the OVA323-339 co-immunized rats, indicating that the immune response was not only suppressed but also altered in these rats.

Oral or nasal administration of AChR in Lewis rats prior to immunization prevented clinical signs of disease and suppressed the AChR specific $B$ and $T$ cell mediated immune response (198). This form of mucosal tolerance was associated with down-regulation of $\mathrm{AChR}$. 
specific IFN- $\gamma$ expressing Thl-like cells and upregulation of TGF- $\beta$ mRNA in mononuclear cells.

Therapeutic manipulation of the idiotype anti-idiotype network has been tested in EAMG. Induction of passive transfer EAMG by a monoclonal antibody directed against the cholinergic binding site of the AChR was prevented by specific anti-idiotypic antibodies raised against this monoclonal antibody (199). Immunization of rats with a peptide complementary to the AChR MIR resulted in the production of anti-idiotypic antibodies which recognized antiMIR antibodies (200). This complementary peptide vaccination was able to block the development of EAMG in rats immunized with AChR. Neonatal administration of anti-idiotypic antibodies in EAMG however, did not result in protection against EAMG (201).

The majority of the anti-AChR antibodies in MG and EAMG is directed against the MIR. Inhibition of binding of these highly pathogenic antibodies by high affinity mutant Fab fragments has been shown to protect AChR against antigenic modulation $(202,203)$. Recent experiments have resulted in the production of anti-human $\mathrm{AChR}$ Fab clones isolated from MG phage display libraries. These Fabs were able to protect against AChR loss induced by antiAChR antibodies from MG patients and may be a potential immune-interventive tool for the treatment of MG patients during the acute phase of a MG crisis (204).

\section{Acknowledgements}

The authors wish to thank Dr. J. Kuks for providing us with clinical data from MG patients of the University Hospital Groningen, The Netherlands.

\section{References}

1 Slater C, Vincent A. Structure and development of the neuromuscular junction. In: Vincent A, Wray D eds. Neuromuscular transmission. Basic and applied aspects, Manchester: Manchester University Press, 1990.

2 Jennekens F, Veldman $H$, Wokke J. Histology and patbology of the human neuromuscular junction with a description of the clinical features of the myasthenic syndromes. In: De Baets M, Oosterhuis H eds. Myasthenia gravis, Boca RAton: CRC Press, 1993. 
3 Dennis M. Development of the neuromuscular junction: inductive interactions between cells. Ann Rev Neurosei 1981; 4:43-68.

4 Grinell A. Dynamics of nerve-muscle interaction in developing and mature neuromuscular junctions. Physiol Rev 1995; 75:789-834.

5 Colman $\mathrm{H}$, Lichtman J. Interactions between nerve and muscle: synapse elimination at the developing neuromuscular junction. Dev Biol 1993; 156:1-10.

Gu $Y$, Hall Z. Characterization of acetylcholine receptor subunits in developing and in denervated mammalian muscle. J Biol Chem 1988; 263:12878-12885.

7 Trautmann A. Curare can open and block ionic channels associated with cholinergic receptors. Nature 1982; 298:272-275.

8. Schuetze S. Embryonic and adult acetylcholine receptors: molecular basis of developmental changes in ion channnel properties. Trends Neurosci 1986; 9:386-388.

9 Mishina M, Takai T, Imoto K, et al. Molecular distinction between fetal and adult forms of muscle acety॥choline receptor. Nature 1986; 321:406-411.

10 Gu Y, Franco A, Gardner $P$, et al. Properties of embryonic and adult muscle acetylcholine receptors transiently expressed in COS cells. Neuron 1990; 5:147-157.

11 Hall Z, Gorin P, Silberstein L, et al. A postnatal change in the immunological properties of the acetylcholine receptor at rat muscle endplates. J Neurosci 1985; 5:730-734.

12 Strader C, Revel J-P , Raftery M. Demonstration of the transmembrane nature of the acetylcholine receptor by labeling with anti-receptor antibodies. J Cell Biol $1979 ; 83 ; 499$ 510.

13. Stroud R, McCarty M, Shuster M. Nicotinic acetylcholine receptor superfamily of ligandgated ion channels. Biochemistry 1990; $29: 11009-11023$.

14 Imoto K, Methfessel C, Sakmann B, et al. Location of a $\delta$-subunit region determining ion transport trough the acetylcholine receptor channel. Nature $1986 ; 324: 670-674$.

15 Imoto K, Busch $\mathrm{C}$, Sakmann $\mathbb{B}$, et al. Rings of negatively charged amino acids determine the acetylcholine receptor channel conductance. Nature $1988 ; 335: 645-648$.

16 Leonard R, Labarca C, Chamet $P$, et al. Evidence that the M2 membrane-spanning region lines the ion channel pore of the nicotinic receptor. Science $1988 ; 242: 1578-1581$.

17 Lindstrom J, Criado M, Hochschwender S, et al. Immunochemical tests of acetylcholine receptor subunit models. Nature 1984; 311:573-575.

18 Lindstrom J, Shelton D, Fujii Y. Myasthenia Gravis. Adv Immunol 1988; 42:233-284.

19 McLane K, Wu X, Diethelm B, et al. Structural determinants of $\alpha$-Bungarotoxin binding to the sequence segment 181-200 of the muscle nicotinic acetylcholine receptor $\alpha$ subunit: Effects of cysteine/cystine modification and species-specific amino acid substitutions. Biochem 1991; 30:4925-4934. 
20 Griesmann $\mathrm{G}_{t}$ MeCormick $\mathrm{D}$, De Aizpurua $H$, et al $\alpha$-Bungarotoxin binds to human acetylcholine receptor $\alpha$-subunit peptide $185-199$ in solution and solid phase but not to peptides 125-147 and 389-409. J Neurochem 1990; 54:1541-1547.

21 Hartman $D$, Claudio T. Coexpression of two distinct muscle acetylcholine receptor $\alpha$ subunits during development. Nature 1990; 343:372-375.

22 Beeson $D$, Morris $A$, Vincent $A$, et al. The human muscle nicotinic acetylcholine receptor a-subunit exists as two isoforms: a novel exon. EMBO J 1990; 9:2101-2106.

23 Newland C, Beeson D, Vincent $A$, et al. Functional and non-functional isoforms of the human muscle acetylcholine receptor. J Physiol 1995; 489:767-778.

24 Goldman D, Tamai K. Coordinate regulation of RNAs encoding two isoforms of the rat muscle nicotinic acetylcholine receptor $\beta$-subunit. Nucl Acids Res 1989; 17:3049-3056.

25 Diamond J, Miledi R. A study of fetal and new-born rat muscle fibres. J Physiol 1962; 162:393-408.

26 Fambrough D. Control of acetylcholine receptors in skeletal muscle Physiol Rev 1979; 59:165-227.

27 Sanes J. The synaptic cleft of the neuromuscular junction. Dev Biol 1995; 6:163-173.

28 Reist N, Werle M, McMahan U. Agrin released by motor neurons induces the aggregation of acetylcholine receptors at neuromuscular junctions. Neuron 1992;8:865-868.

29 Peng $H$, Baker $L$, Chen $Q$. Induction of synaptic development in cultured muscle cells by basic fibroblast growth factor. Neuron 1991; 6:237-246.

30 McMahan U. The agrin hypothesis. Cold Spring Harbor Symp Quant Biol 1990; 50:407418.

31 Porter B, Sanes J. Gated migration: neurons migrate on but not onto substrates containing. s-laminin. Dev Biol 1995; 167:609-616.

32 Noakes P, Gautam $\mathrm{M}_{v}$ Mudd J, et al. Aberrant differentiation of neuromuscular junctions in mice lacking $\$$-laminin/laminin $\beta 2$. Nature $1995 ; 374: 258-262$.

33 Jo $S$, Zhu X, Marchionni $M$, et al. Neuregulins are concentrated at nerve-muscle synapses and activate ACh-receptor gene expression. Nature $1995 ; 373: 158-161$.

34 LaRochelle W, Froehner $S$. Determination of the tissue distribution and relative concentrations of the postsynaptic $43-\mathrm{kDa}$ protein and the acetylcholine receptor in Torpedo. J Biol Chem 1986; 261:5270-5274.

35 Barrantes $F$, Neugebauer D-C, Zingsheim H. Peptide extraction by alkaline treatment is accompanied by rearrangement of the membrane-bound acetylcholine receptor from Torpedo Marmorata. FEBS Lett 1980; 112:73-78.

36 Bloch $\mathrm{R}$, Froehner $S$. The relationship of the postsynaptic $43 \mathrm{~K}$ protein to acetylcholime receptors in receptor clusters isolated from cultured rat myotubes. J Cell Biol 1987; 104:645-654. 
37 Cartaud J, Sobel A, Rousselet A, et al. Consequences of alkaline treatment for the ultrastructure of the acetylcholine-receptor-rich membranes from Torpedo marmorata electric organ. J Cell Biol 1981; 90:41.8-426.

38 Lo M, Garland $\mathrm{P}$, Lamprecht $\mathrm{J}$, et al. Rotational mobility of the membrane-bound acetylcholine receptor of Torpedo electric organ measured by phosphorescence depolarisation. FEBS Lett 1980; 111:407-412.

39 Ohlendieck K, Ervasti J, Matsumura K, et al. Dystrophin-related protein is localized to neuromuscular junctions of adult skeletal muscle. Neuron 1991; 7:499-508.

40 Froehner S. Regulation of ion channel distribution at synapses. Ann Rev Neurosci 1993; 16:347-368.

41 Changeux J-P. Compartimentalized transcription of acetylcholine receptor genes during motor endplate epigenesis. The new biologist 1991; 3:413-429.

42 Duclert A, Changeux J-P. Acetylcholine receptor gene expression at the developing neuromuscular junction. Physiol Rev 1995; 75:339-368.

43 Fontaine B, Sassoon D, Buckingham $\mathrm{M}$, et al. Detection of the nicotinic acetylcholine receptor $\alpha$-subunit mRNA by in situ hybridization at neuromuscular junctions of 15 -dayold chick straited muscles. EMBO J 1988; 7:603-609.

44 Fontaine B, Changeux J-P. Localization of nicotinic acetylcholine receptor $\alpha$-subunit transcripts during myogenesis and motor endplate development in the chick. J Cell Biol 1989; 108: 1025-1037.

45 Kues W, Sakmann B, Witzemann V. Differential expression patterns of five acetylcholine receptor subunit genes in rat muscle during development. Eur I Neurosci 1995; 7:13761385.

46 Pavlath $\mathrm{G}$, Rich $\mathrm{K}$, Webster $\mathrm{S}$, et al. Localization of muscle gene products in nuclear domains. Nature 1989; 337:570-573.

47 Ralston $\mathbb{E}_{\text {; }}$ Hall $Z$. Transfer of a protein encoded by a single nucleus to nearby nuclei in multinucleated myotubes. Science 1989; 244:1066-1069.

48 Fontaine B, Klarsfeld A, Hokfelt T, et al. Calcitonin gene-related peptide, a peptide present in spinal cord motoneurons, increases the number of acetylcholine receptors in primary cultures of chick embryo myotubes. Neurosci Lett 1986; 71:59-65.

49 Usdin T , Fischbach $\mathrm{G}$. Purification and characterization of a polypeptide from chick brain that promotes the accumulation of acetylcholine receptors in chick myotubes. J Cell Biol 1986; 103:493-507.

50 Sandrock A, Dryer $\mathrm{S}$, Rosen $\mathrm{K}$, et al. Maintenance of acetylcholine receptor number by neuregulins at the neuromuscular junction in vivo. Science 1997; 276:599-603.

51 Altiok N, Besserean J-L, Changeux J-P. ErbB3 and ErbB2/neu mediate the effect of beregulin on acetylcholine receptor gene expression in muscle: differential expression at the endplate. EMBO J 1995; 14:4258-4266. 
52 Bessereau J-L, Stratford-Perricaudet $L$, Piette J, et al. In vivo and in vitro analysis of electricall activity-dependent expression of muscle acetylcholine recptor genes using adenovirus. Proc Natl Acad Sci 1994; 91:1304-1308.

53. Piette J, Bessereau J-L, Huchet $M$, et al. Two adjacent MyoD1-binding sites regulate expression of the acetylcholine receptor $\alpha$-subunit gene. Nature 1990; 345:353-355.

54 Weintraub $\mathrm{H}$. The MyoD family and myogenesis: redundancy, networks and thresholds. Cell 1993; 75:1241-1244.

55 Buckingham M. Molecular biology of muscle development. Cell 1994; 78:15-21.

56 Venuti J, Morris J, Vivian J, et al. Myogenin is required for late but not early aspects of myogenesis during mouse development. J Cell Biol 1995; 128:563-567.

57 Duclert A. Savatier N, Changeux J-P. An 83-nucleotide promotor of the acetylcholine $\varepsilon$ subunit gene confers preferential synaptic expression in mouse muscle. Proc Natl Acad Sci 1993: 90:3043-3047.

58. Duclert A, Savatier $\mathbb{N}$, Schaeffer L, et al. Identification of an element crucial for the subsynaptic expression of the acetylcholine receptor E-subunit gene. J Biol Chem 1996; 271: 17433-17438.

59 Koike S, Schaeffer I, Changeux I-P. Identification of a DNA element determining synaptic expression of the mouse acetylcholine receptor $\delta$-subunit gene. Proc Natl Acad Sci 1995; 92:10624-10628.

60 Oda K. Age changes of motor innervation and acetylcholine receptor distribution on human skeletal muscle fibers. J Neurol Sci 1984; 66:327-338.

61 Gutmann E, Hanzlikova V, Vyskacil F. Age changes in cross striated muscle of the rat. J Physiol 1971; 219:331-343.

62 Smith $\mathrm{D}$, Rosenheimer J. Decreased sprouting and degeneration of nerve terminals of active muscles in aged rats. I Neurophysiol 1982; $48: 100-109$.

63 Wokke J, Jennekens F, van den Oord C, et al. Morphological changes in the human end plate with age. I Neurol Sci 1990; 95:291-310.

64 Kriebel M, Hanna R, Muniak C. Synaptic vesicle diameters and synaptic cleft widths at the mouse diaphragm in neonates and adults. Dev Brain Res $1986 ; 27: 19-29$.

65 Steinbach J. Developmental changes in acetylcholine receptor aggregates at rat skeletal neuromuscular junctions. Dev Biol 1981; 84:267-276.

66 Musaro A, Cusella De Angelis M, Germani A, et al. Enhanced expression of myogenic regulatory genes in aging skeletal muscle. Exp Cell Res 1995; 221:241-248.

67 Oosterhuis $H$. Historical introduction. In: De Baets $M$, Oosterhuis $H$ eds. Myasthenia Gravis, Boca Raton: CRC Press, 1993.

68 Engel A, Santa T. Histometric analysis of the ultra structure of the neuromuscular junction in myasthenia gravis and in the myasthenic syndrome. Ann NY Acad Sci 1971; 183:4663. 
69

70

71

72

\section{3} myasthenia gravis in rats and guinea pigs. J exp med 1975; 141:1365-1375.

Waksman B eds. Immunologic mechanisms in neurologic and psychiatric disease, New York: Raven Press, 1990:

75 Lindstrom I, Seybold M, Lennon V, et al. Antibody to acetylcholine receptor in myasthenia gravis. Prevalence, clinical correlates and diagnostic value. Neurology 1976; 26:1054-1059.

76 Toyka K, Drachman D, Pestronk A, et al. Myasthenia Gravis: passive transfer from man to mouse. Science 1975; 190:397-399.

77 Dau P. Response to plasmapheresis and immunosuppressive drug therapy in sixty myasthenia gravis patients. Ann NY Acad Sci 1981; 377:700-70.

78 Newsom-Davis $\mathbf{J}$, Vincent A, Wilson $\mathrm{S}$, et al. Long-term effects of repeated plasma exchange in myasthenia gravis. Lancet $1979 ; \mathbf{i}: 464-468$.

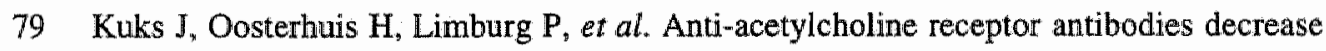
after thymectomy in patients with myasthenia gravis. Clinical correlations. I Autoimmun $1991 ; 4: 197-211$.

80 Oosterhuis H. Clinical aspects. In: De Baets M, Oosterhuis H eds. Myasthenia Gravis, Boca Raton: CRC Press, 1993.

81 Osserman K, Genkins G. Studies in myasthenia gravis: Review of a twenty-year experience in over 1200 patients. Mt Sinai J Med 1971; 38:497-537.

82 Oosterhuis. H. Studies in myasthenia grawis. Part I. A clinical study of 180 patients. I Neurol Sci $1964 ; 1: 512-546$.

83 Drachman B. Myasthenia gravis. N Engl J Med 1994; 330:1797-1810.

84 Tzartos S, Seybold M, Lindstrom J. Specificities of antibodies to acetylcholine receptors in sera from myasthenia gravis patients measured by monoclonal antibodies. Proc Natl Acad Sci 1982; 79:188-192.

85 Vincent A, Whiting $\mathrm{P}$, Schluep $\mathrm{M}$, et al. Antibody heterogeneity and specificity in myasthenia gravis. Ann NY Acad Sci 1987; 505:106-120. 
86 Vincent A, Li Z, Hart A, et al. Seronegative myasthenia gravis. Evidence for plasma factor(s) interfering with acetylcholine receptor function. Ann NY Acad Sci 1993; 681:529-538.

87 Mossman S, Vincent A, Newsom-Davis J. Myasthenia gravis without acetylcholinereceptor antibody: a distinct disease entity Lancet 1986, 116-118.

88. Mygland A, Tysnes O-B, Aarli J, et al. Myasthenia gravis patients with thymoma have antibodies against a high molecular weight protein in sarcoplasmic reticulum. I Neuroimunuol 1992; $37: 1-7$.

89 De Baets M, Einarson B, Lindstrom J, et al. Lymphocyte activation in experimental autoimmune myasthenia gravis. I Immunol 1982; 128:2228-2235.

90 Fujii $Y$, Lindstrom $\mathrm{J}$. Specificity of the $\mathrm{T}$ cell immune response to acetylcholine receptor in experimental autoimmune myasthenia gravis: Response to subunits and synthetic peptides. J Immunol $1988 ; 140: 1830-1837$.

91 Hohlfeld $\mathrm{R}$, Toyka $\mathrm{K}$, Tzartos $\mathrm{S}$, et al. Human $\mathrm{T}$-helper lymphocytes in myasthenia gravis recognize the nicotinic receptor $\alpha$ subunit. Proc Natl Acad Sci 1987; 84:5379-5383.

92 Newsom-Davis $J$, Harcourt $G_{\text {, Sommer }} \mathrm{N}$, et al. T-cell reactivity in myasthenia gravis. J Autoimmunity 1989; 2 (supplement):101-108.

93 Zhang $Y$, Schluep M, Frutiger S, et al. Immunological heterogeneity of autoreactive $T$ lymphocytes against the nicotinic acetylcholine receptor in myasthenic patients. Eur $J$ Immunol 1990; 20:2577-2583.

94 Conti-Tronconi M, McLane K, Raftery M, et al. The nicotinic acetycholine receptor: structure and autoimmune pathology. Crit Revs Biochem Mol Biol 1994; 29:69-123.

95 Manfredi A, Pia Protti M, Bellone M, et al. Molecular anatomy of an autoantigen: $T$ and $B$ epitopes on the nicotinic acetylcholine receptor in myasthenia gravis. J Lab Clin Med 1992; 120:13-21.

96 Berrib-Aknin $\mathrm{S}$, Cohen-Kaminsky $\mathrm{S}$, Lepage $\mathrm{V}$, et al. $\mathrm{T}$-cell antigenic sites involved in myasthenia gravis: correlations with antibody titre and disease severity. J Autoimmun $1991 ; 4: 137-153$.

97 Link $\mathrm{H}$, Olsson 0 , Sun $\mathrm{J}$, et al. Acetylcholine receptor-reactive $\mathrm{T}$ and $\mathrm{B}$ cells in myasthenia gravis and controls. J Clin Invest 1991; 87:2191-2196.

98 Melms A, Malcherek $G$, Gern U, et al. $T$ cells from normal and myasthenic indivuals recognize the human acetylcholine receptor: heterogeneity of antigenic sites on the $\alpha$ subunit. Ann Neurol 1992; 31:311-318.

99 Link J, Soderstrom $M$, Ljungdahl $A_{\text {, }}$ et al. Organ-specific autoantigens induce interferon- $\gamma$ and interleukin-4 mRNA expression in mononuclear cells in multiple sclerosis and myasthenia gravis. Neurology 1994; 44:728-734.

100 Oosterhuis H. Myasthenia gravis. A survey. Clin Neurol Neurosurg 1981; 83:105-135. 
101 Kirchner T, Schalke B, Melms A, et al. Immunological patterns of non-neoplastic changes in the thymus in myasthenia gravis. Virchows Arch B 1986; 52:237-257.

102 Sommer $\mathrm{N}_{\text {, Willcox }} \mathrm{N}$, Harrcourt $\mathrm{G}$, et al. Myasthenic thymus and thymoma are selectively enriched in acetylcholine receptor-reactive T cells. Ann Neurol 1990; 28:312 319.

103 Kirchner T, Tzartos S, Hoppe F, et al. Pathogenesis of myasthenia gravis. Acetylcholine receptor-related antigenic determinants in tumor-free thymuses and thymic epithelial tumors. Am J Pathol 1988; 130:268-280.

104 Wakkach A, Guyon T, Bruand C, et al. Expression of acetylcholine receptor genes in human thymic epithelial cells. Implications for myasthenia gravis. J Immunol 1996; 157:3752-3760.

105 Engel $A$, Tsujihata $M$. The motor end plate in myasthenia gravis and in experimental autoimmune myasthenia gravis. A quantitative ultrastructural study. Ann NY Acad Sci $1976 ; 274: 60-79$.

106 Engel A, Lindstrom J, Lambert $\mathrm{E}$, et al. Ultrastructural hocalization of the acetylcholine receptor in myasthenia gravis and in its experimental autoimmune model. Neurology $1977 ; 27: 307-315$.

107 Pestronk A. Drachman D, Self S. Measurement of junctional acetylcholine receptors in myasthenia gravis: clinical correlates. Muscle Nerve 1985; 8:245-251.

108 Engel A, Sahashi K, Fumagalli G. The immunopathology of acquired myasthenia gravis. Ann NY Acad Sci 1981; 377:158-174.

109 Nakano S, Engel A. Myasthenia Gravis: Quantitative immunocytochemical analysis of inflammatory cells and detection of complement membrane attack complex at the endplate in 30 patients. Neurology $1993 ; 43: 1167-1172$.

110 Maselli $\mathbb{R}$, Richman $\mathrm{D}$, Wollmann $\mathrm{R}$. Inflammation at the neuromuscular junction in myasthenia gravis. Neurology 1991; 41:1497-1504.

111 Plomp J, Kempen van G, Molenaar P. Adaptation of quantal content to decreased postsynaptic sensitivity at single endplates in $\alpha$-bungarotoxin treated rats. J Physiol 1992; 458:487-499.

112 Seybold M. The office tensilon test for ocular myasthenia gravis. Arch Neurol 1986; 43:842-843.

113 Daroff $\mathrm{R}$. The office tensilon test for ocular myasthenia gravis. Arch Neurol 1986; 43:843-844.

114 Lindstrom J. An assay for antibodies to human acetylcholine receptor in serum from patients with myasthenia gravis. Clin Immunol Immunopathol 1977; 7:36-43.

115 Beeson D, Amar M, Bermudez I, et al. Stable functional expression of the adult subtype of human muscle acetylcholine receptor following transfection of the human 
thabdomyosarcoma cell line TE 671 with cDNA encoding the E-subunit. Neurosci Lett $1996: 207: 57-60$.

116 Yamamoto $\mathrm{T}$, Vincent $\mathrm{A}_{,}$Ciulla $\mathrm{T}$, et al. Seronegative myasthenia gravis: a plasma factor inhibiting agonist-induced acetylcholine receptor function copurifies with IgM. Ann Neurol 1991; 30:550-557.

117 Stalberg E, Ekstedt J, Broman A. Neuromuscular transmission in myasthenia gravis studied with single fiber electromyography. J Neurol Neurosurg Psychiat 1974; 37:540547.

118 Elmqvist $D$, Hofman W, Kugelberg J, et al. An electrophysiological investigation of neuromuscular transmission in myasthenia gravis. J Physiol 1964; 174:417-434.

119 Gilchrist J, Massey J, Sanders D. Single fiber EMG and repetitive stimulation of the same muscle in myasthenia gravis: Muscle Nerve 1994; 17:171-175.

120 Sanders D, Stalberg E. AAEM Minimonograph \#25: Single-fiber electromyography. Muscle Nerve 1996; 19:1069-1083.

121 Oh $S$, Kim D, Kuruogli $\mathrm{R}$, et al. Diagnostic sensitiwity of the laboratory tests in myasthenia gravis. Muscle Nerve 1992; 15:720-724.

122 Abramsky O, Aharonow A, Teitelbaum D, et al. Myasthenia gravis and acetylcholine receptor. Effect of steroids in clinical course and cellular immune response to acetylcholine receptor. Arch Neurol 1975; 32:684-687.

123 Seybold M, Drachman D. Gradually increasing doses of prednison in myasthenia gravis. N Engl J Med 1974; 290:81-84.

124 Kaplan I, Blakely B, Pavlath G, et al. Steroids induce acetylcholine receptors on cultured human muscle: implications for myasthenia gravis. Proc Natl Acad Sci 1990; 87:81018104.

125 Matell G. Immunosuppressive drugs: azathioprine in the treatment of myashenia gravis. Ann NY Acad Sci 1987; 505:588-594.

126 Michels M, Hohlfeld R, Hartung H-P, et al Myasthenia gravis: discontinuation of longterm azathioprine. Ann NY Acad Sci 1987; 505:789.

127 Cornelio $\mathrm{F}_{\text {, Antozzi }} \mathrm{C}$, Mantegazza $\mathrm{R}$, et al. Immunosuppressive treatments. Their efficacy on myasthenia gravis patients' outcome and on the natural course of the disease. Ann NY Acad Sci 1993; 681:594-602.

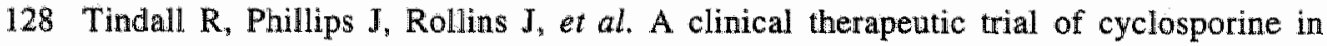
myasthenia gravis. Ann NY Acad Sci 1993; 681:539-551.

129 Samtleben W, Besinger U, Toyka K, et al. Plasma-separation in myasthenia gravis: a new method of rapid plasma exchange. Klin Wochenschr 1980; 58:47-49.

130 Nielsen V, Paulson $O$, Rosenkvist J, et al. Rapid improvement of myasthenia gravis after plasma exchange. Ann Neurol 1982; 11:160-169. 
131 Somnier F, Keiding N, Paulson O. Epidemiology of myasthenia gravis in Denmark. A longitudinal and comprehensive population survey. Arch Neurol 1991; 48:733-739.

132 Christensen $P_{n}$ Jensen $T$, Tsiropoulos $I$, et al. Incidence and prevalence of myasthenia gravis in western Denmark: 1975 to 1989 . Neurology 1993; 43:1779-1783.

133 Theofilopoulos A, Dixon F. Autoimmune diseases. Immunopathology and etiopathogenisis. Am J Pathol 1982; 108:321-356.

134 Donaldson D, Ansher M, Horan S, et al. The relationship of age to outcome in myasthenia gravis. Neurology 1990; 40:786-790.

135 Ferrari G, Lovasta M. Epidemiology of myasthenia gravis in the province of Trento (Northern Italy). Neuroepidemiology 1992; 11:135-142.

136 Antonini G, Morino S, Gragnani F, et al. Myasthenia gravis in the elderly: a hospital based study. Acta Neurol Scand 1996; 93:260-262.

137 Cosi V, Citterio A, Lombardi $\mathrm{M}$, et al. Effectiveness of steroid treatment in myasthenia gravis: a retrospective study. Acta Neurol Scand 1991; 84:33-39.

138 Lindstrom J, Engel A, Seybold M, et al. Pathological mechanisms in experimental autoimmune myasthenia gravis. II. Passive transfer of experimental autoimmune myasthenia gravis in rats with anti-acetylcholine receptor antibodies. I Exp Med 1976; 144:739-753.

139 Meinl E, Klinkert W, Wekerle H. The thymus in myasthenia gravis. Am J Pathol 1991; 139:995-1008.

140 Einarson B, Gullick W, Conti-Tronconi B, et al. Subunit composition of bovine muscle acetylcholine receptor. Biochemistry 1982; 21:5295-5302.

141 Lindstrom J, Einarson B, Lennon V, et al. Pathological mechanisms in experimental autoimmune myasthenia gravis. I. Immunogenicity of syngeneic muscle acetylcholine receptor and quantitative extraction of receptor and antibody-receptor complexes from muscles of rats with experimental autoimmune myasthenia gravis. J Exp Med 1976; 144:726-738.

142 Scadding G, Vincent $A$, Newsom-Davis $J$, et al. Acetylcholine receptor antibody synthesis by thymic lymphocytes: correlation with thymic histology. Neurology $1981 ; 31: 935-943$.

143 Lindstrom J, Einarson B, Merlie J. Immunization of rats with polypeptide chains from torpedo acetylcholine receptor causes an autoimmune response to receptors in rat muscle. Proc Natl Acad Sci 1978; 75:769-773.

144 Lennon V, McCormick D, Lambert E, et al. Region of peptide 125-147 of acetylcholine receptor $\alpha$ subunit is exposed at neuromuscular junction and induces experimental autoimmune myasthenia gravis, $\mathrm{T}$ cell immunity and modulating autoantibodies. Proc Natl Acad Sci 1985; 82:8805-8809. 
145 Matsuo $H$, Tsujihata $M$, Satoh A, et al. Myasthenogenicity of a human acetylcholine receptor $\alpha$-subunit peptide: morphology and immunology. Muscle Nerve 1992; 15:282287.

146 Takamori $M$, Okumura $S$, Nagata $M$, et al. Myasthenogenic significance of synthetic $\alpha-$ subunit peptide 183-200 of Torpedo californica and human acetylcholine receptor. J Neurol Sci 1988; 85:121-129.

147 Lennon $V$, Lambert $\mathbf{E}$, Leiby $\mathbf{K}$, et al. Recombinant human acetylcholine receptor $\alpha$ subunit induces chronic experimental autoimmune myasthenia gravis. J Immunol 1991; 146:2245-2248.

$148 \mathrm{Gu} \mathrm{D}$, Wogensen $\mathrm{L}$, Calcutt $\mathrm{N}$, et al. Myasthenia gravis-like syndrome induced by expression of Interferon $\gamma$ in the neuromuscular junction. J Exp Med 1995; 181:547-557.

149 Richman D, Gomez C, Berman $\mathrm{P}$, et al. Monocional anti-acetylcholine receptor antibodies can cause experimental myasthenia. Nature 1980; 286:738-739.

150 Lennon $V$, Lambert $\mathbb{E}$. Myasthenia gravis induced by monoclonal antibodies to acetylcholine receptors. Nature 1980; 285:238-240.

151 Tzartos S, Hochschwender S, Vasquez $\mathrm{P}$, et al. Passive transfer of experimental autoimmune myasthenia gravis by monoclonal antibodies to the main immunogenic region of the acetylcholine receptor. J Neuroimmunol 1987; 15:185-194.

152 Gomez C, Wollmann R, Richman D. Induction of the morphologic changes of both acute and chronic experimental autoimmune myasthenia by monoclonal antibody directed against acetylcholine receptor. Acta Neuropathol 1984; 63:131-143.

153 Tarrab-Hazdai R, Aharonov A, Silman I, et al. Experimental autoimmune myasthenia induced in monkeys by purified acetylcholine receptor. Nature 1975; 256:128-130.

154 Berman P, Patrick J. Experimental myastenia gravis. A murine system. J Exp Med 1980; 151:204-233.

155 Biesecker G, Koffler D. Resistance to experimental autoimmune Myasthenia Gravis in genetically inbred rats. J Immunol $1988 ; 140: 3406-3410$.

156 Fuchs S, Nevo D, Tarrab-Hazdai R. Strain differences in the autoimmune response of mice to acetylcholine receptors. Nature 1976; 263:329-330.

157 Berman P. Patrick J. Linkage between the frequency of muscular weakness and loci that regulate immune responsiveness in murine experimental autoimmune myasthenia gravis. $\mathrm{J}$ Exp Med 1980; 152:507-520.

158 Christadoss P. Immunogenetics of experimental autoimmune myasthenia gravis. Crit Revs Immunol 1989: 9:247-278.

159 Christadoss P, Shenoy M. Molecular immunopathogenesis of experimental autoimmune myasthenia gravis. Reg Immunol 1994; 4:314-320. 
160 Marzo A, Garlepp M, Schon-Hegrad M, et al. Susceptibility to murine experimental autoallergic myasthenia gravis: the role of antibody specificity. Clin Exp Immunol 1986; 64:101-106.

161 Graus $Y$, van Breda Vriesman $P$, De Baets $M$. Characterization of anti-acetylcholine receptor $(A C h R)$ antibodies from mice differing in susceptibility for experimental autoimmune myasthenia gravis. Clin Exp Immunol 1993; 92:506-513.

162 Hoedemaekers A, Graus $\mathrm{Y}$, Vroomen $\mathrm{M}$, et al. Age- and sex-related resistance to experimental autoimmune myasthenia gravis in BN rats. J Neuroimmunol 1994; 54:168W09.02.

163 Hoedemaekers A, Graus $Y$, Beijleveld $L$, et al. Macrophage infiltration at the neuromuscular junction does not contribute to $\mathrm{AChR}$ loss and age-related resistance to EAMG. J Neuroimmunol 1997; 75:147-155.

164 Roubinian R, Talal N, Greenspan $J$, et al. Effect of castration and sex hormone treatment on survival, anti-nucleic acid antibodies, and glomerulonephritis in NZB/NZW F1 mice. J Exp Med 1978; 147:1568-1583.

165 Melez K, Boegel W, Steinberg A. Therapeutic studies in New Zealand mice. VII. Successful androgen treatment of NZBNRW F1 females of different age. Arthritis Rheumatism 1980; 23:41-47.

166 Verheul H, Stimson W, Den Hollander F, et al. The effects of nandrolon, testosterone and their decanoate esters on murine lupus. Clin Exp lmmunol 1981; 44:11-17.

167 De Baets M, Verschuuren J, Daha M, et al. Effects of the rate of acetylcholine receptor synthesis on the severity of experimental autoimmune myasthenia gravis. Immunologic research $1988 ; 7: 200-211$.

168 Drachman D, Angus C, Adams R, et al. Myasthenic antibodies cross-link acetylcholine receptors to accelerate degradation. $N$ Engl J Med 1978; 298:1116-1122.

169 Tzartos $\mathrm{S}$, Sophianos $\mathrm{D}$, Zimmerman $\mathrm{K}$, et al. Antigenic modulation of human myotube acetylcholine receptor by myasthenic sera. Serum titer determines receptor internalization rate. J Immunol 1986; 136:3231-3238.

170 Sophianos D, Tzartos S. Fab fragments of monoclonal antibodies protect the human acetylcholine receptor against antigenic modulation caused by myasthenic sera. $J$ Autoimmun 1989; 2:1-13.

171 Loutrari L, Kokla A, Tzartos S. Passive transfer of experimental myasthenia gravis via antigenic modulation of acetylcholine receptor. Eur J Immunol 1992; 22:2449-2452.

172 Engel A, Lambert E, Howard F. Immune complexes ( $\operatorname{GG}$ and C3) at the motor endplate in myasthenia gravis. Mayo Clin Proc 1977; 52:267-280.

173 Lennon $V$, Seybold M, Lindstrom $J_{*}$ et al. Role of complement in the pathogenesis of experimental autoimmune myasthenia gravis. J Exp Med 1978; 147:973-983. 
174 Biesecker $G$, Gomez $C$. Inhibition of acute passive transfer experimental autoimmune myasthenia gravis with Fab antibody to complement C6. J Immunol 1989; 142:26542659.

175 Christadoss P. C5 gene influences the development of murine myasthenia gravis. J Immunol 1988; 140:2589-2592.

176 Lang $\mathrm{B}$, Richardson $\mathrm{G}$, Rees $\mathrm{J}$, et al. Plasma from myasthenia gravis patients reduces acetylcholine receptor agonist-induced $\mathrm{Na}+$ flux into TE671 cell line. J Neuroimmunol 1988; 19:141-148.

177 Ballas $M$, Heldman $\mathrm{Y}$, Cabilly $\mathrm{S}$, et al. Identification of a hexapeptide that mimics a conformation-dependent binding site of acetylcholine receptor by use of a phage-epitope library. Proc Natl Acad Sci 1993; 90:10638-10642.

178 Molenaar P, Plomp J, van Kempen G. Differences between the dilator naris and diaphragm muscles of 'myasthenic' rats. J Physiol 1990; 420:25P.

179 Lennon V, Lindstrom J, Seybold M. Experimental autoimmune myasthenia gravis: cellular and humoral immune responses. Ann NY Acad Sci 1976; 274:283-299.

180 Christadoss P, Dauphinee M. Immunotherapy for myasthenia gravis: a murine model. J Immunol 1986; 136:2437-2440.

181 Kaul $\mathrm{R}$, Shenoy M, Goluszko E, et al. Major histocompatibility complex class II gene disruption prevents experimental autoimmune myasthenia gravis. J Immunol 1994; 152:3152-3157.

182 Zhang $\mathrm{G}, \mathrm{Ma} C$, Xiao B, et al. Depletion of CD8+ T cells suppresses the development of experimental autoimmune myasthenia gravis in Lewis rats. Eur J Immunol 1995; 25:11911198.

183 Zhang $G$, Xiao B, Bakhiet $\mathrm{M}_{\text {, et }}$ al. Both $\mathrm{CD} 4+$ and $\mathrm{CD} 8+$ cells are essential to induce experimental autoimmune myasthenia gravis. J Exp Med 1996; 184:349-356.

184 Aime-Sempe C, Cohen-Kaminsky S, Bruand C, et al. In vivo preferential usage of TCR V $\beta 8$ in Torpedo acetylcholine receptor immune response in the murine experimental model of myasthenia gravis. J Neuroimmunol 1995; 58:191-200.

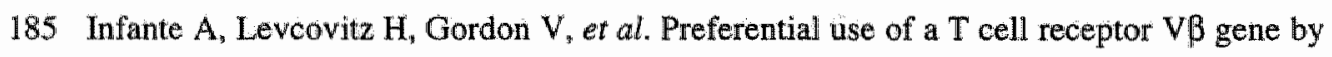
acetylcholine receptor reactive $\mathrm{T}$ cells from myasthenia gravis-susceptible mice. J Immunol 1992; 148:3385-3390.

186 Smith $L_{2}$, Kono D, Asthana D, et al. T cell receptor VB15 dominates the anti-acetylcholine receptor response in Lewis rat T cell lines. J Immunol 1994; 152:2596-2600.

187 Garchon H-J, Djabiri F, Viard J-P, et al. Involvement of human muscle acetylcholine receptor $\alpha$-subunit gene (CHRNA) in susceptibility to myasthenia gravis. Proc Natll Acad Sci $1994 ; 91: 4668-4672$.

188 Asher $\mathrm{O}$, Neumann D, Fuchs $S$. Increased levels of acetylcholine receptor $\alpha$-subunit mRNA in experimental autoimmune myasthenia gravis. FEBS Lett 1988; 233:277-281. 
189 Asher $O$, Neumann D, Witzemenn $V$, et al. Acetylcholine receptor gene expression in experimental autoimmune myasthenia gravis. FEBS Lett 1990; 267:231-235.

190 Asher $\mathrm{O}$, Provenzano C, Fuchs S. Regulation of acetylcholine receptor gene expression in rats treated with $\alpha$-bungarotoxin. FEBS 1991; 282:242-246.

191 Asher O, Fuchs S, Zuk D, et al. Changes in the expression of mRNAs for myogenic factors and other muscle-specific proteins in experimental autoimmune myasthenia gravis. FEBS 1992; 299:15-18.

192 Asher O, Kues W, Witzemarn V, et al. Increased gene expression of acetylcholine receptor and myogenic factors in passively transferted experimental autoimmune myasthenia gravis. J of Immunology $1993 ; 151: 6442-6450$.

193 Guyon T, Levasseur P, Truffault F, et al. Regulation of acetylcholine receptor $\alpha$ subunit variants RNA in human myasthenia gravis. Quantification of steady-state levels of messenger $R N A$ in muscle biopsy using the polymerase chain reaction. $J$ Clin Invest $1994 ; 94: 16-24$

194 Gautam A, Pearson C, Sinha A, et al. Inhibition of experimental autoimmune encephalomyelitis by a nonimmunogenic non-self peptide that binds to $\mathrm{I}-\mathrm{A}^{\mathrm{a}} \mathrm{l} . \mathrm{J}$ Immunol $1992 ; 148: 3049-3054$.

195 Lamont A, Sette A, Fujinami R, et al. Inhibition of experimental autoimmune encephalomyelitis induction in $S J L / J$ mice by using a peptide with high affinity for $\mathrm{IA}^{\mathrm{s}}$ molecules. J Immunol 1990; 145:1687-1693.

196 Smith S, Allen P. Myosin-induced acute myocarditis is a T cell-mediated disease. J Immunol 1991; 147:2141-2147.

197 Wauben M, Hoedemaekers A, Graus Y, et al. Inhibition of experimental autoimmune myasthenia gravis by major histocompatibility complex class II competitor peptides results not only in a suppressed but also in an altered immune response. Eur $\mathrm{J}$ Immunol $1996 ; 26: 2866-2875$.

198 Ma C-G, Zhang G-X, Xiao B-G, et al. Mucosal tolerance to experimental autoimmune myasthenia gravis is associated with down-regulation of AChR-specific IFN- $\gamma$-expressing Th1-like cells and up-regulation of TGF- $\beta$ mRNA in mononuclear cells. Ann NY Acad Sci $1996 ; 788: 273-287$.

199 Souroujon M, Pachner A, Fuchs S. The treatment of passively transferred experimental myasthenia with anti-idiotypic antibodies. Neurology 1986; 36:622-625.

200 Araga S, Blalock J. Use of complementary peptides and their antibodies in B-cellmediated autoimmune disease: prevention of experimental autoimmune myasthenia gravis with a peptide vaccine. Immunomethods 1994; 5:130-135.

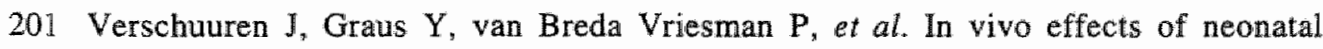
administration of antiidiotype antibodies on experimental autoimmune Myasthenia Gravis. Autoimmunity 1991; 10:173-179. 
202 Toyka K, Lowenadler B, Heiniger $\mathrm{K}$, et al. Passively transferred myasthenia gravis: protection of mouse endplates by Fab fragments from human myasthenic IgG. J Neurol Neurosurg Psychiatry 1980; 43:836-840.

203 Mamalaki A, Trakas N, Tzartos S. Bacterial expression of a single-chain Fv fragment which efficiently protects the acetylcholine receptor against antigenic modulation caused by myasthenic antibodies. Eur I Immunol 1993; 23:1839-1845.

204 Graus $Y$, De Baets M, Parren P, et al. Human anti-nicotinic acetylcholine receptor recombinant Fab fragments isolated from thymus-derived phage display libraries from myasthenia gravis patients reflect predominant specificities in serum and block the action of pathogenic serum antibodies. I Immunol 1997; 158:1919-1929. 


\title{
Chapter 2
}

\section{Age- and sex-related resistance to experimental autoimmune myasthenia gravis (EAMG) in Brown Norway rats}

\begin{abstract}
A. Hoedemaekers, Y. Graus*, P. van Breda Vriesman and M. De Baets
Department of Immunology, Maastricht University, P.O. Box 616,6200 MD, Maastricht, The Netherlands

* The Netherlands Cancer Institute, Division of Immunology, Plesmanlaan 121, $1066 \mathrm{CX}$ Amsterdam, The Netherlands
\end{abstract}

Published in Clin. Exp. Immunol. 1997; 107: 189-197

\section{Summary}

The influence of age and sex on the induction of chronic experimental autoimmune myasthenia gravis (EAMG) was analyzed. Aged male rats, immunised with Torpedo acetylcholine receptor ( $\mathrm{tAChR}$ ) showed no clinical signs of disease or $\mathrm{AChR}$ loss. Immumisation of young male $\mathrm{BN}$ rats resulted in both clinical signs of disease and $65 \% \mathrm{AChR}$ loss. In contrast both young and aged female $\mathrm{BN}$ rats showed comparable $\mathrm{AChR}$ loss (58\% and $50 \%$ respectively), although aged female rats did not develop clinical signs of disease. Differences in antibody titres, isotype distribution, fine specificity or complement activation could not account for the observed resistance. These results suggest that resistance against EAMG in aged rats is due to resistance of the AChR against antibody-mediated degradation or to mechanisms able to compensate for AChR loss. 


\section{Introduction}

Myasthenila gravis $(\mathrm{MG}$ ) is caused by auto-antibodies against the nicotinic $\mathrm{AChR}$. Symptoms of both $M G$ and $E A M G$ result from an antibody mediated destruction of AChR at the neuromuscular junction. Several pathogenic mechanisms are held responsible for loss of functional AChR. These include antibodies that cross-link AChR causing increased internalisation, called antigenic modulation $(1,2)$; anti-AChR antibodies also activate complement resulting in focal lysis of the postsynaptic membrane; thirdly antibodies that interfere with ligand binding or ion channel function cause impairment of AChR function $(3,4)$.

The incidence of MG in humans is both age- and sex-related. The relative incidence is highest in women in the second and third decade. The incidence in men peaks in the sixth and seventh decade $(5,6)$.

EAMG is an animal model that closelly resembles human MG. It can be induced by active immunisation in a large variety of species with purified AChR or by passive transfer of polyclonal or monoclonal anti-AChR antibodies (7-9). Susceptibility to EAMG varies between several rat strains, and is intermediate in BN and Lewis rats that are most commonly used (10). However, aged BN rats are relatively resistant to both passive transfer and chronic EAMG (11), apparently because of a decreased antibody mediated degradation or other mechanisms that compensate for AChR loss.

Several immunological changes have been shown to occur in senescence. Both $\mathrm{T}$ cell and antibody responses to foreign and autoantigens decrease $(12,13)$, whereas the spontaneous occurrence of circulating auto-antibodies increases with ageing (14). Increased $\mathrm{T}$ cell autoreactivity also occurs, but is rarely accompanied by overt disease (15). An age-associated decline in susceptibility to experimental autoimmune models of systemic lupus erythematosus, encephalomyelitis and thyroiditis is usually associated with a decreased activity of $T$ helper cells and lower antibody titres $(16,17)$.

In addition to epidemiological evidence in humans, experimental evidence from spontaneous and induced animal models of autoimmune disease show that sex hormones play an immunomodulatory role $(18,19)$. 
In the present study, the influence of age and gender on induction of chronic EAMG, and possible differences in pathogenic mechanisms that cause $\mathrm{AChR}$ degradation, were further investigated. The results of this study might elucidate putative protective mechanisms operative in the milder clinical form of MG in older patients (5).

\section{Materials and Methods}

\section{Animals}

Inbred male and female BN rats were bred at the local breeding colonies of the Department of Experimental Animal Services and originated from TNO, Leiden, The Netherlands: All animals were bred under specific pathogen free conditions. The animals were sacrificed by exsanguination under ether anaesthesia.

\section{Induction of chronic EAMG}

AChR from electric organs of Torpedo californica (tAChR) (Pacific Biomarine, Venice, CA) was purified by affinity chromatography using Cobra toxin coupled to sepharose 4B (Pharmacia LKB, Woerden, The Netherlands) (20). Rats were immunised at the base of the tail with $10 \mu \mathrm{g} / 100 \mathrm{~g}$ bodyweight purified tAChR emulsified in Complete Freunds Adjuvant (CFA) (Difco Laboratories, Detroit, MI, USA). Four (female rats) or 6 (male rats) weeks after primary immunisation rats were boosted with $10 \mu \mathrm{g} / 100 \mathrm{~g}$ bodyweight $\mathrm{tAChR}$ in Incomplete's Freunds Adjuvant (FA) (Difco Laboratories, Detroit, MI, USA). Control rats received an equal volume of PBS in CFA or IFA.

\section{Clinical assessment}

The severity of EAMG was scored by measuring weight loss and muscular weakness. The animals' muscle strength was assessed by their ability to grasp and lift repeatedly a $300 \mathrm{~g}$ rack from the table, while suspended manually by the base of the tail for 30 seconds. Clinical scoring was based on the presence of tremor, hunched posture, strength and fatiguability. Results were expressed as 0 (no obvious abnormalities), + (no abnormalities before testing, but reduced 
strength at the end) ++ (clinical signs present before testing, i.e. tremor, head down, hunched posture, weak grip), +++ (severe clinical signs present before testing, no grip, moribund) $(21,22)$.

\section{Determination of $A C h R$ concentration}

The concentration of AChR was determined in the complete carcass as described previously with minor modifications $(7,23)$. Briefly, frozen tissue was homogenised and AChR was extracted with $2 \%$ Triton X-100 (Sigma, Brunschwig chemie b.v., Amsterdam, The Netherlands). An aliquot of $250 \mu$ of each extract was labelled with $2 \times 10^{-9} \mathrm{M} 125 \mathrm{I}-\alpha-\mathrm{BT}$, incubated overnight with excess rat anti-AChR IgG and precipitated by goat anti-rat antibodies. $A C h R$ concentration was expressed as pmoles $125 \mathrm{I}-\alpha-\mathrm{BT}$ precipitated.

\section{Determination of anti-AChR antibody titres and isotypes}

The concentration of antibodies reactive with rat AChR ( $\mathrm{ACCR}$ ) from individual sera was determined by radioimmunoassay (RIA) using rAChR labelled with ${ }^{125}$ I- $\alpha$-BT from Bungarus multicinctus (Sigma, Brunschwig Chemie b.v., Amsterdam, The Netherlands) as previously described (7). Titres were expressed as nmoles $\alpha$-BT precipitated per litre. Corrections for interassay variability were made based on serial dilutions of an EAMG standard controll serum pool. tested in each assay.

Pooled senm from young and aged rats was tested for anti- $\mathrm{ACCh}$ antibody isotypes by ELISA. First, antitiAChR antibody concentrations were measured by ELISA to asses the serum dilution in which equal armounts of anti-tAChR antibodies were bound to immobilised LAChR. Polyvinyl 96-well microtitre plates were coated with $50 \mu \mathrm{tAChR}(5 \mu \mathrm{g} / \mathrm{ml})$ for $1 \mathrm{hr}$ at $37^{\circ} \mathrm{C}$. Plates were then incubated with PBS containing $0.5 \%$ bovine serum albumin and $0.5 \%$ Tween-20 (PBSATw) for $15 \mathrm{~min}$ at toom temperature. After washing 3 times with $0.5 \%$ Tween, plates were incubated with $50 \mu \mathrm{l}$ serum diluted in PBSA-Tw for $1 \mathrm{hr}$ at room temperature, followed by peroxidase conjugated polyclonal rabbit anti-rat antibodies $(1.3 \mu \mathrm{g} / \mathrm{L}$ ) (Dako, Glostrup, Denmark). After washing again with $0.5 \%$ Tween, the colorimetric reaction was developed by adding $100 \mu \mathrm{l}$ of $0.1 \mathrm{M}$ sodium-acetate buffer, $\mathrm{pH} 5.5$, containing tetramethylbenzidine (10 
$\mathrm{mg} / \mathrm{ml})$ and $0.01 \% \mathrm{H}_{2} \mathrm{O}_{2}$. After 10 min the reaction was stopped by adding $50 \mu \mathrm{ll} 4 \mathrm{~N} \mathrm{H}_{2} \mathrm{SO}_{4}$. Optical density (OD) was measured at $450 \mathrm{~nm}$ (Titertek Twinreader, Amstelstad, Amsterclam, The Netherlands). To determine the isotype distribution, polyclonal rabbit anti-rat isotype antibodies were used instead (1/250-1/500 dilution) (a generous gift from Prof. H. Bazin, VCL, Louvain, Belgium) for $1 \mathrm{hr}$ at room temperature, followed by 50 ul peroxidase conjugated swine anti-rabbit antibodies (1.3 $\mu \mathrm{g} / \mathrm{L})$ (Dako, Glostrup, Denmark). The colorimetric reaction was developed as described above. The contribution of a particular isotype was expressed as the $\%$ of the total anti-tAChR response.

\section{Determination of anti-AChR antibody fine specificity}

The proportion of antibodies directed against the MIR of $\mathrm{rAChR}$ was determined in pooled sera from young and aged rats by a competitive ELISA using mAb 35 as a reference anti-MIR antibody. Briefly, 96-well ELISA plates were coated with $50 \mu \mathrm{lmAb} 153(15 \mu \mathrm{g} / \mathrm{ml})$ for 2 hrs at $37^{\circ} \mathrm{C}$ and incubated $\mathrm{O} / \mathrm{N}$ with $200 \mu \mathrm{l}$ rAChR extract. MAb 153 is a rat anti-AChR mAb directed against a cytoplasmic epitope of the AChR (24). After washing, plates were incubated with 50 $\mu \mathrm{l}$ pooled serum diluted 1/5-1/320 in PBSA-Tw for $1 \mathrm{hr}$ at $37^{\circ} \mathrm{C}$. Subsequently, $50 \mu \mathrm{lmAb} 35$ coupled to horseradish peroxidase (mAb $35-\mathrm{HRP})(0.1 \mathrm{ng} / \mathrm{ml})$ was added to the wells and incubated for $1 \mathrm{hr}$ at $37^{\circ} \mathrm{C}$. After washing the colorimetric reaction was developed as described above. The percentage inhibition of mAb 35-HRP was calculated as follows: ((average $\mathrm{OD}_{450 \mathrm{~nm}}$ of duplicate wells with mAb $35-\mathrm{HRP}$ alone - average $\mathrm{OD}_{450 \mathrm{~nm}}$ of duplicate wells with both serum and $\mathrm{mAb} 35$-HRP)/average $\mathrm{OD}_{450 \mathrm{~nm}}$ of duplicate wells with mAb 35-HRP alone) $x 100$. Results are expressed as \% inhibition of binding of mAb 35-HRP to rAChR.

Before assaying antibodies directed against the $\alpha$-BT-binding site of tAChR, IgG was isolated from sera pooled from young or aged rats by affinity chromatography on protein $G$ sepharose (Pharmacia LKB, Woerden, The Netherlands). Anti-tAChR titres were determined by ELISA; to correct for differences, the IgG fraction was diluted with normal young rat IgG. Polyvinyl 96well microtitre plates were coated with $\operatorname{tAChR}(5 \mu \mathrm{g} / \mathrm{ml})$ for $1 \mathrm{~h}$ at $37^{\circ} \mathrm{C}$ and subsequently incubated with increasing concentrations $(0.1-100 \mu \mathrm{g} / \mathrm{ml})$ EAMG or control IgG at room temperature for $16 \mathrm{hrs}$. These were removed by aspiration and plates were incubated with a 
limiting concentration of $125 \mathrm{I}-\mathrm{\alpha}-\mathrm{BT}$ ( $2 \mathrm{pmol} / \mathrm{mi})$ for $2 \mathrm{hrs}$ at room temperature. Plates were washed and radioactivity was counted in a gamma counter. The percentage inhibition of ${ }^{125}$ Ia-BT was calculated as follows: ((average CPM of duplicate wells with 125I-a-BT alone average CPM of duplicate wells with both serum and 125 I- $\alpha$-BT)/average CPM of duplicate wells with $125 \mathrm{I}-\alpha$-BT alone) $\times 100$. Results are expressed as $\%$ inhibition of ${ }^{125}$ I- $\alpha$-BT binding to $\mathrm{tACh}$.

\section{In vitro antigenic modulation on TE671}

The capacity of sera to induce loss of AChR by antigenic modulation was tested in resistant old and susceptible young male rats, using TE671 cultures as previously described with minor modifications (25). The rhabdomyosarcoma cell line TE671 expresses human nicotinic AChR (26) TE671 cells were cultured to confluency at $37^{\circ} \mathrm{C}$ in 24 well tissue culture plates (Costar, Europe Ltd, Badhoevedorp, The Netherlands) in Iscove's modified Dulbecco's Medium (IMDM), supplemented with $5 \%$ fetal calf serum, $1 \%$ penicillin/streptomycin, $1 \%$ pyruvate and $2.5 \mu \mathrm{M}$ dexamethasone; for subsequent steps this was supplemented with $40 \mu \mathrm{g} / \mathrm{ml}$ cycloheximide. Serum from young and aged male rats was heated to $56^{\circ} \mathrm{C}$ for 1 hr to inactivate complement components. Confluent cultures were incubated with $250 \mu \mathrm{l}$ of serum dilutions $(1 / 5-1 / 160)$ for 2 hrs. In order to label cell-bound AChR, $50 \mu l$ of fresh medium, containing 2.75 nM 125 I- $\alpha-$ BT was added and incubated for $3 \mathrm{hrs}$. Subsequently, wells were washed twice and cell-bound radioactivity was removed by adding $1 \mathrm{ml} 2 \%$ SDS in PBS and counted in a gammacounter. Background radioactivity was determined by adding 100 fold excess of unlabeled $\alpha$ BT ( $500 \mathrm{nM})$ during the entire course of the experiment. All measurements were determined in triplicate in three separate experiments. The \% loss of surface AChR by antigenic modulation was calculated as follows: /(CPM in the presence of medium alone - CPM in the presence of serum)/CPM in the presence of medium alone) $\} \times 100$.

\section{Lacalisation of membrane attack complex and complement regulatory proteins}

Deposition of complement component C3 or C5b-9 (membrane attack complex (MAC)) was analysed in muscle biopsy cryosections using polyclonal rabbit-anti-rat $\mathrm{C} 3$ antibodies or mouse 
mAb 2A1 directed against rat C5b-9 (a kind gift of Professor W.G. Couser; Department of Medicine, University of Washington, Seattle), Rabbit polyclonal antibodies against (mouse) CD55 (decay accelerating factor (DAF)), CD59 and vitronectin were used to stain for complement regulatory proteins (a kind gift of Professor M. Daha, Department of Nephrology, University Hospital Leiden, The Netherlands and Dr. E. de Heer, Department of Pathology, University of Leiden, The Netherlands). Muscle biopsy cryosections of young and aged male and female rats were acetone-fixed for $10 \mathrm{~min}$ at $4^{\circ} \mathrm{C}$ and air-dried for $5 \mathrm{~min}$. After washing 3 times in PBS, the sections were incubated first in $2 \%$ PBSA and then with the respective monoclonal or polyclonal antibodies together with rhodamine-labelled $\alpha$-BT (Molecular Probes, Eugene, OR) for $1 \mathrm{~h}$ at RT. After washing with PBS the slides were incubated for $1 \mathrm{~h}$ at RT with FITC-conjugated rabbit anti-mouse or swine anti-rabbit antibodies (Cappel, Organon Technika, Boxtel, The Netherlands).

\section{Statistical analysis}

The Wilcoxon rank test was used for statistical analysis.

Table I: Development of muscular weakness in chronic EAMG is age-related

\begin{tabular}{lcccccc}
\hline \hline & Age(weeks) & Rats/graup & \multicolumn{3}{c}{ Clinical EAMG score } \\
\hline Chronic EAMG & & & - & + & ++ & +++ \\
\hline \multirow{2}{*}{ Female } & 10 & $\mathrm{n}=7$ & 2 & 3 & 2 & - \\
& 122 & $\mathrm{n}=8$ & 8 & - & - & - \\
& & & & & & - \\
Male & 10 & $\mathrm{n}=10$ & 4 & 1 & 5 & - \\
& 128 & $\mathrm{n}=10$ & 10 & - & - & - \\
\hline \hline
\end{tabular}

Muscular weakness was measured 6 (female) or 10 (male) weeks after immunisation with $\mathrm{LAChR}$. Young female and young male rats developed clear signs of muscular weakness ( $<<0.05$ ). In contrast, aged female BN ratts were clinically resistant to induction of chronic EAMG, although AChR loss was comparable to aged female rats. Aged male rats were resistant to EAMG. No clinical signs of disease were found in PBS/CFA immunised control rats. Results are expressed on a scale ranging from 0 (no obvious abnormalities) to +++ (severe clinical present before testing, no grip, moribund). 


\section{Results}

\section{Clinical assessment}

Both young male and female rats showed mild to moderate $(+$ or ++$)$ clinical signs of muscular weakness 6 and 10 weeks after primary immunisation respectively, whereas aged male and female rats were clinically resistant to induction of chronic EAMG (Table I). Weight loss was used as a measure of EAMG severity, reflecting difficulty in eating and drinking (Figure 1). Weight loss was significant in the young but not in the aged immunised rats $(p<0.05)$; the PBS immunised controls gained weight.

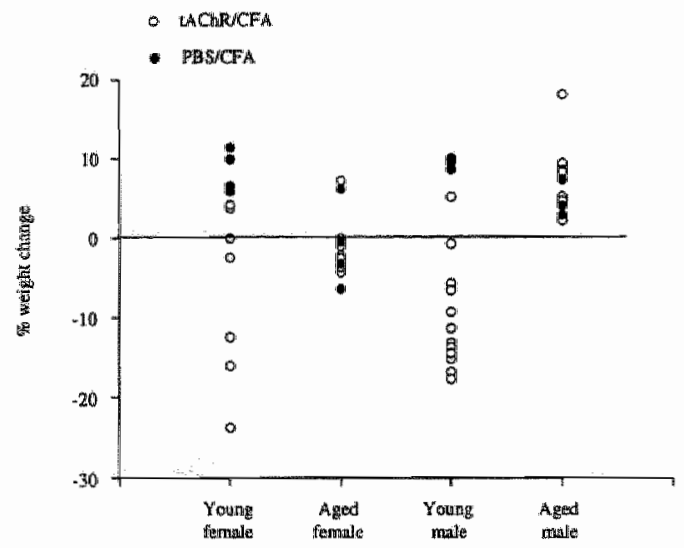

Figure 1: Weight loss as a measure for EAMG severity. Weight loss was measured 6 (female) or 10 (male) weeks after unmunisation with tAChR/CFA or PBS/CFA. Young female and male rats showed $6.7 \pm 8.1 \%$ and $8.0 \pm$ $10.8 \%$ weight loss from the initial weight. In asymptomatic aged rats no weightloss was observed. Results are exprassed as \% weight loss from time of immunisation.

\section{AChR loss from muscle}

The $\mathrm{AChR}$ content was significantly reduced in both young and aged females $(\mathrm{P}<0.05)$, (Figure 2), even though muscular weakness was only observed in the young animals (Table I). Significant AChR loss ( $\mathrm{p}<0.05$ ) was seen in the young male rats, but not in the older rats (Figure 2). 
A

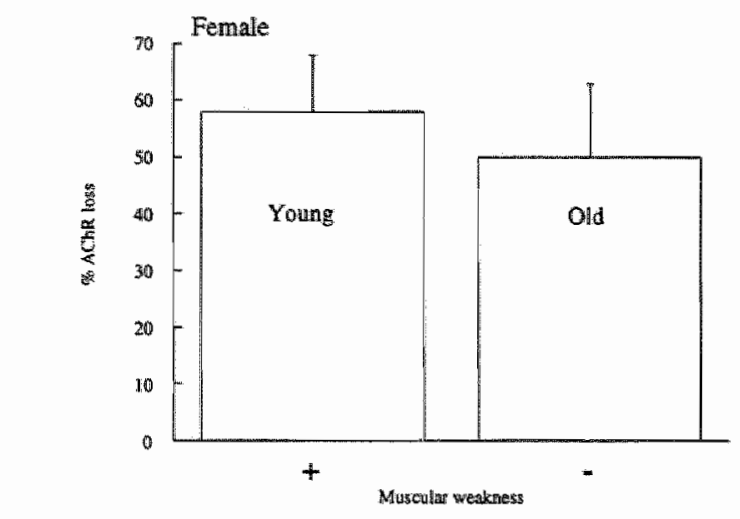

$\mathrm{B}$

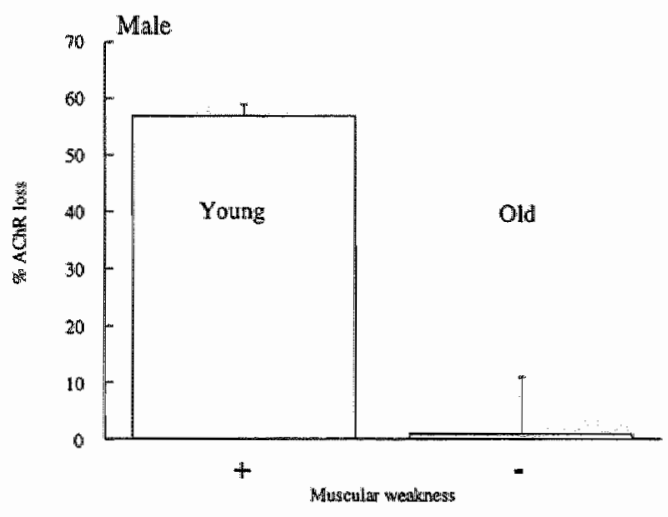

Figure 2: Resistance to chronic EAMG is age and sex related. Muscular weakness and total AChR concentration was measured 6 (female) or 10 (male) weeks after primary immunisation in total muscle. Both young and aged female rats had comparable AChR loss ( $58 \pm 10 \%$ and $50 \pm 13 \%$ respectively). Significant AChR loss $(57 \pm 2 \%)$ was also found in young male rats. Aged male rats were resistant to AChR loss. These results indicate that aged rats are resistant to EAMG. AChR loss is expressed as percentage of the AChR content of PBS/CFA immunised control rats. Each bar represents mean of 5 rats $\pm S D$.

\section{Anti-AChR antibody titres and isotypes}

Anti-rAChR antibody titres were measured at several time points after immunisation in order to detect differences in the kinetics of the antibody response between young and aged animals. At 4 weeks after primary immunisation both young and aged female rats were boosted with $\mathrm{tAChR}$ in IFA. The mean anti-rAChR antibody titre in aged female rats was found to be significantly lower (mean \pm SEM $27.4 \pm 9.3$ vs. $139.3 \pm 22.5 \mathrm{nM}),(\mathrm{p}<0.01)$ than in young female rats (Figure 3A). After a single immunisation, titres were somewhat lower in aged than in young 
A

- Yourrig fitmalle

- Od female

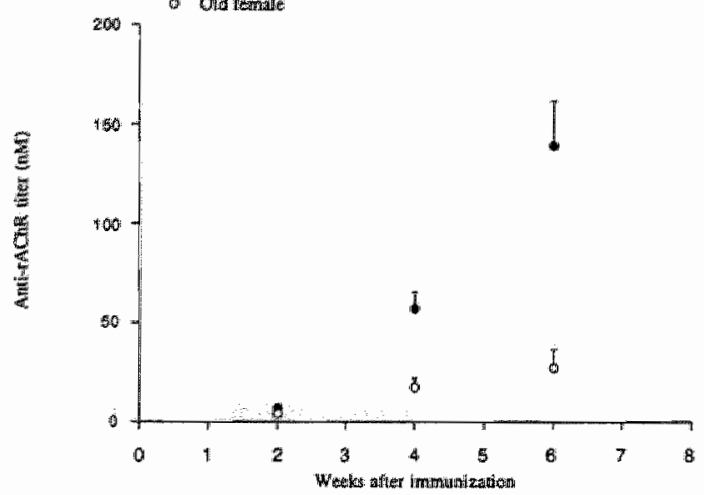

B

- Young minla

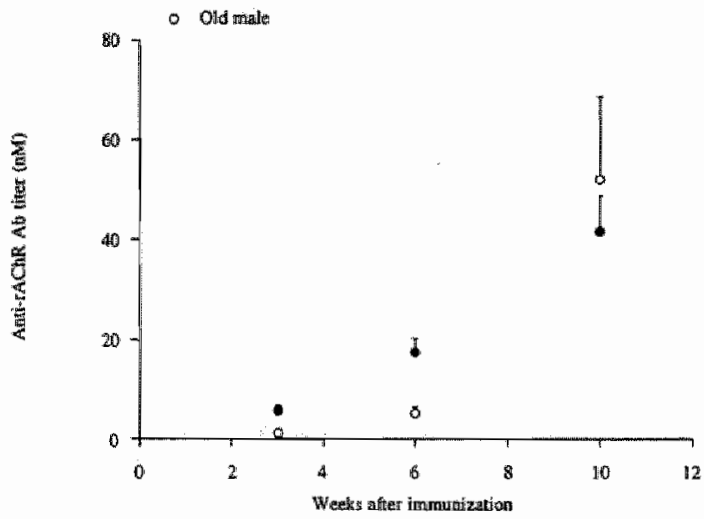

$\mathrm{C}$

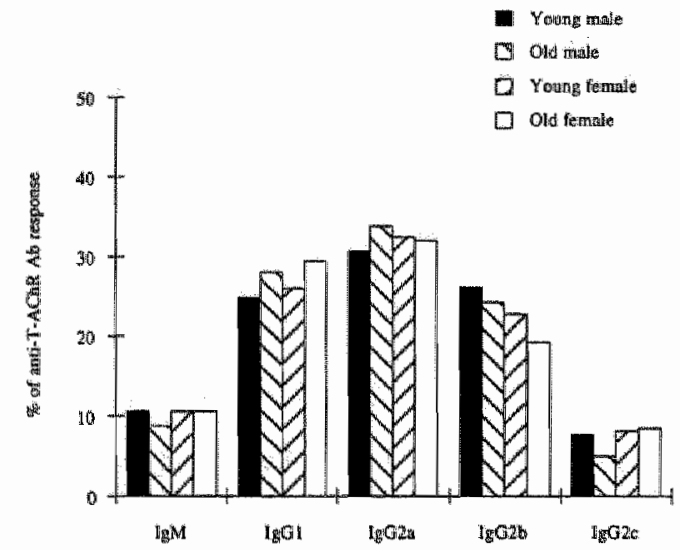

Figure 3: Kinetics of the antibody response against $\mathrm{IAChR}$ and isotype distribution of anti-tAChR antibodies.

A. Young and aged female rats were inmunised with $10 \mu \mathrm{g} / 100 \mathrm{~g}$ bodyweight $\mathrm{tAChR} / \mathrm{CFA}$ and boosted at 4 weeks after primary immunisation with an equal amount of tAChR/IFA. Anti rAChR antibody titres were measured by RIA at 2, 4 and 6 weeks after primary immunisation in female rats. Results are expressed as mean titres \pm SEM 
rats, but increased after the former were boosted (mean \pm SEM $52.2 \pm 16.5$ versus $41.8 \pm 7.1$ $\mathrm{nM}$ ) (Figure 3B). At all stages they were considerably lower in males than in young females.

The isotype distribution of anti-tAChR antibodies in chronic EAMG was similar in both young and aged male and female BN rats (Figure 3C). The isotype distribution of anti-rAChR antibodies was not determined because of technical limitations. However, since the spectrotypes of anti-tAChR antibodies and the crossreactive anti-rAChR antibodies are identical, it is unlikely that the isotype distribution of anti-tAChR and anti-rAChR antibodies is different (27).

$(\mathrm{nM})$, and represent at least 5 rats per point. B. Young and aged male rats were immunised with $10 \mu \mathrm{g} / 100 \mathrm{~g}$ bodyweight LAChR/CFA. Aged male rats were boosted with $10 \mu \mathrm{g} / 100 \mathrm{~g}$ bodyweight LAChR/AFA at 6 weeks after primary immunisation. Young male rats receiwed only primary immunisation. Anti $\mathrm{AAChR}$ antibody titres were measured by RLA at 3,6 and 10 weeks after primary immunisation in male rats. Results are expressed as mean titres \pm SEM (nM), and represent at least 5 rats per point. C. At 6 (fernale) or 10 (malle) weeks after immunisation. pooled serum of young and aged male and female rats was tested for differences in isotype distribution. The isotype distribution of anti-tAChR antibodies in chronic EAMG was similar in all tested groups. The contribution of a particular isotype is expressed as \% of the total anti-tAChR response. 
Anti-AChR antibody fine specificity

We tested whether differences in specificity for the MIR correlated with susceptibility. As suspected (Figure 3A, B), pooled sera from females showed higher total titres than from males, but there were no age-related differences in the proportion specific for the MIR (Figure 4A). Clinical susceptibility might be determined by differences in antibodies interfering with binding

A

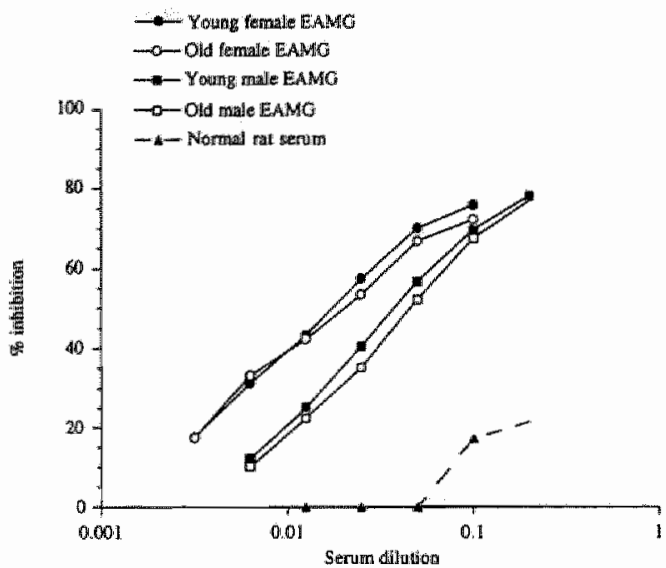

B

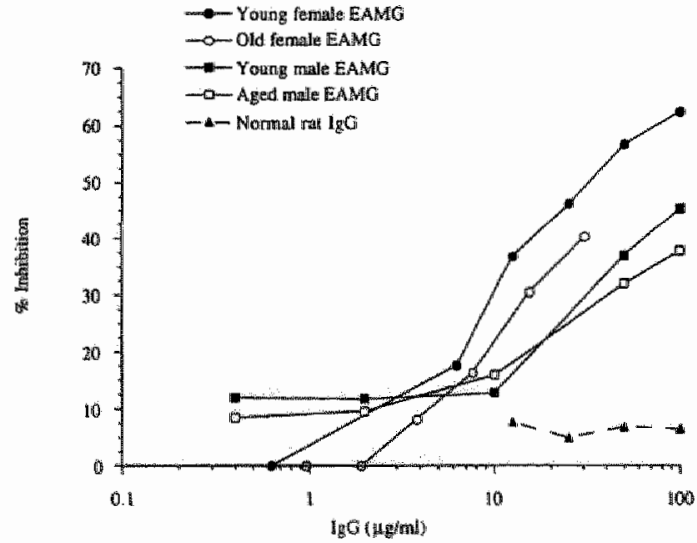

Figure 4: Resistance to EAMG is not a result of differences in antibody fine specificity towards the MIR or $\alpha-B T$ binding site. A. The proportion of anti-AChR antibodies directed against the MIR of $\mathrm{AChR}$ was determined in pooled serum of young and aged male and female rats. No significant age-related differences were detected. Results are expressed as percentage inhibition of binding of mAb 35/HRP to IAChR. B. Purified IgG from pooled sera of young and aged rats was also analysed for binding to the $\alpha-B T$ binding site of $\mathrm{LAChR}$. No significant agerelated differences were detected. Results are expressed as \% inhibition of $125_{I-\alpha-B T}$ binding to AChR. Purified IgG was used to give a higher signal-to-noise ratio. The difference between the fraction of antibodies against the MIR or $\alpha-B$ T binding site between male and female rats was similar to the difference in anti-rAChR or anti-tAChR antibody titres. IgG from control rats did not inhibit binding to the MIR or $\alpha$-BT binding site. 
of acetylcholine to the $\mathrm{AChR}$. We determined the proportion of antibodies directed against the $\alpha$-BT-binding site (Figure 4B). The anti- $\alpha$-BT-binding site titre in serum against $\mathrm{rAChR}$ was below detection level (data not shown). Since the structure homology between the $\alpha-B T$ binding site of rAChR and tAChR is very high $(28,29)$, we measured the inhibition of $125 \mathrm{I}-\alpha=$ BT binding to the $\alpha$-BT-binding site of tAChR using purified IgG derived from serum of young and aged rats. Total IgG antibody levels were about 4 times higher in the females, regardless of age. While the inhibition of $125 \mathrm{I}-\alpha$-BT binding correlated with this difference, there was again no age-related change in the proportion of these inhibitory antibodies.

\section{In vitro antigenic modulation}

Resistance to AChR loss in aged male rats might result from a reduced AChR degrading efficiency of the antibodies. However, decomplemented, pooled serum from young and old male rats caused similar AChR loss from cultured TE671 cells (71\% and 76\% at 0.1 serum dilution of young and old rats respectively) (Figure 5). Since aged female rats were already susceptible to $A C h R$ loss in vivo, the capacity of serum from these rats to induce antigenic modulation in vitro was not tested.

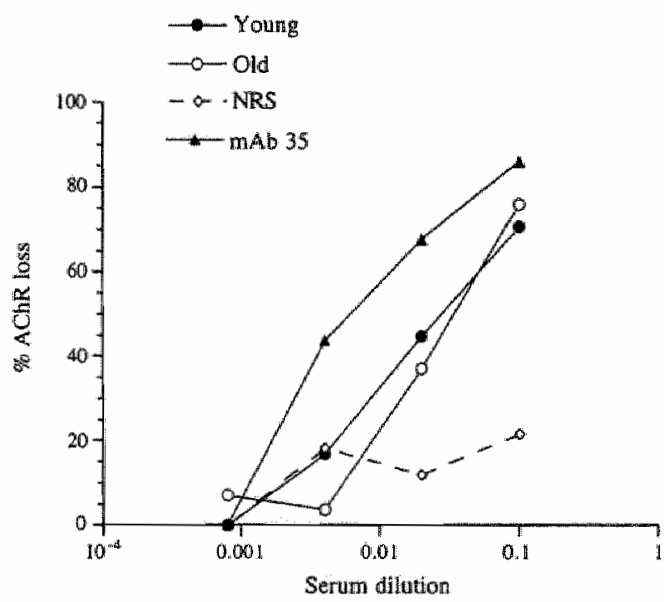

Figure S: Anti-AChR antibodies from old resistant male rats are able to finduce antigenic modulation in witro. In vitro antigenic modulation was measured using TE671 cells. Decomplemented, pooled serum from young and old male rats increased the AChR internalisation rate to the same extent, resulting in similar AChR loss (71\% and $76 \%$ at 0.1 serum dilution in young and old rats respectively). Normal rat serum at 0.1 serum dilution resulted in $21 \% \mathrm{AChR}$ loss. Results are expressed as $\%$ AChR loss in the presence of serum compared to medium alone. 


\section{Membrane attack complex and complement regulatory proteins}

Complement plays a central role in the pathogenesis of EAMG, therefore we analyzed the presence of MAC and complement regulatory proteins in young and aged male and female rats 6 or 10 weeks after induction of chronic EAMG in muscle biopsy cryosections. Deposits of complement component $\mathrm{C} 3$ and MAC coincided with the endplate regions in both young and aged rats (Figure 6A-B), but were not detectable in PBS injected age-matched controls. In addition, deposition of proteins that restrict the cytolytic activity of homologous complement components, ie CD55, CD59 and vitronectin were similar in endplate regions of both susceptible and resistant rats (Figure 6C-H) and again were not seen in the controls.

Figure 6: Resistance to chronic BAMG is not due to an inability to activate complement or its regulatory proteins. Depositions of MAC, CD55, CDS9 and witronectin at the neuromuscular junctions were visualised by two colour fluorescence in the same muscle section from young and aged, male and female rats 6-10 weeks after primary immunisation. Shown are sections from resistant old male rats. Left photographs show muscle sections stained for MAC (A), CD55 (C), CD59 (E) and vitronectin (G). Right photographs show the same muscle sections stained for $\mathrm{AChR}$ with rhodaminated $\alpha-B T(B, D, F, H)$. Similar depositions were found in endplate regions of susceptible and resistant rats. No depositions of complement and its regulatory proteins were found in muscle sections of PBS immunised controll rats. Magnification: $x 350$. 

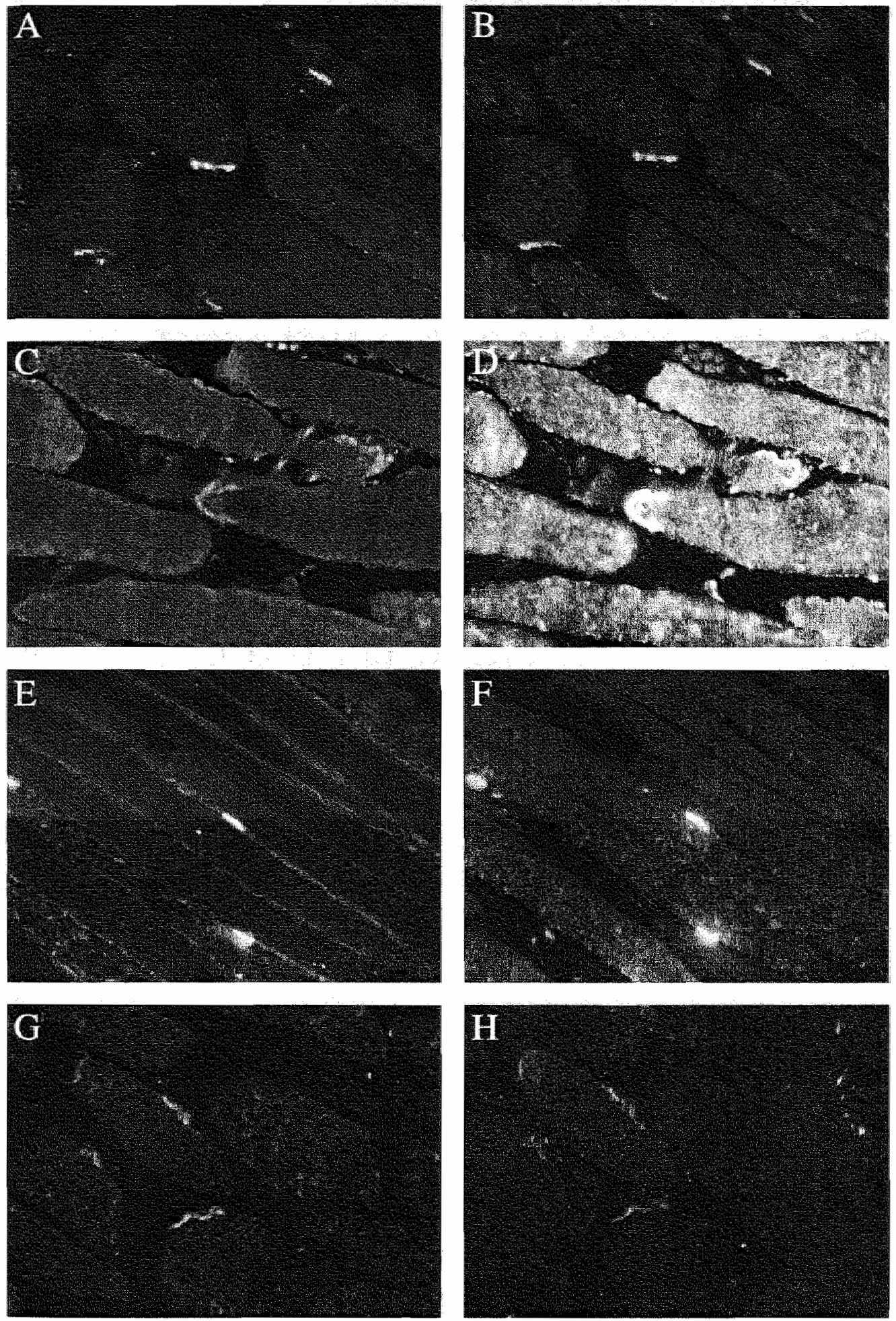


\section{Discussion}

In this study, susceptibility to EAMG was related to age and sex. In the chronic EAMG model, induced by active immunisation with $\mathrm{AChR}$, aged animals were clinically resistant to $\mathrm{EAMG}$, irrespective of their gender. In contrast, young animals of both sexes were susceptible. Aged male rats were resistant to EAMG in terms of AChR loss, whereas young male rats and young and aged female rats all showed significant $\mathrm{AChR}$ loss. Furthermore we have shown that resistance to chronic EAMG is not due to differences in antibodies, isotype distribution, fine specificity or to an inability to activate complement or its regulatory proteins.

Upon immunisation, anti-rAChR antibody titres remained lower in aged than young female rats, as has been observed by others with responses to both autoantigens and alloantigens $(12,13,30,31)$. In aged malle rats boosted with $t A C h R$ in IFA, anti-rAChR antibody titres were similar to young male myasthenic animals after a single injection, but they nevertheless failed to develop EAMG.

We tested for qualitative differences in the isotype distribution and fine specificity of the anti-AChR antibodies. The isotype distribution of the anti-tAChR antibody response proved to be similar in resistant and susceptible BN rats. The anti-tAChR antibody response was equally distributed among the IgG1, IgG2a and IgG2b isotype when measured by ELISA. A dominance of the IgG2a isotype response has been reported in both EAMG-sensitive Lewis and resistant Wistar Furth rats using isoelectric focusing (32). This difference in isotype distribution might be related to strain differences, since immune sera from Lewis and $\mathrm{BN}$ rats show different isoelectric focusing pattems (27). The rat IgG1, IgG2a and IgG2b subclasses are all capable of complement fixation (33). Immunohistochemical staining revealed comparable depositions of complement component $\mathrm{C} 3$ and $\mathrm{MAC}$ in muscle biopsies that coincided with the localisation of $A C h R$ in both age groups. It has been shown that myoblasts express membrane regulatory proteins in order to protect them from complement mediated killing (34). In both young and aged rats, the basal expression of these proteins was under the detection level. Induction of EAMG in susceptible and resistant rats resulted in comparable expression of these factors. These results suggest that resistance to EAMG is not a result of a deficiency in 
immunopathological effector mechanisms in aged animals, since complement deficiency results in resistance to EAMG $(35,36)$. Nevertheless, in aged rats the postsynaptic membrane might be more resistant to focal lysis by MAC.

Differences in antibody fine specificity between young and aged rats could correlate a with particular pathogenic anti-AChR antibody subset in the young animals inducing EAMG. A large proportion of anti-AChR antibodies in $\mathrm{MG}$ and rats immunised with intact $\mathrm{AChR}$ are directed against the MIR, located on the $\alpha$-subunit at residues $67-76(37,38)$. No differences in the proportion of serum anti-MIR antibodies were found between susceptible and resistant rats. These results are in accordance with experiments in mice in which no correlation between susceptibility to EAMG and fraction of anti-MIR antibodies was found (39).

In vitro antigenic modulation experiments with TE671 cells showed that sera from young susceptible and aged resistant male rats are able to induce similar AChR loss. These results indicate that sera from aged rats are capable of inducing antigenic modulation. This suggests that resistance to AChR loss in old male rats is not due to a deficient anti-AChR antibody response, but most likely due to target organ resistance to antibody-mediated $\mathrm{AChR}$ loss. Nevertheless it can not be excluded that in aged rats the antibody heterogeneity is changed (e.g. related to fewer germinal centres) or a subset of protective antibodies is produced.

A small proportion of the anti-AChR antibodies in $M G$ is directed against the $\alpha-\mathrm{BT}$ binding site, causing immunopharmacological blockade of the acetylcholine binding site (40). These blocking antibodies are lower in sera from less severely affected patients (41). No difference in the amount of serum anti- $\alpha-B T$ binding site antibodies was found between susceptible and resistant animals, indicating that the absence of muscular weakness in aged rats is not due to absence of anti- $\alpha$-BT-binding site antibodies in aged rats. These results indicate that resistance to induction of EAMG is not a result of differences in antibody fine specificity towards the MIR or $\alpha$-BT binding site.

The induction chronic EAMG in young female BN rats was accompanied by overt myasthenic symptoms and significant AChR loss. In contrast, aged female $\mathrm{BN}$ rats showed no clinical signs of disease, although AChR loss was comparable to that in young animals. The absence of clinical signs of muscular weakness was verified by single fiber electromyography. 
Single fiber electromyography (SFEMG) is a very sensitive test for the early evaluation of neuromuscular defects in EAMG (22). No significant difference in jitter was found in aged rats before or six weeks after immunisation (data not shown). These results indicate that aged female rats are protected against impairment of neuromuscular transmission effectuated by $\mathrm{AChR}$ loss. Aged rats may compensate for this AChR loss by changes in threshold endplate potentials (safety factors) or by increasing their quantal release more efficiently to compensate for the decreased postsynaptic sensitivity resulting from AChR loss (42). Moreover, differences in susceptibility might be explained by changes at the endplate in aged rats, such as increased length and branching of the postsynaptic membrane and enlargement of the postsynaptic area, or wider spacing of the AChR molecules (43-46).

In contrast with the females, aged male rats did not even show AChR loss. Since resistance to chronic EAMG was not a result of deficient immunopathological mechanisms, this suggests a protective effect of androgens on the target organ in aged males compared to aged females. These results are in concordance with previous studies in experimental autoimmune models and with epidemiological evidence in man that show that androgens in contrast to female sex hormones have protective effects against the induction of disease $(18,19,47)$. Androgens and anabolic steroids, in contrast to female sex hormones have been shown to have protective effects against the manifestation of autoimmune disease in animal models such as murine systemic lupus erythematosus or spontaneous autoimmune thyroiditis in obese strain chickens $(48,49)$. Treatment with the weakly virilizing anabolic steroid nandrolon in chronic EAMG resulted in protection from severe clinical symptoms and diminished AChR loss (50). However, in passive transfer EAMG a deleterious effect was seen.

The results of our study indicate, that resistance to AChR loss in aged male BN rats is not due to a deficiency in antibody-mediated pathogenic effector mechanisms, but more probably to resistance of the target organ. Alternatively, aged animals may have more efficient mechanisms to compensate for AChR loss. To elucidate these possible mechanisms of resistance, in vivo $A C h R$ degradation studies and quantification of compensatory $\alpha$-subunit mRNA synthesis by competitive RT-PCR are in progress. 


\section{Acknowledgements}

The anthors wish to thank Mrs. M. Vroomen for excellent laboratory assistance, Dr. S. Tzartos for supplying mAb 35, Prof. H. Bazin for supplying anti-rat isotype antibodies, Prof W. Couser for supplying anti-rat MAC antibodies, Prof M. Daha for supplying antibodies against CD55 and CD59 and Dr. E. de Heer for supplying antibodies against vitronectin.

This work was supported by a grant from 'Het Prinses Beatrix Fonds' and 'L'Association Française contre les Myopathies:.

\section{References}

1 Drachman D, Angus C, Adams R, et al. Myasthenic antibodies cross-link acetylcholine receptors to accelerate degradation. N Engl J Med 1978; 298:1116-1122.

2 Loutrari L, Kokla A, Tzartos S. Passive transfer of experimental myasthenia gravis via antigenic modulation of acetylcholine receptor. Eur J Immunol 1992; 22:2449-2452.

3. Lang B, Richardson G, Rees J, et al. Plasma from myasthenia gravis patients reduces acetylcholine receptor agonist-induced $\mathrm{Na}+$ flux into TE671 cell line. J Neuroimmunol $1988 ; 19: 141-148$.

4 Anwyl $R$, Appel $S$, Narahashi $T$. Myasthenia gravis serum reduces acetylcholine sensitivity in cultured rat myotubes. Nature $1977 ; 267: 262-263$.

5 Oosterhuis H. Myasthenia gravis. A survey, Clin Neurol Neurosurg 1981; 83:105-135.

6 Oosterhuis $\mathrm{H}$. Clinical aspects. In: De Baets $M$, Oosterthuis $\mathrm{H}$ eds. Myasthenia gravis, Boca Raton: CRC Press, 1993.

7 Lindstrom J, Lennon V, Seybold M, et al. Experimental autoimmune Myasthenia Gravis and Myasthenia Gravis: Biochemical and immunochemical aspects. Ann NY Acad Sei $1976 ; 274: 254-274$.

8 Toyka $\mathbb{K}$, Drachman D, Pestronk A, et al. Myasthenia Gravis: passive transfer from man to mouse. Science 1975; 190:397-399.

9 Tzartos S, Hochschwender $S$, Vasquez $P$, et al. Passive transfer of experimental autoimmune myasthenia gravis by monoclonal antibodies to the main immunogenic region of the acetylcholine receptor. J Neuroimmunol 1987; 15:185 194 .

10 Biesecker $\mathrm{G}$, Koffler D. Resistance to experimental autoimmune Myasthenia Gravis in genetically inbred rats. J Immunol 1988; 140:3406-3410.

11 Graus Y, Verschuuren J, Spaans F, et al. Age-related resistance to experimental autoimmune Myasthenia Gravis in rats. J Immunol. 1993; 150:4093-4103. 
12 Price $G$, Makinodan T. Immunologic deficiencies in senescence. I Characterization of intrinsic deficiencies. J Immunol 1972; 108:403-412.

13 Goidl $E$, Michelis $M$, Siskind $G$, et al. Effect of age on the induction of autoantibodies. Clin Exp Immunol 1981; 44:24-30.

14 Talor $\mathbf{E}$, Rose $\mathrm{N}$. Hypothesis: The aging paradox and autoimmune disease. Autoimmunity $1991: 8: 245-249$.

15 Weigle W, Chu E. Age-related changes in he immune system and associated autoimmunity. Aging: Immunology and infectious disease 1994; 5:133-146.

16 Segal $\mathrm{R}$, Globerson $\mathrm{A}$, Zinger $\mathrm{H}$, et al. The influence of aging on the induction and manifestations of experimental systemic lupus erythematosus. I Clin Immunol 1992; 12:314-346.

17 Romball $\mathrm{C}$, Weigle $\mathrm{W}$. The effect of aging on the induction of experimental autoimmune thyroiditis. J Immunol 1987; 139:1490-1495.

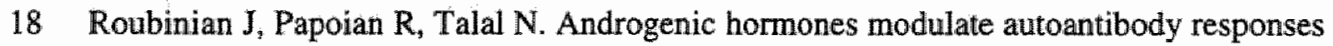
and improve survival in murine lupus. J Clin Invest 1977; 59:1066-1070.

19 Melez K, Boegel W, Steinberg A. Therapeutic studies in New Zealand mice. VII. Successful androgen treatment of NZB/NZW FI females of different age. Arthritis Rheumatism 1980;23:41-47.

20 Lindstrom $J$, Anholt $\mathbb{R}$, Einarson $B$, et al. Purification of acetyllcholine receptors, reconstitution into lipid vesicles and study of agonist-induced cation channel regulation. $J$ Biol Chem 1980; 255:8340-8350.

21 Lennon V, Lindstrom I, Seybold M. Experimental autoimmune myasthenia: a model of myasthenia gravis in rats and guinea pigs. I Exp Med 1975; 141:1365-1375.

22 Verschuuren J, Spaans F, De Baets M. Single-fiber electromyography in experimental autoimmune Myasthenia Gravis. Muscle Nerve 1990; 13:485-492.

23 Verschuren $\mathrm{J}$. Graus $\mathrm{Y}$, Theunissen $\mathrm{R}$, et al. Role of acetylcholine receptor antibody complexes in muscle in experimental autoimmune Myasthenia Gravis. I Neuroimmunol $1992 ; 36: 117-125$.

24 Tzartos $S$, Remoundos M. Precise epitope mapping of monoclonal antibodies to the cytoplasmic site of the acetylcholine $\alpha$-subunit. Dissecting a potentially myasthenogenic epitope. Bur J Biochem 1992; 207:915-922.

25 Sophianos D, Tzartos S. Fab fragments of monoclonal antibodies protect the human acetylcholine receptor against antigenic modulation caused by myasthenic sera. J Autoimmunity $1989 ; 2: 1-13$.

26 Luther $M$, Schoepfer $R$, Whiting $\mathrm{P}$, et al. A muscle acetylcholine receptor is expressed in the human cerebellar medulloblastoma cell line TE671. J Neurosci 1989; 9:1082-1096.

27 Bionda A, De Baets $M$, Tzartos $S$, et al. Spectrotypic analysis of antibodies to acetylcholine receptors in experimental autoimmune myasthenia gravis. Clin Exp Immunol 1984; 57:41-50. 
28 Conti-Tronconi $\mathrm{M}, \mathrm{McLane} \mathrm{K}$, Raftery $\mathrm{M}$, et al. The nicotinic acetycholime receptor: structure and autoimmune pathology. Crit Revs Biochem Mol Biol 1994; 29:69-123.

29 Witzemann $V$, Stein $E$, Barg $B$, et al. Primary structure and functional expression of the $\alpha-, \beta-, \gamma-\delta-$ and $\varepsilon$-subunits of the acetylcholine receptor from rat musele. Eur $J$ Biochem 1990; 194:437-448.

30 Arreaza E, Gibbons J, Siskind G, et al. Lower antibody response to tetanus toxoid associated with higher auto-anti-idiotypic antibody in old compared with young humans. Clin Exp Immunoll 1993; 92:169-173.

31 Price G, Makinodan T. Immunologic deficiencies in senescence. II Characterization of extrinsic deficiencies. J Immunol 1972; 108:413-417.

32 Zoda $T$, Yeh T, Krolick K. Clonotypic analysis of anti-acetylcholine receptor antibodies from experimental autoimmune myasthenia gravis-sensitive Lewis rats and experimental autoimmune myasthenia gravis-resistant Wistar Furth rats. J Immunol 1991; 146:663-670.

33 Bazin, $H$. Rat bybridomas and rat monoclonal antibodies, 1st edn. Boca Raton: CRC Press, 1990.

34 Gasque P, Morgan B, Legoedec J, et al. Human skeletal myoblasts spontaneously activate allogeneic complement but are resistant to killing. J Immunol 1996; 156:3402-3411.

35 Lennon V, Seybold M, Lindstrom J, et al. Role of complement in the pathogenesis of experimental autoimmune myasthenia gravis. J Exp Med 1978; 147:973-983.

36 Christadoss P. C5 gene influences the development of murine myasthenia gravis. J Immunol 1988; 140:2589-2592.

37 Tzartos SJ, Sophianos D, Efthimiadis A. Role of the main immunogenic region of acetylcholine receptor in Myasthenia Gravis. A Fab monoclonal antibody protects against antigenic modulation by human sera. J Immunol 1985; 134:2343-2349.

38 Tzartos $S$, Barkas $T$, Cung $M$, et al. The main immunogenic region of the acetylcholine receptor. Structure and role in Myasthenia Gravis. Autoimmunity 1991; 8:259-270.

39 Graus $\mathrm{X}$, van Breda Vriesman P, De Baets M. Characterization of anti-acetylcholine receptor (AChR) antibodies from mice differing in susceptibility for experimental autoimmune myasthenia gravis. Clin Exp Immunol 1993; 92:506-513.

40 Lefvert A, Cuenoud S, Fulpius B. Binding properties and subclass distribution of antiacetylcholine receptor antibodies in myasthenia gravis. $J$ Neuroimmunol $1981 ; 1: 125-135$.

41 Drachman D, Adams R, Josifek L, et al. Functional activities of autoantibodies to acetylcholine receptors and the clinical severity of myasthenia gravis. $N$ Engl $J$ Med 1982; 307:769-775.

42 Plomp J, Van Kempen G, De Baets M, et al. Acetylcholine release in myasthenia gravis: regulation at single endplate level. Ann Neurol 1995; 37:627-636.

43 Smith D, Williams K, Emmerling $M$. Changes in acetylcholine receptor distribution and binding properties at the neuromuscular junction during aging. Int $\mathrm{J}$ Devl Neuroscience $1990 ; 8: 629-642$. 
44 Wokke $\mathrm{J}_{\text {, Jennekens }} \mathrm{F}$, van den Oord $\mathrm{C}$, et al. Morphological changes in the human end plate with age. J Neurol Sci 1990; 95:291-310.

45 Courtney $\mathrm{J}$, Steinbach $\mathrm{J}$. Age changes in neuromuscular junction morphology and acetylcholine receptor distribution on rat skeletal muscle fibres. J Physiol 1981; 320:435447.

46 Oda $\mathbb{K}$. Age changes of motor innervation and acetylcholine receptor distribution on human skeletal muscle fibers. J Neurol Sci 1984; 66:327-338.

47 Verheul $\mathrm{H}$, Stimson W, Den Hollander $\mathrm{F}$, et al. The effects of nandrolon, testoterone and their decanoate esters on murine lupus. Clin Exp Immunol 1981; 44:11-17.

48 Roubinian R, Talal N, Greenspan J, et al. Effect of castration and sex hormone treatment on survival, anti-nucleic acid antibodies, and glomerolunephritis in NZB/NZW F1 mice. J Exp Med 1978; 147:1568-1583.

49 Schuurs A, Dietrich $\mathrm{H}$, Gruber J, et al. Effects of sex steroid analogs on spontaneous autoimmune thyroiditis in obese strain chickens. Int Arch Allergy Immunol 1992; 97:337344.

50 De Baets M, Verschuuren J, Daha M, et al. Effects of the rate of acetylcholine receptor synthesis on the severity of experimental autoimmune myasthenia gravis. Immunol Res $1988 ; 7: 200-211$. 


\title{
Chapter 3
}

\section{Macrophage infiltration at the neuromuscular junction does not contribute to AChR loss and age-related resistance to EAMG}

\author{
A. Hoedemaekers, Y. Graus ${ }^{*}$, L. Beijleveld *, P. van Breda Vriesman and M. De Baets
}

Maastricht University, Department of Immunology, P.O. Box 616, 6200 MD Maastricht, The Netherlands

* The Netherlands Cancer Institute, Division of Immunology, Plesmanlaan 121, 1066 CX Amsterdam, The Netherlands

\# Hôpital Purpan, Department Pathologie Rénale et Vasculaire, Inserm U28, Place du Dr. Baylac, 31059 Toulouse, France

Published in J. Neuroimmunol. 1997; 75: 147-155

\section{Summary}

Aged rats, resistant to acetylcholine receptor loss in passive transfer experimental autoimmune myasthenia gravis (EAMG), do not reveal infiltrating macrophages at the neuromuscular junction (NMJ) as observed in susceptible rats. It was investigated whether this age-related resistance is due to impaired macrophage function in these aged rats. Reconstitution of aged rats with bone marrow from young donors did not lead to macrophage infiltration, nor did it abolish resistance to EAMG. Subsequently, it was investigated whether macropages are a primary cause of acetylcholine receptor (AChR) loss in EAMG or attracted to the NMJ secondary to tissue damage. In lethally irradiated young susceptible rats infiltrating macrophages were absent at the NMJ. However, AChR loss was observed to the same extent in irradiated and non-irradiated rats. These results suggest that macrophages do not contribute to acetylcholine receptor loss in the effector phase of passive transfer EAMG and that age related resistance to passive transfer EAMG is not primarily determined by the absence of infiltrating macrophages. 


\section{Introduction}

Myasthenia gravis (MG) is caused by auto-antibodies directed against nicotinic acetylcholine receptors (AChR) at the neuromuscular junction (NMJ). Binding of anti-AChR antibodies to $\mathrm{AChR}$ at the postsynaptic membrane causes loss of functional $\mathrm{AChR}$ and defective neuromuscular transmission. This defective neuromuscular transmission leads to weakness and increased fatiguability of voluntary muscles. Experimental autoimmune myasthenia gravis (EAMG) is an excellent animal model to study the pathogenic effector mechanisms in $\mathrm{MG}$. Chronic EAMG can be induced by immunization with AChR in complete Freund's Adjuvant (CFA), resulting in clinicall symptoms and $A C h R$ loss 4 to 6 weeks after immunization, however, no infiltrating macrophages are observed (1). When rats are immunized with AChR in CFA with additionall Bordetella Pertussis vaccine, a bi-phasic course of disease is observed with an acute, transient phase 7-10 days after immunization (2). During this acute phase, endplates are invaded with mononuclear cells (3). When rats have recovered from acute EAMG, no invading mononuclear cells are found during the chronic phase of EAMG.

EAMG can also be induced by passive transfer of polyclonal or monoclonal antibodies directed against the $\mathrm{AChR}(4,5)$. In passive transfer EAMG, muscular weakness and AChR loss already occurs within $24-48$ hours after injection of anti-AChR antibodies. Similar to the Bordetella Pertussis induced acute EAMG, infiltrating mononuclear cells are observed at the endplate region (6). Upon induction of passive transfer EAMG, rats were refractory to induction of a second episode up to 8 weeks after the primary injection $(7,8)$. This refractory state is characterized by absence of infiltrating macrophages at the NMJ. When a chronic form of passive transfer EAMG is induced by repeated administration of anti-AChR antibodies, no infiltrating mononuclear cells are observed in the vicinity of the NMJ (9).

In addition to the differences in macrophage infiltration among the various $\mathrm{EAMG}$ models, difference in macrophage infiltration has also been found in relation to the age at which passive transfer EAMG was induced. Upon induction of passive transfer EAMG, aged rats were resistant to both clinical signs of disease and AChR loss (10). This resistance could not be attributed to deficient antibody uptake or clearance, inaccessability of the AChR for 
antibody or deficient complement activation. However, no infiltrating macrophages were observed at the NMJ in aged rats, in contrast to EAMG susceptible young rats.

In the present study we investigated the contribution of macrophages in the effector phase of EAMG. We tested whether resistance to EAMG in aged rats could be due to impaired macrophage function, by reconstituting aged rats with bone marrow from young syngeneic donors. In addition, we examined the contribution of macrophages to AChR loss in young susceptible rats, by depleting young rats from ED-1 positive macrophages prior to induction of passive transfer EAMG.

\section{Materials and Methods}

\section{Animals}

Inbred young (10 week aged) and aged (2 year aged) female BN rats were obtained from the breeding colonies of the Department of Experimental Animal Services of the Maastricht University, The Netherlands and from TNO, Leiden, The Netherlands. All animals were maintained under specified pathogen free conditions.

\section{Induction of passive transfer EAMG}

Rats were injected intraperitoneally with 20 pmol AChR binding capacity $100 \mathrm{~g}$ bodyweight of concentrated culture supernatant containing rat anti-AChR mAb 35. MAb 35 is a rat $\operatorname{lgG} 1 \mathrm{mAb}$ directed against the main immunogenic region (MIR) on the $\alpha$-subunit of the $A C h R$, crossreactive with manmalian $A C h R$ (11). Control rats were injected intraperitoneally with an equal volume of PBS. Rats were sacrificed 48 hours after induction of passive transfer EAMG. Disease severity was monitored by measuring weight loss.

\section{Bone marrow reconstitution}

Young and aged female BN rats were irradiated and reconstituted with bone marrow from 6 week old syngeneic donor rats as described previously (12). Briefly, young and aged rats were given $9.6 \mathrm{~Gy}$ at $0.5 \mathrm{~Gy} / \mathrm{min}$ using a Röntgen irradiator (Philips MG320, Hamburg, Germany), 1 
day prior to syngeneic bone marrow reconstitution. Bone marrow was collected from tibias and femurs of syngeneic 6 week old donors in Dulbecco's balanced salt solution (DBSS) supplemented with $2 \%$ heat-inactivated fetal calf serum, penicillin $(100 \mathrm{U} / \mathrm{ml})$, and streptomycin $(100 \mu \mathrm{g} / \mathrm{ml})$. Reciptent young rats were given $6 \times 10^{7}$ viable nucleated syngeneic bone marrow cells in $1 \mathrm{ml}$ DBSS intravenously into a tail vein. Aged rats were reconstituted with $1.2 \times 10^{8}$ bone marrow cells derived from young syngeneic donor rats. Passive transfer EAMG was induced in young and aged rats as described above at 4 weeks after irradiation.

\section{Leucocyte depletion by irradiation}

Prior to induction of passive transfer $E A M G$, young female $B N$ rats were irradiated with a dose of $9.6 \mathrm{~Gy}$ at $0.5 \mathrm{~Gy} / \mathrm{min}$ as described above, in order to deplete these rats from monocyte derived macrophages. Leucocyte depletion was monitored 72 hours after irradiation. At 48 hours after irradiation, passive transfer EAMG was induced according to the protocol mentioned above.

\section{Immunohistochemistry}

Presence of macrophages and membrane attack complex (MAC) at endplates was determined in cryosections of muscle biopsies. Mouse mAb ED-1 and ED-2 (a kind gift of Prof. C. Dijkstra, Vrije Universiteit, Amsterdam, The Netherlands) were used as markers for infiltrating inflammatory macrophages and resident tissue macrophages respectively (13, 14). Mouse mAb 2A1 (a kind gift of Prof. W. Couser, University of Washington, Seattle, US) was used to detect MAC (15). Muscle biopsy cryosections of young and aged rats were acetone-fixed for 10 min at $4^{\circ} \mathrm{C}$ and air-dried for $5 \mathrm{~min}$. After washing 3 times in PBS, the sections were pre-incubated in PBS containing $2 \%$ bovine serum albumin and subsequently incubated with the respective mAb or an irrelevant isotype-matched mAb, together with rhodamine labelled $\alpha$-Bungarotoxin (Molecular Probes, Eugene, OR, US) for 1 hr at room temperature, in order to co-localize AChR in the same section. After washing with PBS, the slides were incubated for $1 \mathrm{hr}$ with FITC labelled goat anti-mouse Ig (Cappel, Organon Technika, Boxtel, The Netherlands). A minimum of 5 endplates per section of at least 5 rats per group was analyzed. 


\section{Determination of $A C h R$ concentration}

The concentration of $A C h R$ was determined in whole carcasses as described previously $(16 ; 17)$. Briefly, frozen tissue was homogenized and membrane bound proteins were extracted with $2 \%$ Triton X-100 (Sigma, Brunschwig Chemie b.v., Amsterdam, The Netherlands). An aliquot of

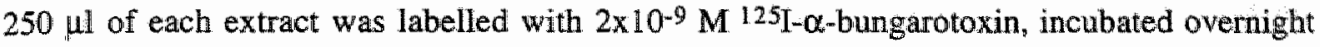
with excess rat anti-AChR IgG and precipitated by goat anti-rat IgG. AChR loss was expressed as \% loss from PBS control samples.

\section{Statistical analysis}

The Wilcoxon rank test was used for statistical analysis.

\section{Results}

Table 1: Resistance to passive transfer EAMG in old rats is not related to absence of infilltrating macrophages at the NMJ

\begin{tabular}{cccccccc}
\hline $\begin{array}{c}\text { Age } \\
\text { weeks }\end{array}$ & $\begin{array}{c}\text { Bone marrow } \\
\text { reconstitution }\end{array}$ & mAb 35 & $\begin{array}{c}\text { Leucocytes } \\
\left(\times 10^{6} / \mathrm{ml}\right)\end{array}$ & $\begin{array}{c}\text { Lympho } \\
(\%)\end{array}$ & $\begin{array}{c}\text { Neutro } \\
(\%)\end{array}$ & $\begin{array}{c}\text { Eos } \\
(\%)\end{array}$ & $\begin{array}{c}\text { Mono } \\
(\%)\end{array}$ \\
\hline 10 & + & + & $5,6 \pm 1,3$ & $84 \pm 6$ & $12 \pm 5$ & $1 \pm 1$ & $3 \pm 2$ \\
10 & + & - & $5,6 \pm 1,3$ & $84 \pm 6$ & $11 \pm 7$ & $1 \pm 1$ & $5 \pm 1$ \\
10 & - & + & $12,3 \pm 2,0$ & $85 \pm 2$ & $11 \pm 1$ & $2 \pm 1$ & $3 \pm 2$ \\
104 & + & + & $6,4 \pm 1,1$ & $65 \pm 3$ & $25 \pm 2$ & $2 \pm 1$ & $8 \pm 2$ \\
104 & - & - & $5,2 \pm 0,2$ & $71 \pm 1$ & $27 \pm 4$ & $1 \pm 0$ & $4 \pm 3$ \\
\hline
\end{tabular}

Bone marrow reconstitution resulted in leucocyte numbers and distribution comparable to age matched controls: Young rats, injected with mAb 35, showed ED-1 positive infiltrates at the NMJ. After irradiation and bone marrow reconstitution, comparable infiltrates were detectable at the NMJ. In old rats no infiltrates of ED-1 positive macrophages were detectable in old rats, reconstituted with bone marrow from young donors. ED-2 positjve macrophages were distributed randornly throughout the muscle, but they did not accumulate at the NMI. The distribution of ED-2 positive macrophages and deposition of MAC was comparable in all groups injected with mAb 35 . 
Table I: continued

\begin{tabular}{cccccccc}
\hline $\begin{array}{c}\text { Age } \\
\text { weeks }\end{array}$ & $\begin{array}{c}\text { Bone marrow } \\
\text { reconstitution }\end{array}$ & mAb35 & ED-1 & ED-2 & MAC $^{*}$ & EAMG $^{\text {E }}$ \\
\hline 10 & + & + & + & + & + & + \\
10 & + & - & - & + & - & - \\
10 & - & + & + & + & + & + \\
104 & + & + & - & + & + & - \\
104 & - & - & - & + & - & - \\
\hline
\end{tabular}

\# Positive staining exclusiwely at the neuromuscular junction

* Positive staining random throughout the muscle section

$\$$ EAMG indicates presence of muscular weakness and AChR loss

Passive transfer EAMG in young and aged rats after reconstitution with bone marrow from young syngeneic donors

The absence of invading macrophages at the NMJ of EAMG resistant aged rats may be due to an impaired macrophage function in aged rats. Therefore, young and aged rats were lethally irradiated and reconstituted with bone marrow from young donors, 4 weeks prior to induction of EAMG.

At the moment of induction of passive transfer EAMG, total number of leucocytes in reconstituted young and aged rats were $5.6 \pm 1.3$ and $6.4 \pm 1.1 \times 10^{6} / \mathrm{ml}$ blood respectively (Table 1). Leucocyte differentiation was determined at 48 hours after induction of passive transfer EAMG. The leucocyte population in young control rats, injected with mAb 35 , consisted of $85 \%$ lymphocytes, $11 \%$ neutrophils, $2 \%$ eosinophils and $3 \%$ monocytes (Table 1). This leucocyte differentiation pattern was similar to that of normal young rats, injected with PBS (not shown). Compared to young rats, lymphocyte numbers in aged control rats were reduced to $71 \%$, while the number of neutrophils increased to $25 \%$. The relative amounts of eosinophils and monocytes were simillar to young rats. Reconstitution of aged rats with bone marrow from young donors resulted in a differentiation pattem similar to aged control rats.

The presence of macrophages was assessed in muscle biopsy cryosections. Infiltration of ED-1 positive activated macrophages in the vicinity of the $\mathrm{NMJ}$ and necrotic muscle fibers were 

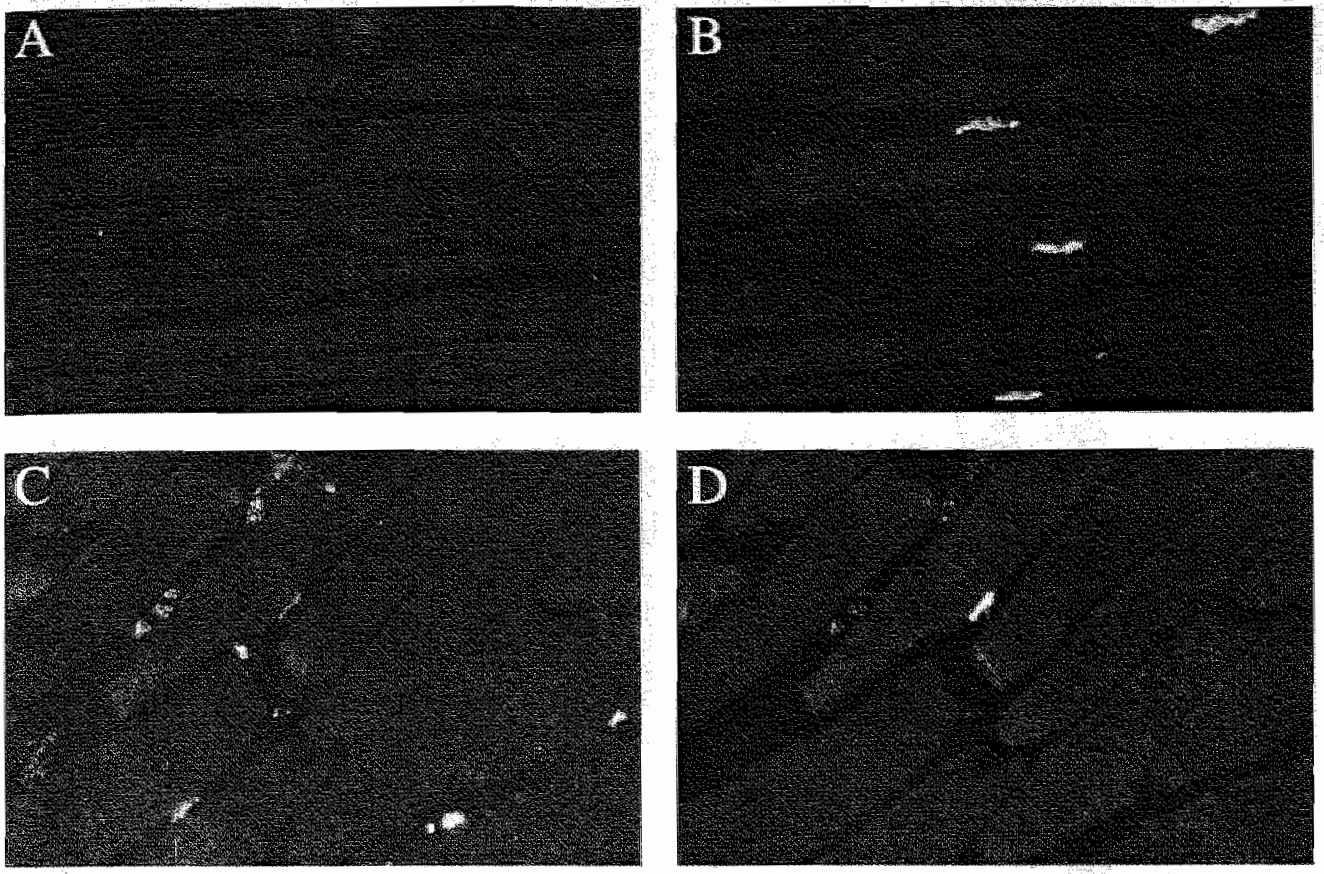

Figure 1: Reconstitution of aged rats with young bone marrow does not lead to macrophage infiltration at the NMJ. $A C h R$ and ED-1 or ED-2 positive macrophages were visualized by two-color immunofluoresence in muscle sections obtained 48 hours after injection with mAb 35. (A) No ED-1 positive macrophages were present at the NMJ in aged EAMG rats, reconstituted with young bone marrow. (B) The same muscle section stained for $A C h R$ with rhodaminated $\alpha$-Bungarctoxin. (C) ED-2 positive tissue macrophages could be demonstrated throughout the muscle section in aged rats, but did not accumulate at the NMIJ. (D) The same muscle section stained for AChR. Magnification 350x.

found in both reconstituted and non-reconstituted young rats, treated with mAb 35 (EAMG rats) (Table 1). Despite reconstitution with bone marrow from young donors, no ED-1 positive macrophages could be detected at the NMJ of reconstituted aged EAMG rats (Figure 1A/B). Resident ED-2 positive tissue macrophages, were distributed randomly throughout the entire muscle section, but they did not accumulate at the NMJ (Figure ICID). The distribution of these ED-2 positive tissue macrophages was comparable in all groups. Deposition of MAC was present in both young and aged rats injected with mAb 35, indicating that complement activation to the final stage of MAC had occurred (Figure 2A/B). ED-1 positive macrophages or MAC depositions were absent in muscle sections from PBS treated (control) rats (not shown). 

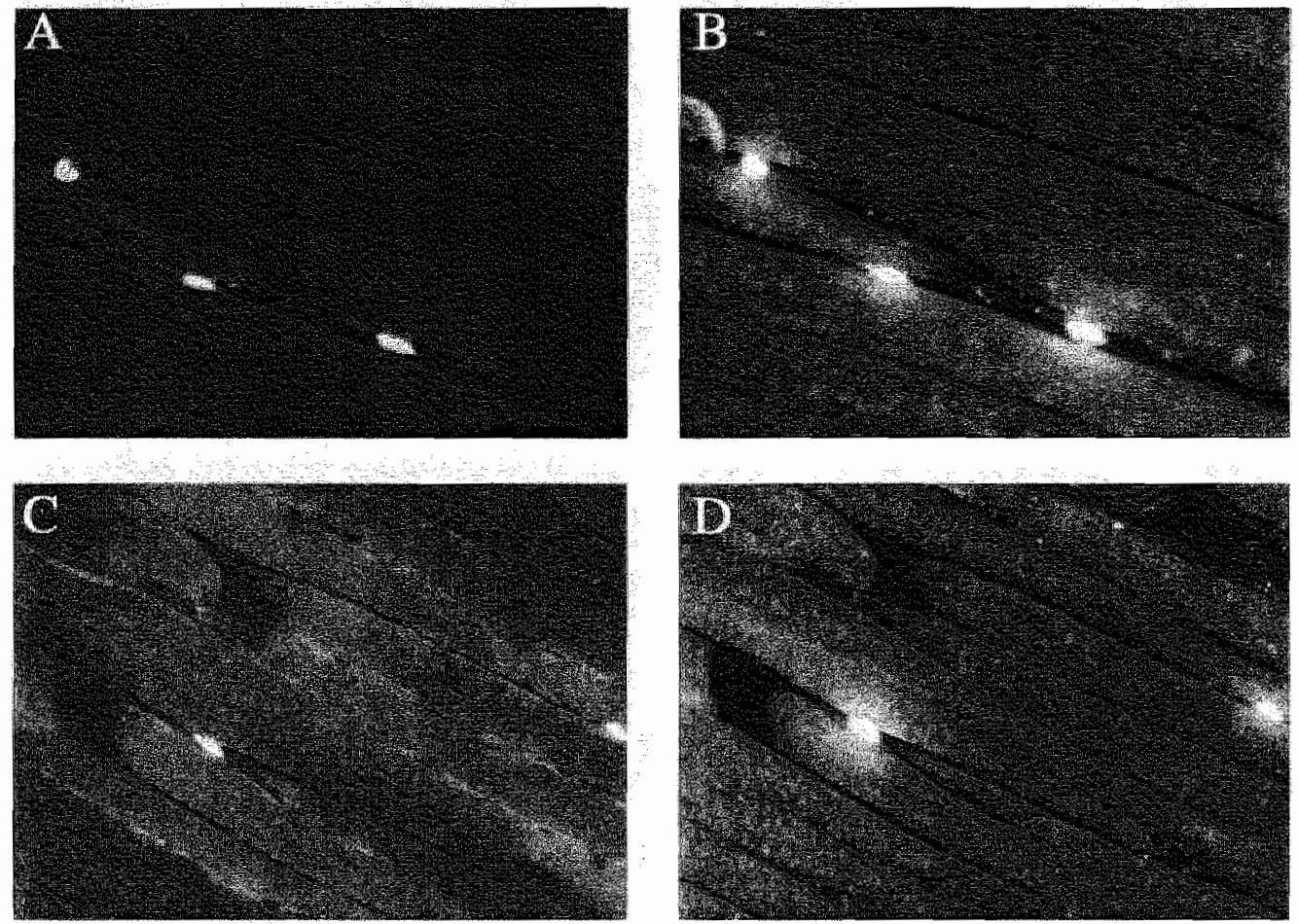

Figure 2: Depositions of MAC are present in resistant aged rats and irradiated susceptible young rats. Deposition of $\mathrm{MAC}$ and $\mathrm{AChR}$ were visualized by two-color immunofluorescence in muscle sections obtained 48 hours after injection with inAb 35. (A) Deposition of MAC was found in the vicinity of the NMJ in resistant aged rats. (B) The same muscle section stained for AChR. (C) Lethal irradiation, prior to induction of passive transfer EAMG did not affect the formation of MAC at the NMJ. (D) The same muscle section stained for AChR. Magnification: 350x.

Induction of passive transfer EAMG in both reconstituted and non-reconstituted young rats resulted in severe clinical signs of disease and significant weight loss of $14 \pm 2 \%$ from their initial weight (Figure 3). Aged rats, reconstituted with young bone marrow, were clinically resistant to induction of EAMG and suffered minor weight loss of $4 \pm 3 \%$ of their initial weight (NS). No significant weight change was observed in young and aged PBS treated rats.

Susceptibility to EAMG after bone marrow reconstitution was monitored by measuring AChR loss. Young; non-irradiated rats showed significant AChR loss of $53 \pm 6 \%$ compared to control rats ( $p<0.01$ ) (Figure 4). Similar AChR loss was found in young rats after bone marrow reconstitution $(59 \pm 6 \%, \mathrm{p}<0.01)$. Aged rats, irradiated and reconstituted with young bone marrow, were resistant to $\mathrm{AChR}$ loss $(2 \pm 6 \% \mathrm{AChR}$ loss compared to control rats). 


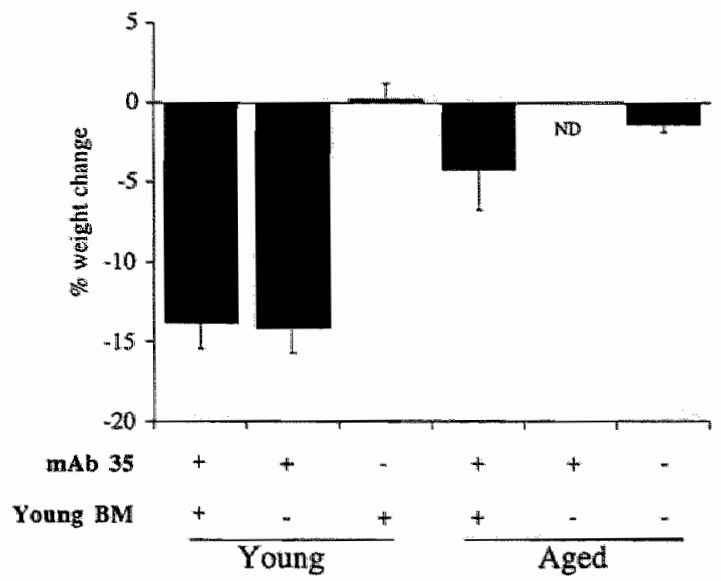

Figure 3: Reconstitution with young bone marrow does not abolish clinical resistance to EAMG in old rats. Rats, recovered from initial weight loss caused by irradiation, were injected with 20 pmol anti-AChR mAb 35 or PBS. Induction of EAMG in young bone marrow (BM) reconstituted and control rats resulted in significant weight loss after 48 hours of $14 \pm 2 \%$ from the initial weight. Aged rats, reconstituted with bone marrow from young donors were clinically resistant and showed no significant weight loss from the initial weight. Results are expressed as \% weight loss from the initial weight at the time of induction of EAMG. Each value represents mean weight change of $4-7$ rats.

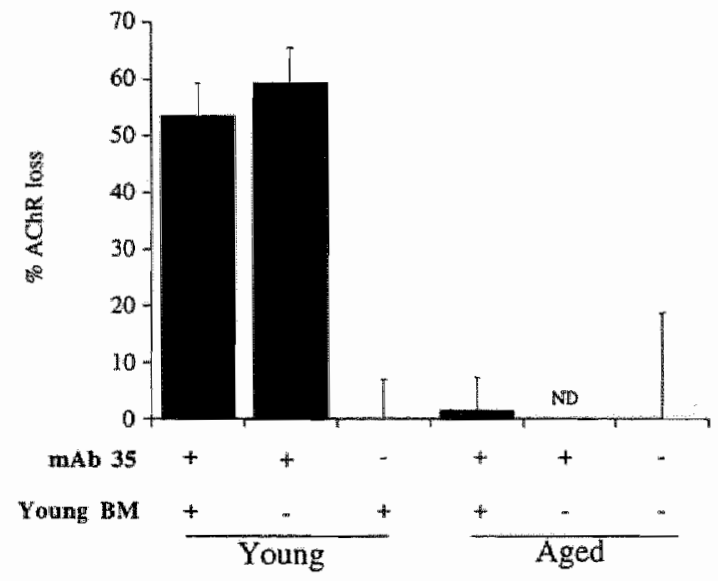

Figure 4: Reconstitution witt young bone marrow does not abolish resistance to AChR loss in old rats. AChR concentration was measured at 48 hours after induction of passive transfer EAMG. Young irradiated and reconstituted rats and young non-reconstituted rats showed comparable AChR loss of $59 \pm 6 \%$ and $53 \pm 6 \%$ respectively, compared to control rats. Aged rats, reconstituted with young $B M$, were resistant to AChR loss ( $2 \pm$ 6\% AChR loss). Results are expressed as \% AChR loss compared to age matched PBS treated control groups. Results represent mean values from $4-7$ rats. 
Passive transfer EAMG in young rats after monocyte depletion

The contribution of macrophages to the pathogenesis of EAMG was investigated in rats depleted of circulating monocytes by lethal irradiation, 48 hours prior to induction of passive transfer EAMG. Leucocyte numbers were significantly reduced to $0.2-0.4 \times 106 / \mathrm{ml}$ blood in irradiated compared to $4.4-5.3 \times 10^{6} / \mathrm{ml}$ in non-irradiated rats $72 \mathrm{hrs}$ after irradiation (Table 2).

Table 2: Leucocyte depletion prevents macrophage infiltration at the NMJ

\begin{tabular}{cccccccc}
\hline $\begin{array}{c}\text { Age } \\
\text { weeks }\end{array}$ & Irradiation & mAb 35 & $\begin{array}{c}\text { Leucocytes } \\
\left(\times 10^{6} / \mathrm{ml}\right)\end{array}$ & ED-1 & ED-2 $^{*}$ & MAC $^{\#}$ & EAMG $^{\$}$ \\
\hline 10 & + & + & $0,4 \pm 0,2$ & - & + & + & + \\
10 & + & - & $0,2 \pm 0,1$ & - & + & - & - \\
10 & - & + & $5,3 \pm 3,7$ & + & + & + & + \\
10 & - & - & $4,4 \pm 1,5$ & - & + & - & + \\
\hline
\end{tabular}

Lethal irradiation resulted in a strong reduction of leticocyte numbers in peripheral blood. ED-1 positive infiltrates at the neuromuscular junctions were only observed in non-irradiated EAMG rats. No ED-1 positive macrophages were detectable in irradiated rats. The distribution of ED-2 positive tissue macrophages was similar in irradiated and non-irradiated rats and randomly distributed throughout the muscle section. Deposition of MAC at the neuromuscular junction was not affected by irradiation.

\# Positive staining exclusively at the neuromuscular junction

* Positive staining random throughout the muscle section

$\$ \quad$ EAMG indicates presence of muscular weakness and AChR loss

Upon induction of passive transfer EAMG, infiltration of ED-1 positive macrophages in the vicinity of NMJ and necrotic muscle fibers were found in non-irradiated EAMG rats (Figure 5A/B). ED-2 positive tissue macrophages were distributed randomly throughout the entire muscle section, but they did not accumulate at the NMJ. In contrast, no infiltration of ED-1 positive macrophages was observed in irradiated EAMG rats (Figure 5C/D). The distribution of ED-2 positive tissue macrophages was similar to non-irradiated rats, indicating that resident tissue macrophages are relatively resistant to irradiation (Figure 5E/F). Depositions of MAC at the NMJ were similar in irradiated and non-irradiated rats, suggesting that formation of MAC was not affected by irradiation (Figure $2 \mathrm{C} / \mathrm{D}$ ). No ED-1 positive macrophages nor MAC depositions were found in control rats (not shown). 

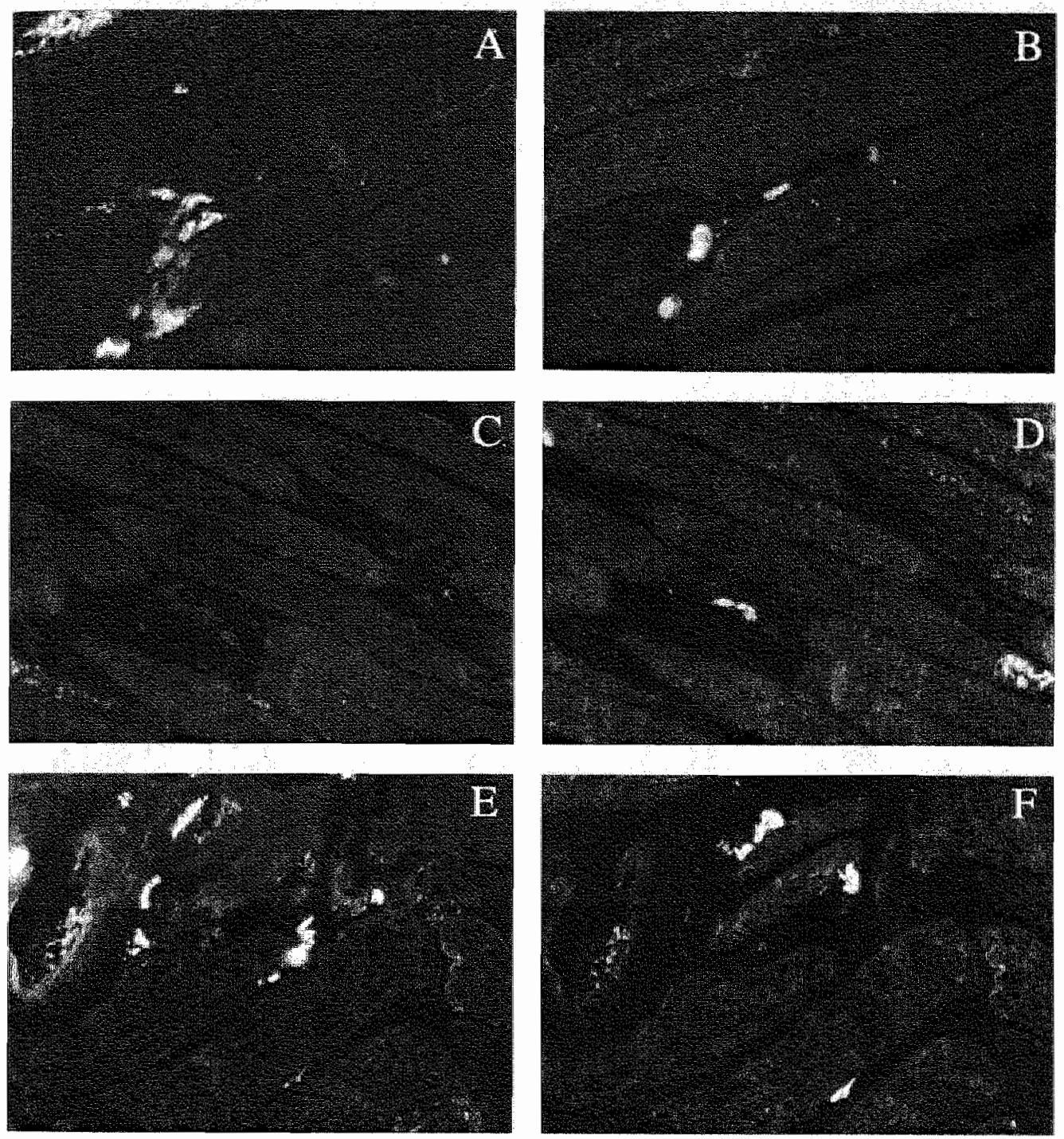

Figure 5: Lethal irradiation results in absence of infiltrating ED-1 positive macrophages at the NMJ. AChR and ED-1 or ED-2 positive macrophages were visualized by two-color immunofluoresence in muscle sections from EAMG rats. (A) Infiltration of ED-1 positive macrophages was found in the vicinity of the NMJ in young, nonirradiated EAMG rats. (B) The same muscle section stained for AChR. (C) Lethal irradiation, prior io induction of passive transfer EAMG, prevented infiltration of ED-1 positive macrophages at the NMT. (D) The same miuscle section stained for AChR. (E) ED-2 positive macrophages were distributed randomlly throughout the muscle section in irradiated young EAMG rats. (F) The same muscle section stained for AChR. Magnification: $350 \mathrm{x}$. 
Weight loss, as a measure for severity of disease, was determined 48 hours after the induction of EAMG. Non-irradiated EAMG rats developed clinical signs of disease and significant weight loss of $5 \pm 2 \%$ of their initial weight $(p<0.05)$, whereas non-irradiated control rats remained at their initial weight. Induction of passive transfer EAMG in irradiated rats also resulted in muscular weakness, whereas control rats showed no clinical signs of disease. Weight loss in irradiated EAMG and control rats was comparable $(8 \pm 1 \%$ and $5 \pm 1 \%$ weight loss from the initial weight) as a result of the irradiation.

Loss of AChR in total muscle was determined 48 hours after the induction of EAMG. Non-irradiated EAMG rats showed significant AChR loss ( $49 \pm 5 \%$ ) compared to non-irradiated control rats $(\mathrm{p}<0.05$ ) (Figure 6). Irradiated EAMG rats showed $47 \pm 5 \% \mathrm{AChR}$ loss compared to irradiated control rats $(\mathrm{p}<0.01$ ). Total $\mathrm{AChR}$ concentration was not reduced by lethal irradiation, since in both irradiated and non-irradiated control rats AChR concentrations were not significantly different $(77 \pm 13$ and $81 \pm 7$ pmol/100g respectively, NS). These results indicate that macrophages do not contribute to AChR loss in passive transfer EAMG.

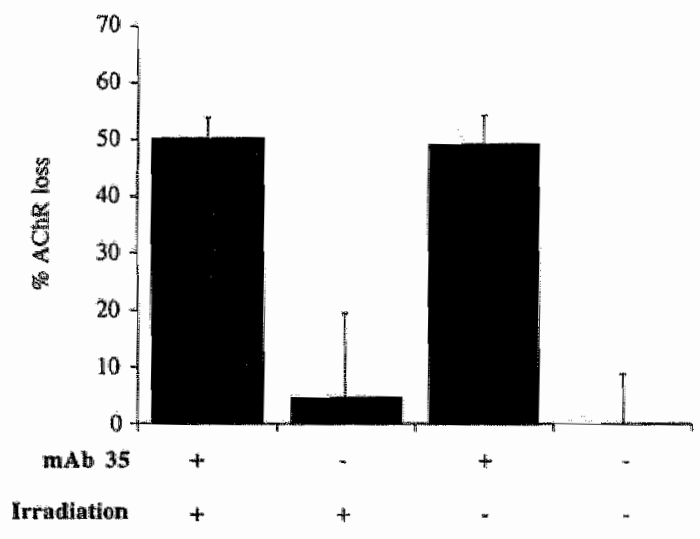

Figure 6: Macrophage depletion at the NMJ does not result in resistance to AChR loss. AChR concentration was determined in total muscle 48 hours after the induction of passive transfer EAMG. Non-irradiated EAMG rats showed $49 \pm 5 \%$ AChR loss. Irradiation prior to induction of passive transfer EAMG resulted in similar AChR loss of $47 \pm 5 \%$. Results are expressed as $\%$ AChR loss compared to PBS treated control groups. Results represent mean values from 7 rats in each irradiated group and 4 rats in each non-irradiated group. 


\section{Discussion}

In this study we examined the contribution of macrophages to AChR loss and age related resistance to EAMG. Reconstitution of aged rats with young bone marrow prior to induction of EAMG, did not restore macrophage infiltration and did not abolish resistance to EAMG. Furthermore, leucocyte depletion of young EAMG susceptible rats by lethal irradiation resulted in absence of ED-1 positive infiltrating macrophages at the NMJ. However, the absence of macrophage infiltration at the NMJ did not protect against antibody mediated AChR loss. Therefore, invading macrophages do not contribute to AChR loss in the effector phase of EAMG and resistance to passive transfer EAMG in aged rats is not primarily determined by the absence of infiltrating macrophages.

In order to investigate whether the resistance to passive transfer EAMG in aged rats was related to an inability of macrophages to invade the NMJ, aged rats were irradiated and reconstituted with bone marrow from young syngeneic donors prior to induction of EAMG. Aged rats, reconstituted with bone marrow from young donors, have a similar leucocyte differentiation as unmanipulated aged rats. This indicates that the differentiation of (young) stem cells is determined by the aged micro-environment: However, the number of circulating monocytes in reconstituted aged rats was similar to young rats. Nevertheless, no macrophage infiltration at the NMJ was found and rats remained resistant to induction of passive transfer EAMG. A general decline in irmune function is associated with aging $(18,19)$. In addition to functional and structural defects in T and B cells, several studies show that macrophage function also changes with aging. Both phagocytic capacity and cytotoxic activity were diminished in aged BALB/c mice (20). In aged rats, the superoxide generation by alveolar macrophages was decreased , but improved when treated in vitro with IFN- $\gamma(21)$. In contrast, only the number of phagocytized particles per monocyte were diminished in aged humans, whereas qualitative analysis of blood monocytes revealed no changes with aging (22). However, other studies claim that the phagocytic capacity of macrophages in aged mice is not impaired (23). Moreover, it has been shown that in aged rats macrophages are able to infiltrate myocardial tissue to the same extent as in young rats (24). In addition, it has been shown that reconstitution of young mice 
with bone marrow from aged syngeneic mice resulted in phagocytosis which was equally effective as in young untreated mice, suggesting that bone marrow stem cells from young and aged animals are functionally comparable (25).

Induction of passive transfer EAMG in susceptible rats is characterized by infiltration of NMJ with macrophages. These macrophages are ED-1 positive and represent newly recruited exudate macrophages (26). Irradiation of rats, prior to induction of passive transfer EAMG, resulted in absence of macrophage infiltration at NMJ. However, macrophage depletion did not protect rats from clinical signs of disease or AChR loss. These results indicate that macrophages do not contribute to the pathogenesis of neuromuscular dysfunction in passive transfer EAMG. It is more likely that macrophages infiltrate the muscle secondary to tissue necrosis. In accordance with these results is the observation that macrophages do not seem to play a primary role in the pathogenesis of human MG. Although mononuclear cells are detected throughout the muscle in the majority of MG patients, only a small percentage of endplates are infiltrated by macrophages $(27,28)$. Partial depletion of macrophages in chronic EAMG by intraperitoneal injection of silica dust, resulted in lower antibody titers and longer survival of rats (29). The effect seen is more likely a consequence of the depletion of antigen-presenting cells in the induction phase of the antibody response rather than depletion of effector cells that invade the NMJ.

In contrast to MG and EAMG, macrophages can play a primary role in the effector phase of (experimental) autoimmune disease. Selective depletion of macrophages is known to have beneficial effects in several experimental autoimmune diseases. In experimental autoimmune encephalomyelitis (EAE), macrophages play a crucial role in the generation of tissue damage. Elimination of macrophages in EAE by pretreatment with dichloromethylene diphosphonate containing liposomes or $\mathrm{mAb}$ against complement receptor type 3 , resulted in a marked suppression of the disease $(30,31)$. Treatment with toxic liposomes also prevented clinical signs of experimental autoimmune neuritis (32). Administration of a nitric oxide synthase inhibitor in mice resulted in suppression of low dose streptozotocin induced diabetes (33). 
The predominant immune effector response in EAMG is antibody mediated and involves activation of the lytic phase of the complement cascade. Despite the absence of infiltrating macrophages, ubiquitous depositions of MAC were found at all endplates of young irradiated EAMG rats. Activation of the complement cascade also results in the production of chemotactic factors, including $\mathrm{C} 3 \mathrm{a}$ and $\mathrm{C5}$. Despite the apparent depositions of $\mathrm{MAC}$, no infiltrating macrophages were found in resistant aged rats. This indicates that antibody mediated immunopathological effector mechanisms were operational and chemotactic factors for the attraction of macrophages were present. The concentration of these chemotactic factors may be lower in aged rats. It has been shown previously however, that aged rats remained resistant upon injection of a 3-fold higher amount of mAb 35 than used in this study (10). Therefore, it is more likely, that chemotactic factors alone are insufficient for attraction of macrophages; additional factors such as muscle fiber necrosis are probably required to induce macrophage infiltration.

The results of our study suggest that the absence of infiltrating macrophages in aged rats in passive transfer EAMG is not due to decreased macrophage function in these rats, but more likely the absence of $\mathrm{AChR}$ loss and muscle fiber necrosis prevents chemotaxis of macrophages towards the NMJ. Aged resistant rats seem to have similar effective immunopathogenic effector mechanisms compared to susceptible young rats (34). Hence the resistance to induction of EAMG in aged rats appears to reside in the target organ. Furthermore, in susceptible rats macrophages do not contribute to AChR loss in the effector phase of EAMG but are more likely a phenomenon secondary to $\mathrm{ACh} R$ loss and tissue damage.

\section{Acknowledgements}

The authors wish to thank Mrs M. Vroomen and J. van de Gaar for excellent technical assistance, Dr. S. Tzartos for supplying mAb 35, Prof. W. Couser for supplying anti-rat MAC antibodies, Prof. C. Dijkstra for supplying antibodies against macrophage ED-1 and ED-2 and Dr. J. Damoiseaux for helpful discussions.

This work was supported by grants from 'Het Prinses Beatrix Fonds', 'L'Association Française contre les Myopathies' and EC Biomed (BMHI-CT93-1100). 


\section{References}

1 Lindstrom J, Einarson B, Lennon $\mathrm{V}$, et al. Pathological mechanisms in experimental autoimmune myasthenia gravis. I. Immunogenicity of syngeneic muscle acetylcholine receptor and quantitative extraction of receptor and antibody-receptor complexes from muscles of rats with experimental autoimmune myasthenia gravis. I Exp Med 1976; 144:726-738.

2. Lennon V, Lindstrom J, Seybold M. Experimental autoimmune myasthenia: a model of myasthenia gravis in rats and guinea pigs. J Exp Med 1975; 141:1365-1375.

3 Engel A, Tsujihata M. The motor end plate in myasthenia gravis and in experimental autoimmune myasthenia gravis. A quantitative ultrastructural study. Ann N Y Acad Sci $1976 ; 274: 60-79$.

4 Toyka $K$, Drachman D, Pestronk A, et al. Myasthenia Gravis: passive transfer from man to mouse. Science $1975 ; 190: 397-399$.

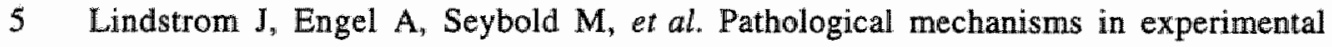
autoimmune myasthenia gravis. II. Passive transfer of experimental autoimmune myasthenia gravis in rats with anti-acetylcholine receptor antibodies. J Exp Med 1976; 144:739-753.

6 Engel A, Sakakibara $\mathrm{H}$, Sahashi $\mathrm{K}$, et al. Passively transferred experimental autoimmune Myasthenia Gravis. Sequential and quantitative study of the motor end-plate fine structure and ultrastructural localization of immune complexes ( $\mathrm{IgG}$ and $\mathrm{C} 3$ ), and of the acetylcholine receptor. Neurology 1979; 29:179-188.

7 Corey A, Richman D, Shuman C, et al. Use of monoclonal antiacetylcholine receptor antibodies to investigate the macrophage inflammation of acute experimental Myasthenia Gravis: refractoriness to a second episode of acute disease. Neurology $1985 ; 35: 1455$ 1460 .

8 Corey A, Richiman D, Agius M, et al. Refractoriness to a second episode of experimental Myasthenia Gravis. Correlation with $\mathrm{AChR}$ concentration and morpholigic appearance of the postsynaptic membrane. J Immunol 1987; 138:3269-3275.

9 Gomez C, Richman D. Chronic experimental autoimmune myastenia gravis induced by monoclonal antibody to the acetylcholine receptor: biochemical and electrophysiologic criteria. J Immunol 1987; 139:73-76.

10 Graus $\mathrm{Y}$, Verschuuren J, Spaans F, et al. Age-related resistance to experimental autoimmune Myasthenia Gravis in rats. J Immunol 1993; 150:4093-4103.

11 Tzartos $S$, Hochschwender $S$, Vasquez $P$, et al. Passive transfer of experimental autoimmune myasthenia gravis by monoclonal antibodies to the main immunogenic region of the acetylcholine receptor. J Neuroimmunol 1987; 15:185-194. 
12 Bos G, Majoor G, van Breda Vriesman P. Cyclosporim A induces a selective, reversible suppression of $T$-helper lymphocyte regeneration after syngeneic bone marrow transplantation: Association with syngeniec graft-versus-host disease. Clin Exp Immunol $1988 ; 74: 1457-1465$.

13 Dijkstra $C$, Dopp $E_{\text {, Joling }} \mathrm{P}$, et al. The heterogeneity of mononuclear phagocytes in lymphoid organs: distict macrophage subpopulations in the rat recognized by monoclonal antibodies ED1, ED2 and ED3. Immunology 1985; 54:589-599.

14 Damoiseaux J, Dopp E, Calame W, et al. Rat macrophage lysosomal membrane antigen recognized by monoclonal antibody ED1. Immunology 1994; 83:140-147.

15 Schulze M, Baker $P$, Perkinson D, et al. Increased urinary excretion of C5b-9 distinguishes passive heymann nephritis from other forms of experimental glomerulonephritis in the rat. Kidney Int 1989; 36:60-?

16 Lindstrom $\mathrm{J}$, Lennon V, Seybold $\mathrm{M}$, et al. Experimental autoimmune Myasthenia Gravis and Myasthenia Gravis: Biochemical and immunochemical aspects. Ann NY Acad Sci 1976; $274: 254-274$.

17 Verschuuren J, Graus $Y$, Theunissen $\mathbb{R}$, et al. Role of acetylcholine receptor antibody complexes in muscle in experimental autoimmune Myasthenia Gravis. I Neuroimmunol 1992; 36:117-125.

18. Price $G$, Makinodan T. Immunologic deficiencies in senescence. I Characterization of intrinsic deficiencies. J Immunol 1972; 108:403-412.

19 Price $\mathrm{G}$, Makinodan $\mathrm{T}$. Immunologic deficiencies in senescence. II Characterization of extrinsic deficiencies. J Immunology $1972 ; 108: 413-417$.

20 De La Fuente $M$. Changes in the macrophage function with aging. Comp Biochem Physiol 1985; 81A:935-938.

21 Hayakawa H, Sato A, Yagi T, et al. Superoxide generation by alveolar macrophages from aged rats: improvement by in vitro treatment with IFN- $\gamma$. Mech Ageing Dev 1995; 80:199. 211.

22 Nielsen H, Blom J, Larsen S. Human blood monocyte function in relation to age. Acta Path Microbiol Immunol Scan 1984; 92:5-10.

23 Ortega E, Forner M, Barriga C, et al. Effect of age and of swimming induced stress on the phagocytic capacity of peritoneal macrophages from mice. Mech Ageing Dev 1993; 70:53-63.

24 Hinglais $\mathrm{N}$, Heudes $\mathrm{D}$, Nicoletti $\mathrm{A}$, et al. Colocalization of myocardial fibrosis and inflammatory cells in rats. Lab Invest 1994; 70:286-294.

25 Grounds M. Phagocytosis of necrotic muscle in muscle isografts is influenced by the strain, age and sex of host mice. I Pathol 1987; 153:71-82.

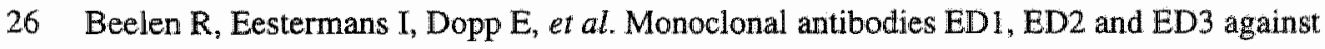
rat macrophages: expression of recognized antigens in different stages of differentiation. Transp] Proc 1987; 19:3166-3170. 
27 Nakano S , Engel AG. Myasthenia Gravis: Quantitative immunocytochemical analysis of inflammatory cells and detection of complement membrane attack complex at the endplate in 30 patients. Neurology 1993; 43:1167-1172.

28 Maselli R, Richman D, Wollmann R. Inflammation at the neuromuscular junction in myasthenia gravis. Neurology 1991; 41:1497-1504.

29 Kinoshita I, Nakamura $T$, Satoh A, et al. Role of macrophage in the pathogenesis of experimental autoimmune myasthenia gravis. J Neurol Sci 1988; 87:49-59.

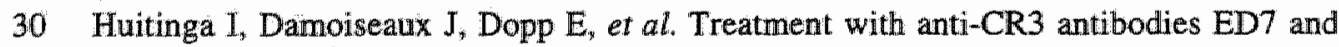
ED8 suppresses experimental autoimmune allergic encephalomyelitis in Lewis rats. Eur J Immunol 1993; 23:709-715.

31 Huitinga I, Rooijen $\mathrm{N}$, de Groot $\mathrm{C}$, et al. Suppression of experimental allergic encephalomyelitis in Lewis rats after elimination of macrophages. J Exp Med 1990; 172: 1025-1033.

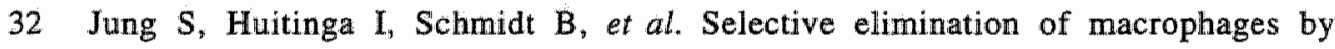
dichlormethylene diphosphonate-containing liposomes suppresses experimental autoimmune neuritis. J Neurol Sci 1993; 119:195-202.

33 Kolb $\mathrm{H}$, Kiesel $\mathrm{U}$, Kronke $\mathrm{K}$, et al. Suppression of low dose streptozotocin induced diabetes in mice by administration of a nitric oxide synthase inhibitor. Life Sci 1991; 49:PL213-PL217.

34 Hoedemaekers A, Graus Y, van Breda Vriesman P, et al. Age- and sex-related resistance to experimental autoimmune myasthenia gravis in Brown Norway rats. Clin Exp Immunol 1997; 107:189-197. 


\section{Chapter 4}

\section{Age-related resistance to EAMG: immunological and electrophysiological aspects}

A. Hoedemaekers, J. Verschuuren ${ }^{*}$, F. Spaans $\#$, Y. Graus $\$$, S. Riemersma, P. van Breda Vriesman and $\mathrm{M}$. De Baets

Department of Immunology, Maastricht University, P.O. Box 616, 6200 MD Maastricht, The Netherlands.

* Department of Neurology, University Hospital Leiden, P.O. Box 9600, 2300 RC Leiden, The Netherlands.

\# Department of Clinical Neurophysiology, University Hospital Maastricht, P.O. Box 5800, 6202 AZ Maastricht, The Netherlands.

$\S$ The Netherlands Cancer Institute, Division of Immunology, Plesmanlaan 121, $1066 \mathrm{CX}$ Amsterdam, The Netherlands.

Published in Muscle Nerve (in press)

\section{Summary}

Susceptibility to EAMG was found to decrease with aging in both Lewis and Brown Norway (BN) rats. In this study, the difference in susceptibility between young and aged Lewis and BN rats was used to analyze factors determining the clinical severity of EAMG. The incidence and severity of muscular weakness did not correlate with acetylcholine receptor (AChR) loss nor with the ability of antibodies to interfere with AChR function. Aged rats showed significantly lower anti-rat AChR antibody titers compared to young rats and developed less severe or no clinica] signs of disease. However, in individual young or aged rats no significant correlation was found between clinical signs of disease and anti-rat AChR titer. Neuromuscular transmission was found to change with aging as measured by single fiber electromyography (SFEMG). In aged BN rats, increased jitter and blockings were already found before EAMG induction. Despite this disturbed neuromuscular transmission, these aged BN rats were clinically resistant upon induction of EAMG. The results of this study indicate that the age-related susceptibility to EAMG is influenced by factors determined by the immune attack as well as mechanisms at the level of the neuromuscular junction. 


\section{Introduction}

Myasthenia gravis (MG) is an autoimmune disease mediated by auto-antibodies against the nicotinic acetylcholine receptor (AChR) at the neuromuscular junction. Binding of auto-antibodies to $A C h R$ at the postsynaptic membrane causes loss of functional AChR, and focal lysis of the postsynaptic membrane which results in defective neuromuscular transmission. The principal features of MG are weakness and fatiguability of skeletal muscles. Experimental Autoimmune Myasthenia Gravis (EAMG) is an animal model that closely resembles the effector phase of human MG. It can be induced by active immunization with purified AChR or by passive transfer of polyclonal or monoclonal anti-AChR antibodies (1-5). Disease severity can be assessed on the basis of weight loss and clinical symptoms $(6,7)$. Single fiber electromyography (SFEMG) is the most sensitive test for the in vivo detection of neuromuscular transmission defects in $\mathrm{MG}$ and EAMG $(7,8)$. With this technique neuromuscular dysfunction can be detected prior to decrement or clinical symptoms.

Although the pathogenesis of MG and EAMG involves an antibody mediated immune attack, anti-AChR antibody titers or the amount of AChR complexed with antibody poorly correlate with the severity of neuromuscular dysfunction (9-13). In addition, AChR loss by itself does not correlate with the severity of neuromuscular dysfunction $(7,14)$. In contrast, clinical severity of disease correlates well with functional activities of anti-AChR antibodies, such as the capacity to reduce AChR function (12). In addition, a strong correlation between severity of disease and $\mathrm{AChR}$ degradation rates was found using immunoglobulins from MG patients on cultured myotubes (15). Furthermore, the blocking of acetylcholine binding by antibodies positively correlated with the severity of disease.

Susceptibility to EAMG is influenced by both age (16) and the genetic background in different rat strains (17).

In the present study, we used the difference in susceptibility to EAMG between young and aged Lewis and BN rats to further analyze factors determining the clinical severity of EAMG. We compared clinical symptoms, AChR loss, SFEMG measurements and the functional effect of anti- 
AChR antibodies on AChR ion channel function in vitro. The results of this study may help to elucidate the mechanisms underlying the variation in clinical status of individual MO patients.

\section{Materials and Methods}

\section{Animals}

Inbred young (10 week old) and old (122-140 week old) female Lewis and BN rats were obtained from the breeding colonies of the Department of Experimental Animal Services of the Maastricht University or from TNO, Leiden, The Netherlands. All animals were maintained under specified pathogen free conditions.

\section{Induction of chronic EAMG}

AChR from electric organs of Torpedo californica (tAChR) (Pacific Biomarine, Venice, CA, USA) was purified by affinity chromatography using Cobra toxin coupled to sepharose $4 \mathrm{~B}$ (1). Rats were immunized at the base of the tail with $10 \mu \mathrm{g} / 100 \mathrm{~g}$ bodyweight purified $\mathrm{tAChR}$ emulsified in Complete Freund's Adjuvant (CFA) (Difco Laboratories, Detroit, MI, USA). Four or six weeks after primary immunization rats were boosted with $10 \mu \mathrm{g} / 100 \mathrm{~g}$ bodyweight purified tAChR emulsified in Incomplete Freund's Adjuvant (IFA) (Difco Laboratories, Detroit, MI, USA). Control rats received an equal volume of PBS in CFA or IFA.

\section{Induction of passive transfer EAMG}

Rats were injected intraperitoneally with $20 \mathrm{pmol} A \mathrm{ChR}$ binding capacity/100g bodyweight of concentrated culture supernatant containing rat anti-AChR mAb 35. MAb 35 is a rat $\operatorname{IgG} 1 \mathrm{mAb}$ directed against the main immunogenic region (MIR) on the $A C h R \quad \alpha$-subunit (3). Control rats were injected intraperitoneally with an equal volume of PBS.

\section{Chinical assessment}

The severity of clinical signs of disease in EAMG was scored by measuring muscular weakness. The animals' muscle strength was assessed by their ability to grasp and lift repeatedly a $300 \mathrm{~g}$ 
rack from the table, while suspended manually by the base of the tail for 30 seconds. Clinical scoring was based on the presence of tremor, hunched posture, muscle strength and fatiguability. Disease severity was expressed as 0 (no obvious abnormalities), + (no abnormalities before testing, but reduced strength at the end), + (clinical signs present before testing, i.e. tremor, head down, hunched posture, weak grip), +++ (severe clinical signs present before testing, no grip, moribund) $(6,7)$.

\section{Determination of $A C h R$ concentration}

The concentration of $\mathrm{AChR}$ was determined in whole carcass as described previously (1) with minor modifications (12). Briefly, frozen tissue was homogenized and AChR extracted with $2 \%$ Triton X-100 (Sigma, Brunschwig Chemie b.v., Amsterdam, The Netherlands). An aliquot of $250 \mu \mathrm{l}$ of each extract was labelled with $2 \times 10^{-9} \mathrm{M}^{125} \mathrm{I}-\alpha$-Bungarotoxin, incubated overnight with excess rat anti-AChR IgG and precipitated by goat anti-rat antibodies. $\mathrm{AChR}$ concentration was expressed as pmoles ${ }^{125} \mathrm{I}-\alpha-$-Bungarotoxin precipitated.

\section{Determination of anti-AChR antibody titers}

The concentration of antibodies reactive with rat $\mathrm{AChR}$ or human $\mathrm{AChR}$ from individual sera was determined by radioimmunoassay (RIA) as previously described (1). Rat AChR was extracted from denervated rat muscle with $2 \%$ Triton $X-100$ as described (18). Human AChR was extracted from the rhabdomyosarcoma cell line TE671 that expresses human nicotinic AChR $(19,20)$. AntitAChR antibody titers were measured by ELISA $(21,22)$, using AChR purified from the electric organs of the Torpedo Californica (1). Results are expressed as OD at $450 \mathrm{~nm}$ at the one dilution in the linear part of the curve.

\section{${ }^{22} \mathrm{Nat}^{+}$-flux assay in TE 671 cells}

The ${ }^{22} \mathrm{Na}+$-flux assay was performed as described previously with minor modifications (23). Briefly, TE671 cells were cultured in Dulbecco's modified eagle medium (Life Technologies, B. V. Breda, The Netherlands) supplemented with $10 \%$ fetal calf serum (Integro BV). Cells were grown in $172 \mathrm{~cm}^{2}$ flasks and split every 6-7 days using trypsin (0.1\%) and EDTA (0.02\%) and 
plated out in $32 \mathrm{~mm}$ multidishes (Costar, Cambridge, UK) at a density of $10^{6}$ per well. Cells were then grown until confluency. TE671 cells were incubated for $60 \mathrm{sec}$ with carbachol at a final concentration of $0.18 \mathrm{mM}$ and $0.14 \mu \mathrm{Ci} / \mathrm{ml}^{22} \mathrm{Na}^{+}-$in Hepes-Locke buffer (Amersham Life Science, Buckinghamshire, UK) (144 mM NaCl, $2.7 \mathrm{mM} \mathrm{KCl}, 1.8 \mathrm{mM} \mathrm{CaCl}$, 10 ml Hepes (Life Technologies, B.V. Breda, The Netherlands), $5 \mathrm{mM}$ glucose). Cells were rapidly washed with Hepes-Locke buffer to remove excess $22 \mathrm{Na}^{+}$and then incubated for 30 min to allow the ${ }^{22} \mathrm{Na}^{+}$to diffuse from the cells into the buffer. Supernatants were counted in a gamma counter. The effect of sera from young and aged rats in chronic EAMG on the $22 \mathrm{Na}-\mathrm{flux}$ was studied by preincubating the cells in 1/20-1/180 dilutions for 30-60 min at room temperature. The effect of the sera was expressed as percentage of values from wells treated with medium alone after substraction of values in wells treated with $\alpha$-Bungarotoxin to inhibit $A C h \mathbb{R}$ function.

\section{Electrophysiological assessment}

Stimulation SFEMG of the gluteus medius muscle was performed in rats as described previously (7). Briefly, rats were anaesthetized with $100 \mathrm{mg} / 100 \mathrm{~g}$ bodyweight ketamine (Nimatek). Body temperature was monitored with a dermal thermistor probe and skin temperature was kept constant at $33-35^{\circ} \mathrm{C}$. Intramuscular nerve stimulation at 3,5 , and $10 \mathrm{~Hz}$ was performed with monopolar Teflon coated steel needles. When SFEMG was performed before and after immunization in the same rat, the right gluteus muscle was studied before and the left gluteus muscle after immunization. Common single fiber electrodes were used for recording. A stimulus strength was chosen for each fiber that was at least $20 \%$ above threshold value. The jitter of the muscle fiber potentials was computed as mean consecutive difference (MCD) of 50 intervals between stimulus artefact and muscle fiber potential. Measurements were analyzed automatically by a Viking EMG machine (Nicolet Biomedical Instruments, Madison, WI, USA) and reanalyzed afterwards. MCD values below $6 \mu \mathrm{sec}$ were considered to result from direct muscle stimulation and excluded from further analysis.

\section{Statistical analysis}

The Wilcoxon rank test and Student t-test were used for statistical analysis. 


\section{Results}

Resistance to clinical signs of disease is age-related in both Lewis and $B N$ rats Chronic EAMG

Susceptibility to clinical signs of disease was assessed by measuring the animals" muscle strength 6-9 weeks after induction of chronic EAMG. Young (10 week old) Lewis rats (7/9) showed mild to moderate (grade + to ++ ) signs of muscular weakness at 6 weeks after immunization (Table LA). Aged (2 year old) Lewis rats (4/5) had only mild signs of disease (grade + ).

Young (10 week old) BN rats $(5 / 7)$ developed mild to moderate (grade + to + ) muscular weakness, whereas aged BN rats were clinically resistant to induction of chronic EAMG. No muscular weakness was observed in age-matched PBS/CFA immunized control rats. These results indicate that aged rats are clinically more resistant to EAMG than young rats.

\section{Passive transfer EAMG}

Passive transfer EAMG was induced in young and aged Lewis and BN rats in order to test whether resistance to EAMG is a result of intrinsic resistance of the AChR to an antibody mediated attack. Susceptibility to muscular weakness was assessed 48 hours after passive transfer of $\mathrm{mAb} 35$. Young Lewis and $\mathrm{BN}$ rats showed moderate to severe (++ to +++$)$ muscular weakness (Table IB). Both aged Lewis and BN rats were clinically resistant.

The age at which clinical resistance to passive transfer EAMG developed was determined in Lewis and BN rats of different age. In Lewis rats (from 43 weeks on) mild disease was observed in $4 / 8$ at 43 weeks and $1 / 8$ at 60 weeks of age; from 91 weeks on resistance was complete. In contrast, all BN rats of 31 weeks and older were clinically resistant.

No muscular weakness was observed in PBS injected age matched control rats.

Aged rats show AChR loss in chronic but not in passive transfer EAMG

\section{Chronic EAMG}

To verify whether clinical susceptibility to EAMG was proportional to AChR loss, AChR content was measured in the carcasses of tAChR/CFA and PBS/CFA immunized rats at 6-8 weeks after 
Table I: Muscular weakness in EAMG is age-related in both Lewis and BN rats

\section{Age(weeks) Rats/group}

Clinical EAMG score

\begin{tabular}{lccccc} 
A. Chronic EAMG & & & - & $+\ldots++$ & +++ \\
\hline Lewis rats & 10 & $\mathrm{n}=5$ & 2 & 1 & 2 \\
& 140 & $\mathrm{n}=5$ & 1 & 4 & -
\end{tabular}

\section{B. Passive transfer EAMG}

\begin{tabular}{lllllll}
\hline Lewis rats & 10 & $\mathrm{n}=4$ & - & - & 3 & 1 \\
43 & $\mathrm{n}=8$ & 4 & 4 & - & - \\
60 & $\mathrm{n}=9$ & 8 & 1 & - & - \\
91 & $\mathrm{n}=5$ & 5 & - & - & - \\
116 & $\mathrm{n}=5$ & 5 & - & - & - \\
$\mathrm{BN}$ rats & & & & & & \\
& 10 & $\mathrm{n}=4$ & - & - & 2 & 2 \\
31 & $\mathrm{n}=9$ & 9 & - & - & - \\
58 & $\mathrm{n}=3$ & 3 & - & - \\
\hline \hline
\end{tabular}

Muscular weakness was measured 6 weeks after primary immunization in chromic EAMG (panel A) and 48 hours after injection of mAb 35 in passive transfer EAMG (panel B). Results are expressed on a scale ranging from 0 (no obvious abnormalities) to t+4 (severe clinical signs present before testing, no grip, moribund).

immunization. Young and aged Lewis rats showed significant AChR loss of $53 \pm 11 \%$ and $40 \pm$ $9 \%$ respectively, compared to control rats $(p<0.05)$ (Figure $1 \mathrm{~A})$.

Young and aged $\mathrm{BN}$ rats had similar $\mathrm{AChR}$ loss $(58 \pm 10 \%$ and $50 \pm 13 \%$ respectively, $\mathrm{p}<0.05)$

(Figure IB). Although significant AChR loss was found in both young and aged rats, aged rats 
A

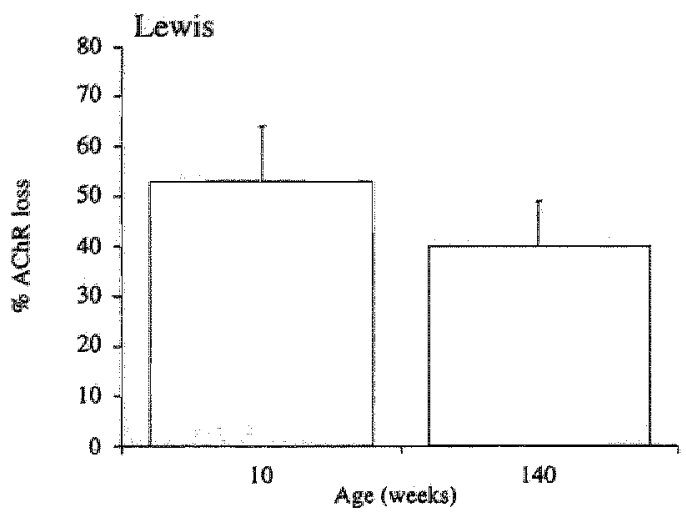

B

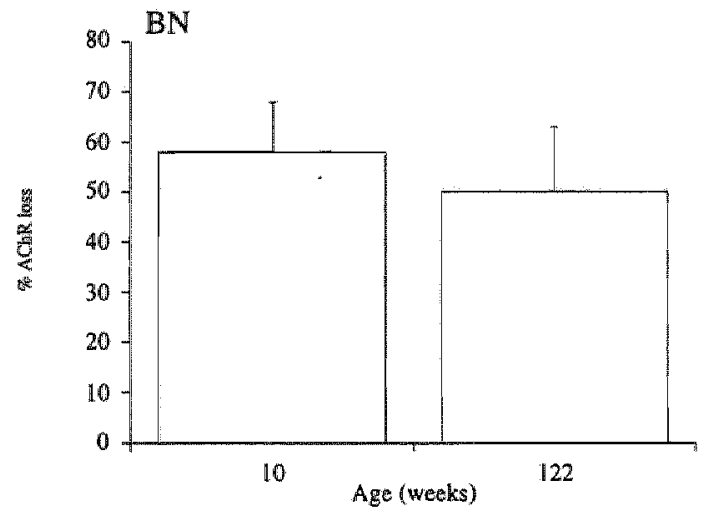

Figure 1: Both young and aged Lewis and BN rats show AChR loss in chronic EAMG. Total AChR concentration was measured in complete carcasses at 6-9 weeks after immunization with $\mathrm{AAChR}$ CFA. Significant $\mathrm{AChR}$ loss was found in both young and aged Lewis (panel A) and BN (panel B) rats. AChR loss is expressed as percentage AChR loss compared to PBS/CFA immunized age matched control rats. Each bar represents mean of $4-9$ rats \pm SD.

were clinically more resistant to EAMG than young rats. Moreover, in individual young or aged rats $\mathrm{AChR}$ loss did not correlate with the clinical severity of disease (Figure $2 \mathrm{~A}, \mathrm{~B}$ ).

\section{Passive transfer EAMG}

Total AChR concentration was measured in the carcasses at 48 hours after administration of the $\mathrm{mAb} 35$ (Figure 3). Both young Lewis and $\mathrm{BN}$ rats injected with mAb 35 showed $59 \pm 8 \%$ and $52 \pm 7 \%$ AChR loss respectively $(\mathrm{p}<0.05)$ 
A

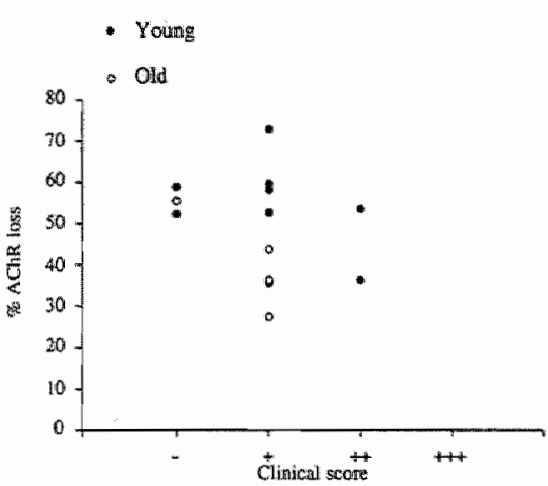

C

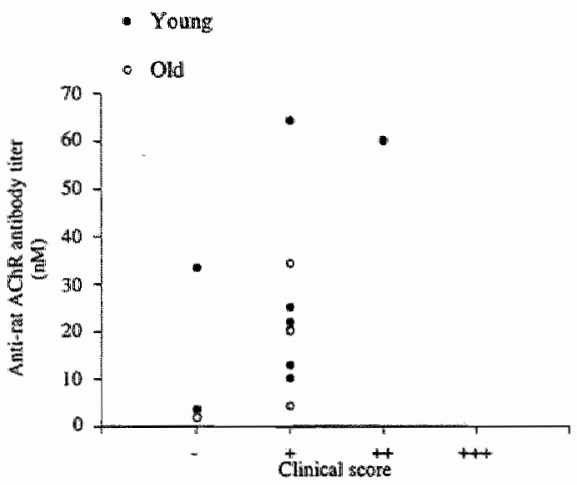

$\mathrm{E}$

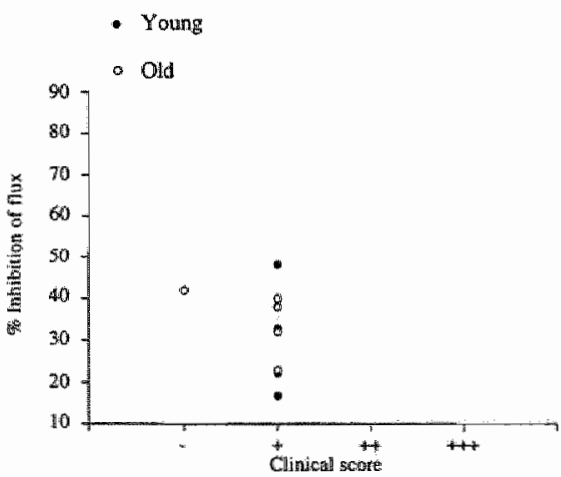

B

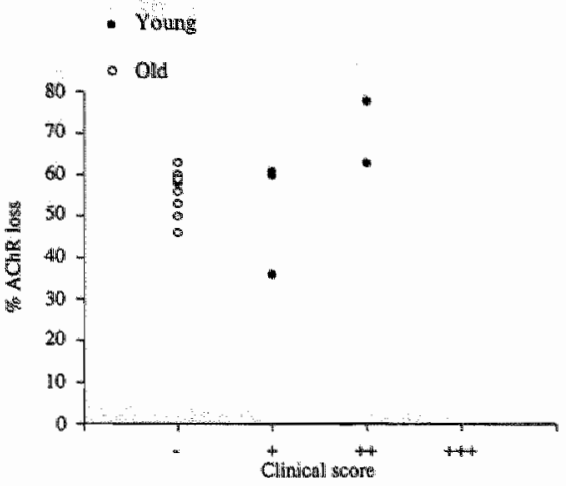

$\mathrm{D}$

- Younig

- old

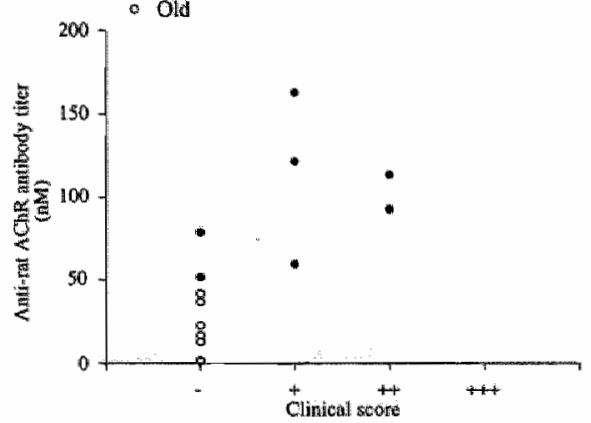

F

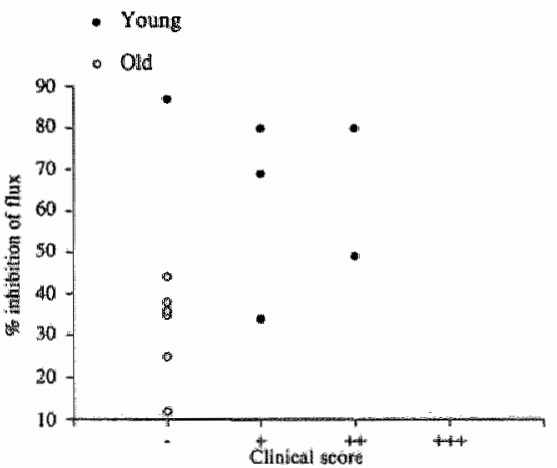

Figure 2: Clinical severity of disease does not correlate with $\mathrm{AChR}$ loss, anti-AChR antibody tirers, nor inhibition of ${ }^{22} \mathrm{Na}^{+}$-influx. A/B. In individual Lewis (A) and BN (B) rats, no correllation was found between clinical severity of disease and amount of AChR loss. $\mathrm{CD}$. In individual Lewis (C) and $\mathrm{BN}$ (D) rats no significant correlation was found between clinical score and anti-rat AChR antibody titers, E/F. Inhibition of carbachol induced ${ }^{22} \mathrm{Na}^{+}$-influx did not correlate with clinical severity of disease in Lewis (E) nor BN (F) rats.

The age at which resistance to passive transfer EAMG developed was determined in Lewis and BN rats of different age. Female Lewis rats of 10,43 and 60 weeks old had significant AChR loss of $59 \pm 8 \%, 40 \pm 17 \%$ and $41 \pm 14 \%$ respectively ( $p<0.05$ ). At 91 and 116 weeks of age 30 
$\pm 18 \%$ and $23 \pm 11 \%$ AChR loss was measured, but this loss was not significantly different from PBS controls. In BN rats of 31 weeks and older no significant AChR loss in carcass was measured compared to age matched PBS control rats.

Resistance to $\mathrm{AChR}$ loss occurred at younger age in $\mathrm{BN}$ rats than in Lewis rats.

A

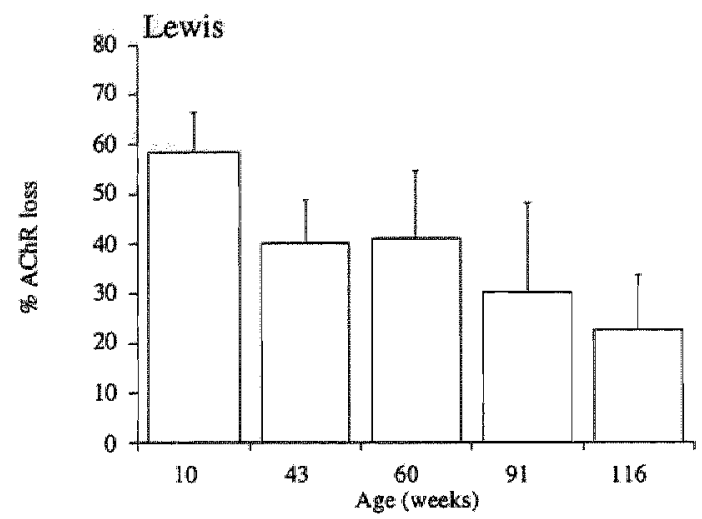

B

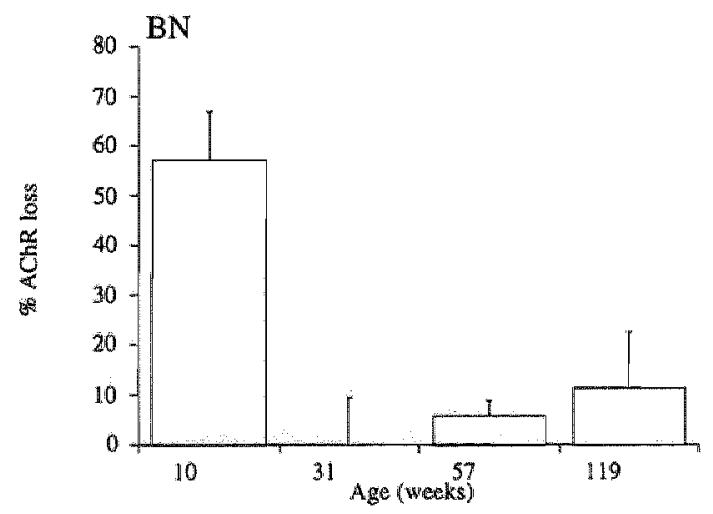

Figure 3: Resistance to AChR loss induced by passive transfer EAMG occurs at younger age in BN rats compared to Lewis rats. Total AChR concentration was measured at 48 hours after passive transfer of mAb 35 in complete carcasses of Lewis (panel A) and BN (panel B) rats. AChR loss is expressed as percentage AChR loss compared to PBS injected control rats. Each bar represents mean of 3-8 rats $\pm S D$. 
Clinical susceptibility is related to differences in anti-AChR antibody concentrations able to interfere with $A C h R$ function

Upon immunization with $\mathrm{tAChR}$ in chronic EAMG young and aged Lewis rats developed comparable anti-tAChR antibody titers (OD at $450 \mathrm{~nm} 0.97 \pm 0.06$ versus $0.93 \pm 0.07$, respectively (mean $\pm S D$ )). Anti-tAChR antibody titers were slightly higher in young $B N$ rats (OD at $450 \mathrm{~nm} 1.12 \pm 0.05)$ compared to aged $B N$ rats (OD at $450 \mathrm{~nm} 1.00 \pm 0.06)(\mathrm{p}<0.05)$. No correlation was found between clinical severity of disease and individual anti-tAChR antibody titers (data not shown).

At 6 weeks after induction of chronic EAMG, crossreactive (pathogenic) anti-rat $\mathrm{AChR}$ titers were measured in young and aged Lewis and BN rats. The mean anti rat-AChR titer in aged Lewis rats was significantly lower than in young Lewis rats $(16.3 \pm 5.3 \mathrm{nM}$ versus $32.5 \pm 7.4 \mathrm{nM}$, mean \pm $S E M),(p<0.05)$. Anti-rat $A C h R$ titers were also significantly lower in aged $B N$ rats compared to young $\mathrm{BN}$ rats (19.3 $\pm 5.6 \mathrm{nM}$ and $97.6 \pm 13.5 \mathrm{nM}$ respectively). Aged Lewis and $\mathrm{BN}$ rats, having lower anti-tat $\mathrm{AChR}$ antibody titers compared to young rats, were clinically less susceptible to EAMG. However, in individual young or aged rats no correlation was found between clinical severity of disease and anti-rat AChR antibody titers (Figure 2C, D). Moreover, it has been shown previously that even with similar anti-rat antibody titers in young and aged BN rats, aged BN rats still fail to develop EAMG (16).

To test whether differences in susceptibility between young and aged rats were due to functional differences in anti-AChR antibodies, inhibition of carbachol-induced ${ }^{22} \mathrm{Na}+$ influx in the human cell line TE671 by serum anti-AChR antibodies was examined. Sera from young and aged Lewis rats inhibited the carbachol-induced ${ }^{22} \mathrm{Na}+$ influx to a similar level $(30.0 \pm 12.0$ and $35.0 \pm 6.9 \%$ respectively), (Figure $4 \mathrm{~A}$ ). Carbachol-induced ${ }^{22} \mathrm{Na}^{+}$influx was inhibited $66.5 \pm 18.9 \%$ by sera from young $\mathrm{BN}$ rats versus $31.8 \pm 10.1 \%$ inhibition by sera from aged $\mathrm{BN}$ rats $(\mathrm{p}<0.05)$, (Figure $4 \mathrm{~B}$ ). Normal rat serum did not significantly inhibit ${ }^{22} \mathrm{Na}+$ influx. In individual Lewis and $\mathrm{BN}$ rats no correlation was found between clinical severity of disease and inhibition of ${ }^{22} \mathrm{Na}^{+}$ influx (Figure $2 \mathrm{E}, \mathrm{F}$ ). Mean anti-human $\mathrm{AChR}$ antibody titers were comparable between young and aged Lewis rats $(40.4 \pm 20.2 \mathrm{nM}$ and $44.9 \pm 20.2 \mathrm{nM}$ respectively), whereas cross-reactive anti-human $\mathrm{AChR}$ antibody titers were significantly higher in young compared to aged $\mathrm{BN}$ rats 

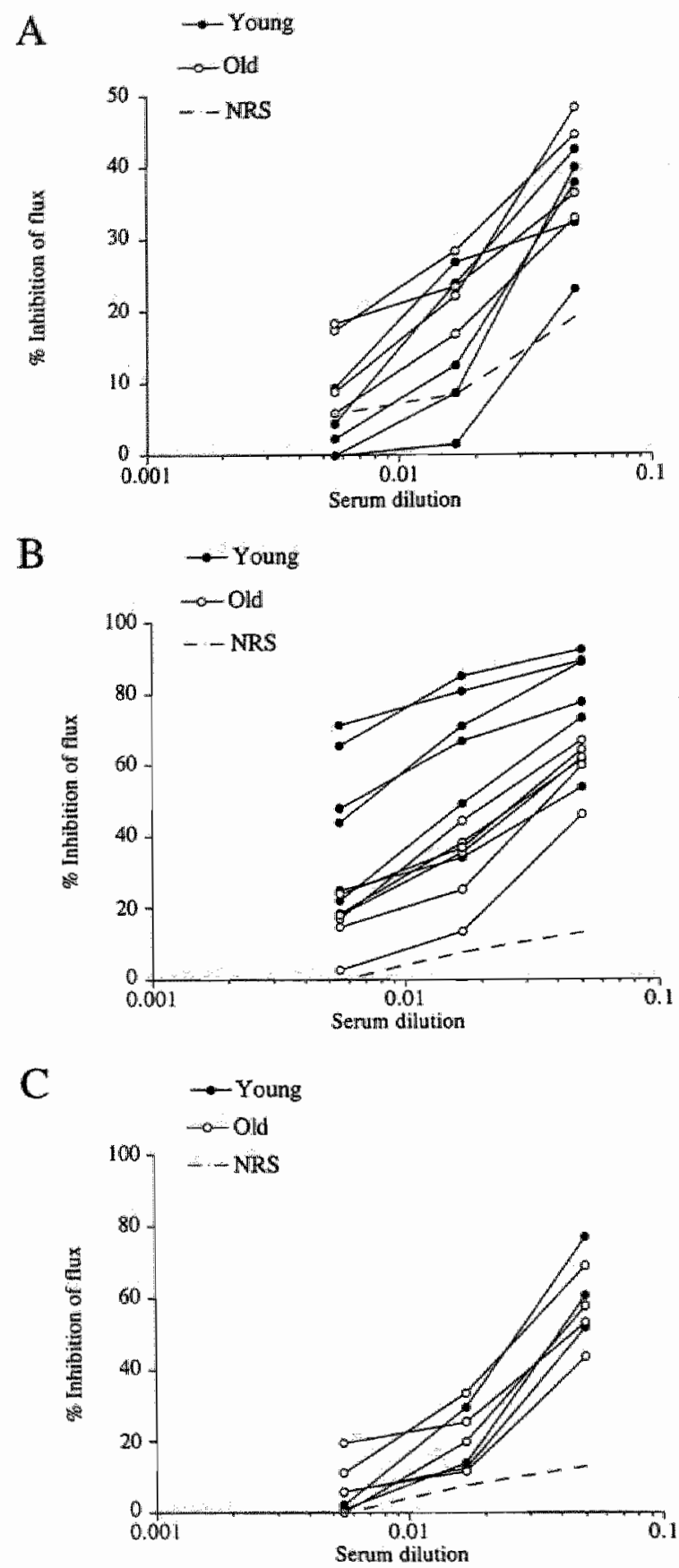

Figure 4: Clinical susceptibility is related to difference in anti-AChR antibody concentrations able to interfere with nomal $A C h R$ function. $A / B$. Inhibition of carbachol-induced ${ }^{22} \mathrm{Na}^{+}$-influx in young and aged Lewis (panel $A$ ) and BN (panel B) rats. C. Carbachol-induced ${ }^{22} \mathrm{Na}^{+}$-influx under conditions of equal anti-AChR antibody concentrations by sera from young and aged BN rats. Values represent \% inhibition of agonist induced ${ }^{22} \mathrm{Na}^{+}$. influx of at 4-6 individual sera in each group at $1 / 20-1 / 180$ dilution. NRS $=$ normal rat serum. 
$(76.5 \pm 25.9 \mathrm{nM}$ versus $16.6 \pm 11.2 \mathrm{nM}$ ). However, when performing the flux assay under conditions of equal anti- $\mathrm{AChR}$ antibody concentrations, no differences in inhibition of $22 \mathrm{Na}^{+}$ influx were found between young and aged BN rats (Figure 4C). This indicates that the differences in inhibition of ${ }^{22} \mathrm{Na}^{+}$influx between young and aged $\mathrm{BN}$ rats is related to differences in antibody titers.

Neuromuscular transmission is different in aged Lewis and BN rats before immunitation Neuromuscular jitter, expressed as mean consecutive difference (MCD), was measured at stimulation frequencies of 3,5 and $10 \mathrm{~Hz}$. Young Lewis rats had significantly lower MCD values at $10 \mathrm{~Hz}$ (mean MCD $10.8 \mu \mathrm{sec}$ ) as compared to 3 and $5 \mathrm{~Hz}$ (mean MCD 14.3 and 14.7 $\mu \mathrm{sec}$ ), $(\mathrm{p}<0.001)$, (Figure 5A). With increasing age MCD values in Lewis rats decreased significantly at stimulation frequencies of 3 and $5 \mathrm{~Hz}$ (mean MCD 10.3 and $11.3 \mu \mathrm{sec}$ respectively at 116 weeks), $(p<0.01)$, while at $10 \mathrm{~Hz}$ no effect of aging on the jitter was found. In young and aged Lewis rats no blocking of neuromuscular transmission was found.

Young BN rats showed no significant differences in MCD values at the 3 stimulation frequencies (mean MCD values 14.5, 14.9 and $15.6 \mu \mathrm{sec}$ at 3,5 and $10 \mathrm{~Hz}$ ) (Figure 5B). At old age MCD values increased significantly to $20.8,22.8$ and $23.5 \mu \mathrm{sec}$ at respectively 3,5 and $10 \mathrm{~Hz}$ $(\mathrm{p}<0.02)$. Furthermore, in $3 / 5$ aged $\mathrm{BN}$ rats blocking of neuromuscular transmission was found (7.0\% of all neuromuscular junctions tested).

Apparently aging induces strain-specific changes in neuromuscular transmission properties in Lewis and BN rats.

\section{Neuromuscular jitter increases upon induction of chronic $E A M G$}

In order to analyze if differences in neuromuscular transmission between Lewis and BN rats were related to differences in susceptibility to EAMG, SFEMG was performed in chronic EAMG. In young Lewis rats significantly increased jitter (mean MCD 17.1, 18.4 and 18.5 $\mu \mathrm{sec}$ ) was found at all stimulation frequencies at 6 weeks after immunization $(p<0.05)$, (Figure $5 \mathrm{~A})$; blockings were recorded in $3 / 4$ animals (6.0\% of all neuromuscular junctions tested). Clinical signs of disease (score + or ++ ) were present in 2 rats, 1 rat presented no signs of muscular weakness, 
despite of abnormal SFEMG recordings. In 140 week old Lewis rats, 6 weeks after induction of chronic EAMG, jitter was significantly increased to $17.6,18.8$ and $20.8 \mu \mathrm{sec}$ at 3,5 and $10 \mathrm{~Hz}$ $(\mathrm{p}<0.01)$ and blocking occurred in $4 / 5$ rats $(8.0 \%$ of all neuromuscular junctions). Increased MCD values and blockings coincided with the occurrence of mild clinical symptoms (score + ).

Aged female BN rats did not show clinical signs of muscular weakness nor significant differences in MCD values compared to age-matched control rats. At 9 weeks after immunization with $20 \mu \mathrm{g}$ tAChR mean MCD values were 20.4,26.1 and $30.6 \mu \mathrm{sec}$ respectively at 3,5 and $10 \mathrm{~Hz}$ (Figure

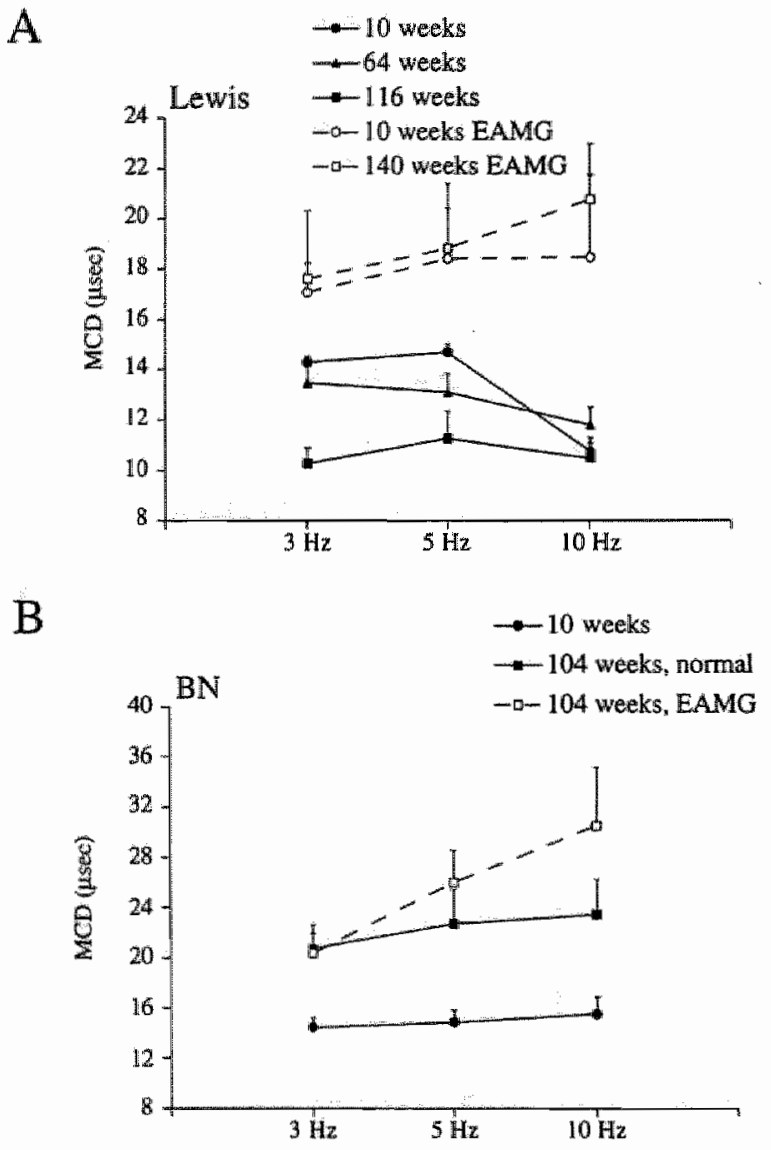

Figure 5: Neuromuscular jitter decreases with aging, but increases after immunization with tAChR in Lewis rats. Neuromuscular transmission was studied by SFEMG before and after induction of chronic EAMG in young and aged female Lewis and BN rats. Values represent mean $M C D$ values \pm SEM. 
$5 \mathrm{~B}$ ). Abnormal intermittent blocking of neuromuscular transmission ( $10.2 \%$ of all neuromuscular junctions) was recorded in $3 / 5$ aged $\mathrm{BN}$ rats.

These results confirm that SFEMG is a very sensitive method for the in vivo detection of disturbed neuromuscular transmission, irrespective of the preexisting quality of this transmission.

\section{Discussion}

In this study we analyzed several parameters determining susceptibility to EAMG in Lewis and BN rats. Susceptibility to chronic and passive transfer EAMG was found to decrease with aging in both Lewis and BN rats. The incidence and severity of muscular weakness were not proportional to the amount of $\mathrm{AChR}$ loss. Clinically resistant aged rats developed lower anti-rat antibody titers compared to young rats. However, anti-rat antibody titers did not correlate with clinical severity of disease in individual rats. Moreover, resistance to EAMG was also observed in the passive transfer model in which the anti-AChR antibody load is similar in young and aged rats. Resistance to EAMG was correlated with the capacity of serum to inhibit $22 \mathrm{Na}^{+}$-influx. In both Lewis and $\mathrm{BN}$ rats neuromuscular jitter was found to change with aging. In aged $\mathrm{BN}$ rats only, increased jitters and blockings were already found before immunization. Despite this disturbed neuromuscular transmission, these aged BN rats were clinically resistant to EAMG.

Aged female $B N$ rats showed no clinical signs of disease in chronic $\mathbb{E} A M_{G}$, despite significant AChR loss. Previous studies have indicated that no direct correlation exists between AChR loss; AChR-antibody complexes at the neuromuscular junction or anti-AChR antibody titers and the clinical signs of disease (10-12,14). Indeed, AChR loss in individual Lewis and BN rats did not correlate with clinicall severity of disease. Furthermore, it has been shown that induction of EAMG in both susceptible and resistant rats results in complement activation to the final step of membrane attack complex formation and expression of complement regulatory proteins such as CD55 (decay accelerating factor), CD59 and vitronectin (16,22).

The correlation between serum antibody titer and signs of disease was more complex. Aged rats showed significantly lower anti-rat $A C h R$ antibody titers compared to young rats and developed no or only mild signs of muscular weakness. This may suggest that resistance to 
EAMG in aged rats is related to lower anti-rat AChR antibody titers. A role for a dose dependent effect of antibodies is also supported by the fact that aged rats were more susceptible to AChR loss in chronic EAMG, in which the endplates are exposed to a higher concentration of antibody for a longer period of time, as compared to passive transfer EAMG. In chronic EAMG the antibody to AChR ratio is estimated to be $20: 1$, while this ratio is $1: 2.5$ in passive transfer EAMG. Furthermore, it has been shown previously, that the capacity to induce antigenic modulation by myasthenic sera on human myotubes is determined by serum titer (24). However, it has been shown previously that aged rats with similar anti-AChR antibody titers compared to young rats nevertheless fail to develop clinical signs of disease (16). Moreover, in individual young or aged rats no significant correlation was found between clinical signs of disease and antirat $\mathrm{AChR}$ titer. Although sera of susceptible young $\mathrm{BN}$ rats inhibited the carbachol-induced ${ }^{22} \mathrm{Na}^{+}$-influx significantly more than the sera of resistant old BN rats, this difference was due to differences in anti-AChR antibody titers. In addition, it has been shown previously that young and aged rats have similar concentrations of antibodies directed against the MIR and $\alpha-$ Bungarotoxin binding sites (22). This suggests that both young and old rats produce similar subsets of pathogenic antibodies, but that only rats with high anti-AChR antibody titers show clinical signs of a disturbed neuromuscular transmission.

In order to explain differences in the age-related severity of clinical disease, previous studies investigated parameters of the immune attack against the $\mathrm{AChR}$, like anti- $\mathrm{AChR}$ antibody titer, modulating capacity of antibodies or complement activation (16,22). In these studies, it has been suggested that the neuromuscular junction in aged rats is more resistant against antibody mediated attack. Stimulation SFEMG is the most sensitive test for in vivo detection of neuromuscular transmission defects in EAMG (7). The magnitude of the jitter is inversely correlated with the safety factor of neuromuscular transmission. In humans it was found that after injection of a given dose of curare those motor endplates with the highest initial jitter showed the greatest increase in MCD values (25). In Lewis rats, jitters progressively decrease with age, suggesting that neuromuscular transmission is facilitated in aged Lewis rats. In old female BN rats however, signs of a disturbed neuromuscular transmission were found before immunization. Upon immunization, jitters increased in young and aged Lewis rats, similar to previous studies in 
young Lewis rats (7). However, in BN rats only young rats showed an increase in neuromuscular jitter, whereas in the resistant aged rats no significant increase was found. Possibly aging had resulted in a dysfunction of neuromuscular transmission in BN rats, which in turn had activated mechanisms at the level of the postsynaptic membrane, making the neuromuscular junction less susceptible for an antibody mediated attack. At the level of the neuromuscular junction such mechanisms have been shown to result in increased acetylcholine release proportional to the reduction of $A C h R$ numbers by injection of $\alpha$-Bungarotoxin or induction of EAMG $(26,27)$. After a first period of passive transfer EAMG, which disturbs the neuromuscular junction, rats are known to be resistant to a second injection of anti-AChR antibodies $(28,29)$. Maybe similar mechanisms play a role in aged $\mathrm{BN}$ rats. Alternatively the preexisting neuromuscular transmission defect in aged $\mathrm{BN}$ rats could be due to a strain specific aging process. An important role of compensating mechanisms at the neuromuscular junction is also suggested by a study showing increased expression of mRNA coding for the $A C h R ~ \alpha$-subunit mRNA in severely affected patients but not in moderately affected patients, independently of the anti-AChR antibody titers (30).

The results of this study indicate that the age-related susceptibility to EAMG is influenced by anti-rat antibody titers. In addition, differences in preexisting neuromuscular transmission properties may be involved in determining clinical outcome in EAMG. A similar phenomenon is observed in MG patients. In patients with only ocular MG, anti-AChR antibody titers are generally lower compared to patients with severe generalized MG (9). However, no correlation was found between clinical severity of disease and anti-AChR titers in individual patients with generalized MG $(9,10)$. It is therefore likely that the neuromuscular dysfunction in both MG and EAMG is the result of a combination of several factors. More important, the contribution of each of these factors may differ between individual MG patients. The comparison of the immune response and compensating mechanisms at the level of the neuromuscular junction between young and aged rats is a well suited model to elaborate these mechanisms. 


\section{Acknowledgments}

The authors wish to thank Mrs M.Vroomen for excellent laboratory assistance, Mr. P. Berghs and Mrs. L. Geraets for skilful assistance during SFEMG recordings, and Dr. S. Tzartos for supplying mAb 35. This work was supported by a grant from 'Het Prinses Beatrix Fonds' and "L'Association Française contre les Myopathies".

\section{References}

1 Lindstrom I, Lennon V, Seybold M, et al. Experimental autoimmune Myasthenia Gravis and Myasthenia Gravis: Biochemical and immunochemical aspects. Ann NY Acad Sci 1976; 274:254-274.

2 Toyka K, Drachman D, Pestronk A, et al. Myasthenia Gravis: passive transfer from man to mouse. Science 1.975; 190:397-399.

3 Tzartos S, Hochschwender S, Vasquez P, et al. Passive transfer of experimental autoimmune myasthenia gravis by monoclonal antibodies to the main immunogenic region of the acetylcholine receptor. J Neuroimmunol 1987; 15:185-194.

4 Lennon V, Lambert E. Myasthenia gravis induced by monoclonal antibodies to acetylcholine receptors. Nature 1980; 285:238-240.

5 Patrick J, Lindstrom J. Autoimmune response to acetylcholine receptor. Science 1973; 180:871-872.

6 Lennon V, Lindstrom J, Seybold M. Experimental autoimmune myasthenia: a model of myasthenia gravis in rats and guinea pigs. J Exp Med 1975; 141:1365-1375.

7 Verschuuren $J_{*}$ Spaans F, De Baets M. Single-fiber electromyography in experimental autoimmune Myasthenia Gravis. Muscle Nerve 1990; 13:485-492.

8 Stalberg E, Ekstedt J, Broman A. Neuromuscular transmission in myasthenia gravis studied with single fiber electromyography. J Neurol Neurosurg Psychiat 1974; 37:540-547.

9 Lindstrom $J$, Seybold $M$, Lennon $V$, et al. Antibody to acetylcholine receptor in myasthenia gravis. Prevalence, clinical correlates and diagnostic value. Neurology 1976; 26:10541059 .

10 Roses A, Olanow W, McAdams M, et al. No direct correlation between serum antiacetylcholine receptor antibody levels and clinical state of individual patients with myasthenia gravis. Neurology 1981; 31:220-224.

11 Pachner A, Kantor F. The relation of clinical disease to antibody titre, proliferative response and neurophysiology in murine experimental autoimmune Myasthenia Gravis. Clin Exp Immunol 1983; 51:543-550. 
12 Verschuuren $\mathrm{J}$, Graus $\mathrm{Y}$, Theunissen $\mathrm{R}$, et al. Role of acetylcholine receptor antibody complexes in muscle in experimental autoimmune Myasthenia Gravis. IJ Neuroimmunol 1992; 36:117-125.

13 Graus Y, van Breda Vriesman P, De Baets M. Characterization of anti-acetylcholine receptor (AChR) antibodies from mice differing in susceptibility for experimental autoimmune myasthenia gravis. Clin Exp Immunol 1993; 92:506-513.

14 Mossman S, Vincent A, Newsom-Davis J. Passive transfer of myasthenia gravis by immunoglobulins: lack of correlation between AChR with antibody bound, acetylcholine receptor loss and transmission defect. J Neurol Sci 1988; 84:15-28.

15 Drachman D, Adams R, Josifek L, et al. Functional activities of autoantibodies to acetylcholine receptors and the clinical severity of myasthenia gravis. N Engl J Med 1982; 307:769-775.

16 Graus Y, Verschuuren J, Spaans F, et al. Age-related resistance to experimental autoimmune Myasthenia Gravis in rats. J Immunol 1993; 150:4093-4103.

17 Biesecker G, Koffler D. Resistance to experimental autoimmune Myasthenia Gravis in genetically inbred rats. J Immunol 1988; 140:3406-3410.

18 Lindstrom J. An assay for antibodies to human acetylcholine receptor in serum from patients with myasthenia gravis. Clin Immunol Immunopathol 1977; 7:36-43.

19 Lindstrom J, Criado M, Ratnam M, et al. Using monoclonal antibodies to determine the structures of acetylcholine receptors from electric organs, muscles and neurons. Ann $\mathrm{N} \mathrm{Y}$ Acad Sci 1987; 505:208-225.

20 Luther M, Schoepfer R, Whiting P, et al. A muscle acetylcholine receptor is expressed in the human cerebellar medulloblastoma cell line TE671. J Neurosci 1989; 9:1082-1096.

21 Wauben M, Hoedemaekers A, Graus Y, et al. Inhibition of experimental autoimmune myasthenia gravis by major histocompatibility comlex class II competitor peptides results not only in a suppressed but also in an altered immune response. Eur J Immunol 1996; 26:2866-2875.

22 Hoedemaekers A, Graus Y, van Breda Vriesman P, et al. Age- and sex-related resistance to experimental autoimmune myasthenia gravis in Brown Norway rats. Clin Exp Immunol 1997; 107:189-197.

23 Lang $B$, Richardson $G$, Rees $\mathrm{J}$, et al. Plasma from myasthenia gravis patients reduces acetylcholine receptor agonist-induced $\mathrm{Na}+$ flux into TE671 cell line. J Neuroimmunol $1988 ; 19: 141-148$.

24 Tzartos S, Sophianos D, Zimmerman K, et al. Antigenic modulation of human myotube acetylcholine receptor by myasthenic sera. Serum titer determines receptor internalization rate. J Immunol 1986; 136:3231-3238.

25 Schiller H, Stalberg E, Schwartz M. Regional curare for the reduction of the safety factor in human motor endplates studied with single fibre electromyography. J Neurol Neurosurg Psychiatry 1975; 37:540-547. 
26 Plomp J, Kempen van G, Molenaar P. Adaptation of quantal content to decreased postsynaptic sensitivity at single endplates in $\alpha$-bungarotoxin treated rats. J Physiol 1992; 458:487-499.

27 Plomp $J$, Van Kempen G, De Baets $M$, et al. Acetylcholine release in myasthenia gravis: regulation at single endplate level. Ann Neurol 1995; 37:627-636.

28 Corey A, Richman D, Shuman C, et al. Use of monoclonal antiacetylcholine receptor antibodies to investigate the macrophage inflammation of acute experimental Myasthenia Gravis: refractoriness to a second episode of acute disease. Neurology $1985 ; 35$ :14551460.

29 Corey A, Richman D, Agius M, et al. Refractoriness to a second episode of experimental Myasthenia Gravis. Correlation with AChR concentration and morpholigic appearance of the postsynaptic membrane. J Immunol 1987; 138:3269-3275.

30 Guyon T, Levasseur P, Truffault F, et al. Regulation of acetylcholine receptor $\alpha$ subunit variants RNA in human myasthenia gravis. Quantification of steady-state levels of messenger RNA in muscle biopsy using the polymerase chain reaction. J Clin Invest 1994; 94:16-24. 


\title{
Chapter 5
}

\section{Role of the target organ in determining susceptibility to}

\section{experimental autoimmune myasthenia gravis}

\author{
A. Hoedemaekers, J-L. Bessereau* "Y. Graus", T. Guyon $\$$, J-P. Changeux ${ }^{*}$, S. Berrih-Aknin $\$$, \\ P. van Breda Vriesman, and M. De Baets.
}

Maastricht University, Department of Immunology, P.O. Box 616,6200 MD Maastricht, The Netherlands.

* CNRS-UAD-1284, Institut Pasteur, Unité de Neurobiologie Moleculaire, 25 Rue du Dr Roux, 75724 Paris Cedex 15, France.

\# The Netherlands Cancer Institute, Division of Immunology, Plesmanlaan 121, $1066 \mathrm{CX}$ Amsterdam, The Netherlands.

§CNRS-URA-1159, Hôpital Marie Lannelongue, 133 Avenue de la Résistance, 92350

Le Plessis-Robinson, France.

Subrnitted to Ann. Neurol.

\section{Summary}

Susceptibility and clinical course of myasthenia gravis (MG) is influenced by both the immune attack and the target organ. Passive transfer experimental autoimmune myasthenia gravis (EAMG) is a good model to study the response of the acetylcholine receptor (AChR) to the antibody-mediated immune attack in MG. Previously we have shown that passive transfer of anti-Main Immunogenic Region (MIR) mAb 35 in aged rats does not induce clinical signs of disease nor AChR loss. This age-related resistance to EAMG could not be attributed to defects in the immune attack towards the neuromuscular junction in aged rats, but may be caused by the existence of more efficient compensatory mechanisms or by increased resistance of the $A C h R$ protein to degradation in aged rats. The expression of the $A C h R$ subunit genes was analyzed in susceptible and resistant rats. In aged EAMG resistant rats, no increase in the amount of AChR $\alpha$-subunit mRNA was measured by quantitative RT-PCR or by in situ hybridization. In wivo AChR degradation experiments did not show any increase in $A C h R$ degradation rates in aged resistant rats, in contrast to young susceptible rats. Taken together, these data demonstrate that resistance of the $\mathrm{AChR}$ protein to antibody-mediated degradation is the primary mechanism that accounts for the resistance to passive transfer EAMG in aged rats. Semiquantitative analysis of several proteins of the postsynaptic membrane revealed changes in the composition of the basal lamina and cytoskeleton with aging, which may render the postsynaptic membrane in aged rats resistant against internalization and antigenic modulation. 


\section{Introduction}

MG is an autoimmune disease characterized by weakness of voluntary muscles and excessive fatigue (reviewed in (1)). Signs and symptoms of MG are caused by an antibodymediated attack against $\mathrm{AChR}$ in the postsynaptic membrane, resulting in impairment of neuromuscular transmission. The $\mathrm{AChR}$ is a transmembrane glycoprotein composed of 4 different subunits in a stochiometry $\alpha_{2} \beta \gamma \delta$ in embryonic type $\mathrm{AChR}$. In the adult form, the $\gamma$ subunit is replaced by an $\varepsilon$ subunit (reviewed in $(2,3)$ ). The immunopathogenic mechanisms responsible for loss of functional $\mathrm{AChR}$ include: cross-linking of $\mathrm{AChR}$ by antibodies, resulting in increased internalization; activation of the complement system causing focal lysis of the postsynaptic membrane; direct interference of a small subset of anti-AChR antibodies with binding of acetylcholine to the $\mathrm{AChR}$ or with ionchannel function.

Although the pathogenesis of $\mathrm{MG}$ is entirely antibody-mediated, anti-AChR antibody titers or the amount of AChR complexed with antibody correlate poorly with the severity of neuromuscular dysfunction (4-6). However, it has been shown previously that certain AChR $\alpha$ subunit gene haplotypes are associated with a higher susceptibility for MG (7). Furthermore, a higher frequency of microsatellite variants was found in MG patients compared to controls. In addition, analysis of $\mathrm{AChR} \alpha$-subunit mRNA concentrations in muscle biopsies from MG patients revealed increased levels in the amounts of $\alpha$-subunit mRNA in severely affected MG patients, whereas no increase was found in moderately ill MG patients, independently of the antj-AChR antibody titers (8). It seems therefore likely that the autoantigen itself influences susceptibility and clinical course of MG.

Passive transfer experimental autoimmune myasthenia gravis (EAMG) is a good model to analyse the response of the target organ to the antibody mediated immune attack in MG. It is induced by injection of monoclonal or polyclonal anti-AChR antibodies. In susceptible rats, clinical signs of disease and AChR loss develop within 24-48 hours $(9,10)$. Impairment of meuromuscular transmission in these rats triggers a cascade of events, resulting in increased levels of mRNA coding for the different subunits of the AChR $(11,12)$. The increase in $A C h R$ 
mRNA is accompanied by elevated levels of the mRNAs encoding the myogenie transcription factors of the MyoD family (13).

Aged BN rats, in contrast to young BN rats, are resistant to induction of EAMG $(14,15)$. Passive transfer of monoclonal anti-AChR antibodies does not induce muscular weakness nor clinical signs of disease in aged rats. This resistance could not be attributed to deficient antibody uptake, increased antibody clearance, inaccessibility of the AChR for antibody, absence of infiltrating macrophages or deficient complement activation (14-16). Therefore, it is most likely that resistance to EAMG in aged rats resides at the level of the target organ. The mechanisms that could account for this age-related resistance include a more efficient AChR neosynthesis in aged rats or resistance of the $\mathrm{AChR}$ protein to degradation. In order to test these hypotheses, we analyzed the AChR gene expression in young susceptible and aged resistant rats upon induction of passive transfer EAMG. Furthermore, we determined the in viwo AChR degradation rates and analyzed possible differences in the composition of the postsynaptic membrane in young and aged rats. The results of this study may elucidate possible factors determining susceptibility and severity of disease in MG patients at the level of the target organ.

\section{Materials and Methods}

\section{Animals}

Inbred young (10 weeks old) and aged (2 years old) female $B N$ rats were obtained from the breeding colonies of the Department of Experimental Animal Services of the Maastricht University or from TNO, Leiden, The Netherlands. All animals were maintained under specified pathogen free conditions.

\section{Induction of passive transfer EAMG}

Rats were injected intraperitoneally with 20 pmol AChR binding capacity/100g bodyweight of concentrated culture supernatant containing rat anti-AChR mAb 35 as previously described (14). MAb 35 is a rat IgG1 mAb directed against the MIR on the $\alpha$-subunit of the AChR $(10,17)$. Control rats were injected intraperitoneally with an equal volume of PBS. All rats were 
sacrificed at 48 hours after induction of EAMG. The severity of clinical illness in EAMG was assessed by measuring weight loss and signs of muscular weakness $(18,19)$.

\section{Determination of $A C h R$ concentration}

The concentration of AChR in carcass or hind limb was determined as described previously $(6,20)$. Briefly, frozen tissue was homogenized and AChR was extracted with $2 \%$ Triton X-100

(Sigma, Brunschwig chemie b.v., Amsterdam, The Netherlands). An aliquot of $250 \mu l$ of each extract was labelled with $2 \times 10^{-9} \mathrm{M}^{125} \mathrm{I}-\alpha-\mathrm{B}$ ungarotoxin (125I- $\alpha-\mathrm{BT}$ ), incubated overmight with excess rat anti-AChR antibodies and precipitated by goat anti-rat antibodies. The AChR concentration was expressed as proles ${ }^{125} \mathrm{I}-\alpha-\mathrm{BT}$ precipitated.

\section{Quantification of a-subunit AChR MRNA by RT-PCR}

The amount of rat $\alpha$-subunit mRNA was determined in a competitive RT-PCR. Intermal control RNA, transcribed from a mutant fragment of human $\alpha$-subunit AChR DNA, containing the P3A+ exon, was used as an internal control as described previously (8). Total RNA was isolated from Extensor Digitorum Longus (EDL) muscle by guanidine isothiocyanate extraction (21). The EDL muscle used for quantification of $A C h R \alpha$-subunit mRNA levels was removed in toto, to ensure that the amount of RNA extracted derived from comparable numbers of neuromuscular junctions in all samples.

Sense and anti-sense primers were chosen to be complementary to the rat $\alpha$-subunit cDNA sequence spaming the region from AA 20 to 230 .

5' Primer (QPCR-1R): 5'-GGC-TCC-GAA-CAT-GAG-ACT-CG-3"

3' Primer (QPCR-2R): 5-GCA-GAC-GCT-GCA-TGA-CGA-AG-3'

RNA was reverse transcribed into first strand cDNA in a $20 \mu$ reaction volume containing $1 \mu \mathrm{g}$ of total rat RNA together with serial dilutions of internal control RNA, using 25 pmoles QPCR$2 \mathrm{R}$ and Expand reverse transcriptase (Boehringer Mannheim GmbH, Grermany). Subsequent amplification was carried out in the presence of trace amounts of $32 \mathrm{P}$ labelled $\mathrm{QPCR}-1 \mathrm{R}$ (approximately $10^{5} \mathrm{cpm} /$ reaction), PCR products were electrophoresed in an $8 \%$ acrylamide gel, dried and subsequently analyzed in a phosphor imager. The amount of radioactivity in the 2 
amplified PCR products was determined and graphed as a function of the amount of internal control RNA. The initial concentration of target RNA was deduced from the graph at the point where the target /internal control ratio $=1$, and was expressed as the number of molecules of rat AChR $\alpha$-subunit mRNA/ $\mu \mathrm{g}$ total RNA. The amplification efficiencies of target and internal control RNA were verified in a kinetic PCR and found to be comparable (data not shown).

\section{In situ hybridization}

Extensor carpi radialis muscle was frozen in isopentane and kept at $-80^{\circ} \mathrm{C}$ until use. Cryostat sections were fixed in $4 \%$ paraformaldehyde in PBS. CRNA probes from AChR $\varepsilon$-and $\alpha$-subunit were transcribed using T7 or SP6 RNA polymerase (Promega Corporation, Madison, WI, USA) and labelled with uridine $5^{\prime}-\left(\alpha-{ }^{35} \mathrm{~S}\right)$ thiotriphosphate $(1000 \mathrm{Ci} / \mathrm{mmol})$. The $\varepsilon$-subunit probe was derived from a rat cDNA template, subcloned in pSP72 (a kind gift of Dr. V. Witzemann, Heidelberg, Germany), whille the $\alpha$-subunit probe was derived from a mouse cDNA template (22). Hybridization was performed as previously described (23). To identify muscle endplate regions, serial sections were stained for acetylcholinesterase activity using a modified Karnovsky-Roots staining (24). Sections were examined by light- or dark-field microscopy and recorded with a Hamamatsu $\mathrm{C} 4880 \mathrm{CCD}$ camera. Semi-quantitative analysis was performed using the Khoros software package under the Unix operating system (25). Levels of extrasynaptic transcription were analyzed by dark-field microscopy and expressed as number of grains per $\mathrm{mm}^{2}$. Synaptic expression of AChR mRNAs was analysed on light field images. A fixed sized circular region of $12 \mu \mathrm{m}$ radius was superimposed on the synaptic regions. The fraction of the area occupied by grains was taken as an index of mRNA abundance and expressed as arbitrary units.

\section{Denervation of hind limb muscle}

Denervation of the left hind limb muscle was performed under ether anaesthesia by excision of $5-10 \mathrm{~mm}$ of the left sciatic nerve. At 10 days post denervation rats were sacrificed and left and right hind limb muscles were separately frozen in liquid nitrogen. The AChR concentration was measured in each hind limb as described. 
In vivo $A C h R$ degradation

In vivo AChR degradation was measured using ${ }^{1251-\alpha-B T}$ as described previously (26), with modifications. Briefly, rats were given a subcutameous sublethal injection of $2.5 \mu \mathrm{g} 125 \mathrm{I}-\alpha-$ BT/100g bodyweight, 24 hours prior to induction of EAMG. The dose injected had been determined in preliminary experiments and was chosen to label approximately $30 \%$ of the available $\alpha$-BT binding sites. At 24 hours after the ${ }^{125}$ I- $\alpha$-BT administration, animals received an intraperitoneal injection of mAb 35 or PBS as described above. Rats were sacrificed 48 hours after the initial $125 \mathrm{I}-\alpha-\mathrm{BT}$ injection. To determine the amount of $\mathrm{AChR}$ labelled in vivo, excess rat anti-AChR antibodies were added to aliquots of (in vivo labelied) AChR extracts and precipitated using goat-anti-rat antibodies. Total $\mathrm{AChR}$ concentration was measured by adding $2 \times 10^{-9} \mathrm{M}^{125} \mathrm{I}-\alpha-\mathrm{B}$ T in a radioimmunoassay as described above.

\section{Immunohistochemistry}

Muscle biopsy cryosections of young and aged rats were acetone-fixed for $10 \mathrm{~min}$ at $4^{\circ} \mathrm{C}$ and air-dried for $5 \mathrm{~min}$. After washing 3 times in PBS, the sections were pre-incubated in PBS containing $2 \%$ bovine serum albumin and subsequently incubated with the respective mAb or an irrelevant isotype-matched $\mathrm{mAb}$, together with rhodamine-labelled $\alpha$-Bungarotoxin (Molecular Probes, Eugene, OR, US) for $1 \mathrm{hr}$ at room temperature, in order to co-localize AChR in the same section. Mouse anti-s-laminin IgGl mAb was purchased from the Developmental Studies Hybridoma Bank (University of lowa, IA, US). Goat polyclonal anti-agrin antibodies were kindly donated by Dr. J. van den Born, University Hospital Nijmegen, The Netherlands. Mouse anti-43K IgG I mAb were kindly donated by Prof. Dr. S. Froehner (University of NorthCarolina, Chapel Hill, NC) (27). Mouse anti-utrophin mAb MANCHO 7 is specific for the Cterminal domain of utrophin (28) and was kindly donated by Prof. G. Morris (North East Wales Institute, Wrexham, UK). After washing with PBS, the slides were incubated for $1 \mathrm{hr}$ with FITC labelled anti-mouse or anti-goat Ig (Cappel, Organon Technika, Boxtel, The Netherlands). A minimum of 10-15 endplates per group were examined semi-quantitatively under confocal laser optics with appropriate filters. Results were corrected for differences in endplate size and expressed as ratio mean fluorescence intensity of FITC to rhodamine staining. 


\section{Statistical analysis}

The Wilcoxon rank and Student test were used for statistical analysis.

\section{Results}

Aged rats are resistant to induction of passive transfer EAMG.

Upon induction of passive transfer EAMG, serum mAb 35 levels were comparable in young and aged rats as determined by ELISA using Torpedo AChR as antigen (14). Furthermore, immunohistochemical analysis of muscle biopsies revealed similar depositions of membrane attack complex in young and aged rats (14). These results confirm pervious experiments showing that the interaction of the mAb 35 with the AChR is similar in young and aged rats.

Upon injection of the mAb 35 aged rats developed no weight loss nor muscular weakness (Table I). Young rats showed severe signs of muscular weakness and lost $9.6 \pm 1.3 \%$ of their initial weight (mean $\pm \mathrm{SD})(\mathrm{P}<0.05)$. No weight loss nor muscular weakness was observed in PBS treated (control) rats. Determination of $\mathrm{AChR}$ concentration revealed no $\mathrm{AChR}$ loss in $\mathrm{mAb} 35$ injected aged rats compared to age matched control rats (Figure $1 \mathrm{~A}$ ). In contrast, $52 \pm$ 7\% (mean $\pm \mathrm{SD}$ ) AChR loss was measured in young female rats $(\mathbf{P}<0.05)$ compared to agematched control rats. The clinical resistance in aged rats was in accordance with the absence of: AChR loss.

Table I: Aged BN rats are clinically resistant to passive transfer EAMG

\begin{tabular}{|c|c|c|c|c|c|c|c|}
\hline \multirow{2}{*}{$\begin{array}{l}\text { Age } \\
\text { (weeks) }\end{array}$} & \multirow{2}{*}{$\begin{array}{c}m A b 35 / \\
P B S \\
\end{array}$} & \multirow{2}{*}{$\begin{array}{l}\text { Rats/ } \\
\text { group }\end{array}$} & \multirow{2}{*}{$\begin{array}{c}\text { Weight change } \\
(\%)\end{array}$} & \multicolumn{4}{|c|}{ Clinical EAMG score } \\
\hline & & & & - & + & ++ & $+t+$ \\
\hline 10 & $\operatorname{mAb} 35$ & $n=5$ & $-9.7 \pm 2.8$ & - & - & 3 & 2 \\
\hline 10 & PBS & $\mathrm{n}=5$ & $+1.3 \pm 1.6$ & 5 & - & - & - \\
\hline 130 & $\mathrm{mAb} 35$ & $\mathrm{n}=7$ & $-0.2 \pm 0.9$ & 7 & - & - & - \\
\hline 130 & PBS & $n=6$ & $-0.8 \pm 0.6$ & 6 & - & - & - \\
\hline
\end{tabular}

Passive transfer EAMG was induced in young and aged BN rats. Aged rats were clinically resistant, whereas young rats developed significant weight loss and muscular weakness. Weight change is expressed as mean \pm SD of at least 5 rats. 
AChR $\alpha$-subunit mRNA levels remain stable in EAMG resistant aged rats.

Induction of EAMG in susceptible rats has been shown to result in an increase in AChR mRNA levels (13). We measured the amount of $A C h R \alpha$-subunit mRNA in young and aged rats, before and after injection of mAb 35. $\alpha$-subunit mRNA was quantified by competitive RT-PCR. The number of $\alpha$-subunit mRNA molecules measured in aged control rats was $4.6 \pm 0.7 \times 10^{8} / \mu \mathrm{g}$ RNA (mean \pm SEM) and found to be comparable to that in young control rats (Figure 1B). Injection of mAb 35 did not result in an increase in the number of $\alpha$-subunit mRNA molecules ( $3.4 \pm 0.5 \times 10^{8} / \mu \mathrm{g}$ RNA) in resistant aged rats. In contrast, the mean number of $\alpha$-subunit mRNA molecules increased significantly in young rats, from $4.1 \pm 0.5 \times 10^{8} / \mu \mathrm{g}$ RNA in young control rats to $12.1 \pm 1.6 \times 10^{8} / \mu \mathrm{g}$ RNA in susceptible young rats at 48 hours after injection of mAb $35(\mathrm{P}<0.05)$.

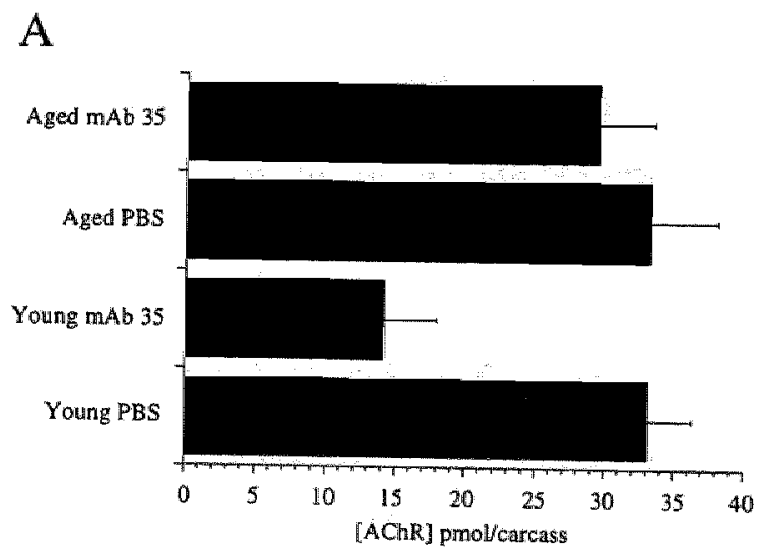

B

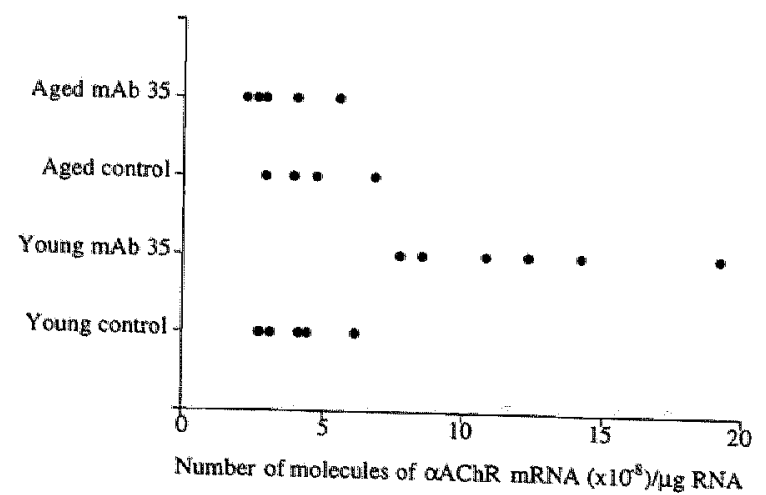


A

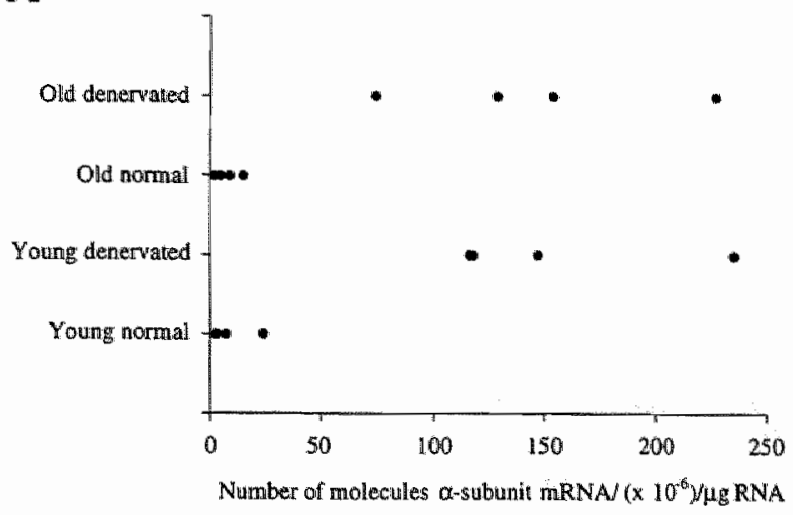

B

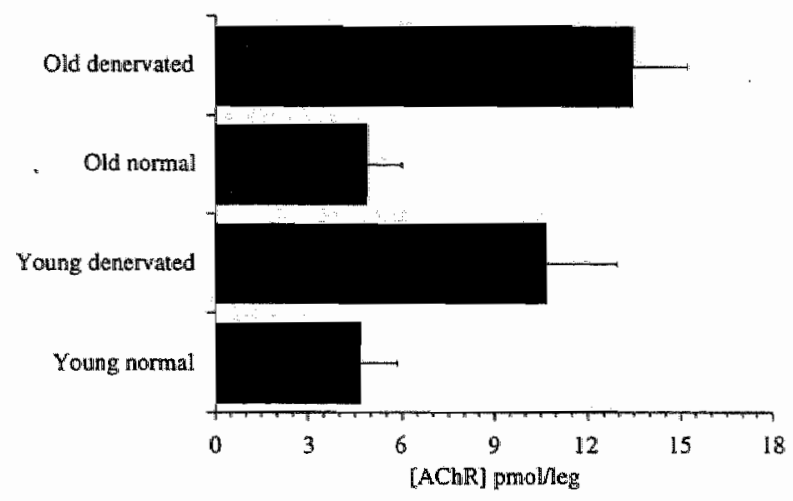

Figure 2: Denervation results in upregulation of $A C h R$ a-subunit mRNA and protein synthesis in EAMG resistant aged rats. The amount of $\alpha$-subunit mRNA (A) and total AChR concentration (B) was measured in young and aged rats 10 days after denervation. A. A similar increase in the number of AChR $\alpha$-subunit mRNA molecules was found in young and aged rats. The amount of $\alpha$-subunit mRNA is expressed as number of molecules per $\mu \mathrm{g}$ total RNA extracted. Points represent individual rats. B. This increased AChR $\alpha$-subunit mRNA synthesis resulted in similarly increased AChR concentrations in young and aged rats. AChR concentration is expressed as pmol AChR per leg. Bars represent the mean \pm SD of at least 5 rats.

Figure 1: Resistance to EAMG in aged rats is not a result of increased AChR $\alpha$-subunit MRNA synthesis. Total. $A C h R$ concentration ( $A$ ) and number of $A C h R \alpha$-subunit mRNA molecules (B) were measured in young and aged rats at 48 hours after induction of passive transfer EAMG. A. EAMG resistant aged rats had similar concentrations of AChR compared to aged control rats, whereas EAMG susceptible young rats showed significant AChR loss $(\mathrm{P}<0.05)$. AChR concentration is expressed as pmoll AChR/carcass. Bars represent the mean \pm SD of all least 5 rats. $B$. In EAMG resistant aged rats no increase in the number of $\alpha$-subunit mRNA molecules was found compared to age-matched control rats. In young rats however, a significant increase in the mean number of o-subunit mRNA molecules was measured $(\mathrm{P}<0.05)$. The amount of $\alpha$-subunit mRNA is expressed as number of molecules per $u g$ total RNA extracted. Points represent individual rats. 
Denervation results in upregulation of $\alpha$-subunit mRNA synthesis in EAMG resistant aged rats.

To establish whether aged rats are still capable of increasing their AChR $\alpha$-subunit $\mathrm{MRNA}$ and protein synthesis, hind legs of young and aged female rats were denervated. Motor nerve section is known to cause a dramatic increase in AChR $\alpha$-subunit mRNA and protein synthesis (reviewed in (2)). In aged rats, the number of $\alpha$-subunit mRNA molecules/ $\mu$ g RNA increased from $7.6 \pm 2.5$ to $146 \pm 27.5 \times 10^{8} / \mu \mathrm{g}$ RNA (mean $\pm S E M$ ) at 10 days after denervation $(\mathrm{P}<0.05)$ (Figure 2A). A comparable increase was found in young rats, viz. from $9.1 \pm 4.4$ to $154 \pm 24.2 \times 10^{8} / \mu g$ RNA $(\mathrm{P}<0.05)$. To verify whether the $\alpha$-subunit mRNA was also translated into protein, AChR concentration was measured in individual hind limbs. In aged rats, the AChR concentration increased from $4.9 \pm 1.1$ to $13.4 \pm 1.8$ pmol/leg $(\mathrm{P}<0.05)$. Similar increases were found in young rats $(4.7 \pm 1.2$ to $10.7 \pm 2.3$ pmol/leg, $\mathrm{P}<0.05)$ (Figure 2B).

\section{Synaptic expression of $\alpha$ - and $\varepsilon$-subunit mRNAs is not affected in aged EAMG rats}

In normal innervated muscle, $A C h R$ genes are preferentially expressed in the subjunctional regions of the muscle fiber. Yet, synaptic domains represent less than one percent of the fibers (3). Variations in AChR mRNA levels quantified in total muscle RNA by mass techniques, mainly represent variations in extrasynaptic regions of the myofiber. This implies that synaptic compensatory mechanisms would have remained unnoticed in the RT-PCR experiments described above. Therefore, $\alpha$ - and $\varepsilon$ - subunit mRNA expression was analysed by means of in situ hybridisation experiments.

Figure 3: Induction of passive transfer EAMG does not affeet synaptic nor extrasynaptic expression of AChR $\alpha$ and E-subunit mRNA in aged rats. Dark-field photographs from muscle biopsies of young and aged EAMG and control rats showing autoradiographic grains. A-D. Longitudinal muscle section of aged control (A), aged EAMG (B) young control (C) and young EAMG (D) rat hybridized with AChR a-subunit probe. E-H. Longitudinal muscle section of aged control (A), aged EAMG (B), young control (C) and young EAMG (D) rat hybridized with AChR e-subunit probe. Bar is $100 \mu \mathrm{m}$ 

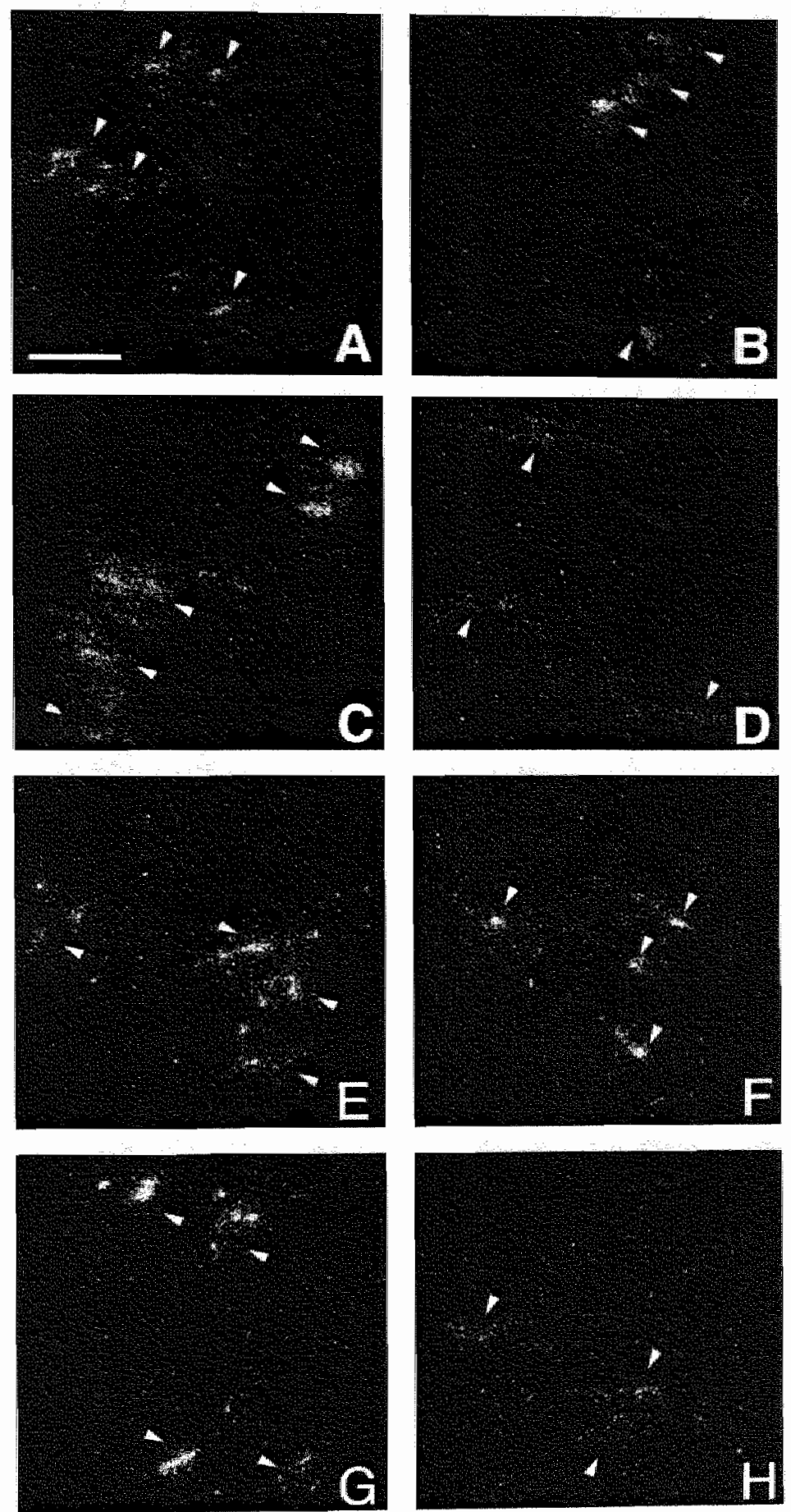
In aged control tats, both $\alpha$ - and $\varepsilon$ - subunit transcripts were densely accumulated at the endplate regions (Figure 3). Yet, the density and size of the synaptic $\alpha$-and $\varepsilon$ - subunit clusters were lower than those observed in young control rats ( $\mathrm{P}<0.001$ ), (Figure 4 ). Injection of $\mathrm{mAb} 35$ in aged rats did not result in any apparent changes in the distribution or density of the clusters of grains at the level of the endplates (Figures 3,4). Extrasynaptic distribution of both $\alpha$ - and $\varepsilon$ subunit transcripts did not exceed background levels as determined by hybridization with $\alpha$ - and $\varepsilon$-subunit sense RNA probes (Figure 3,4 ). In contrast, injection of mAb 35 in young rats

A.

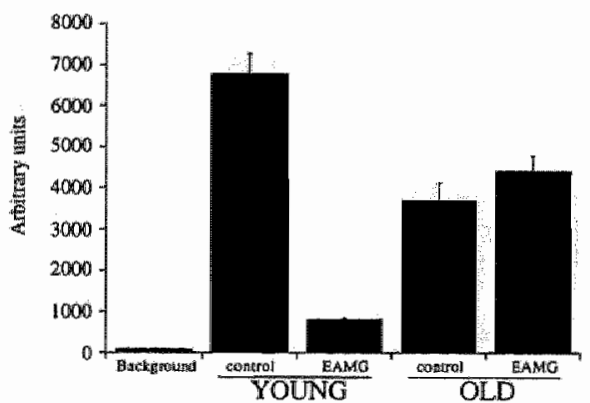

C

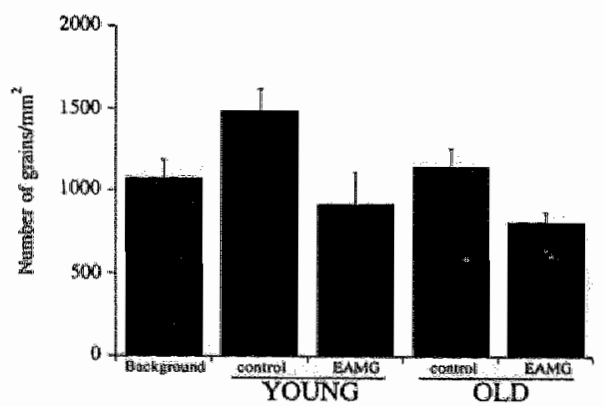

B

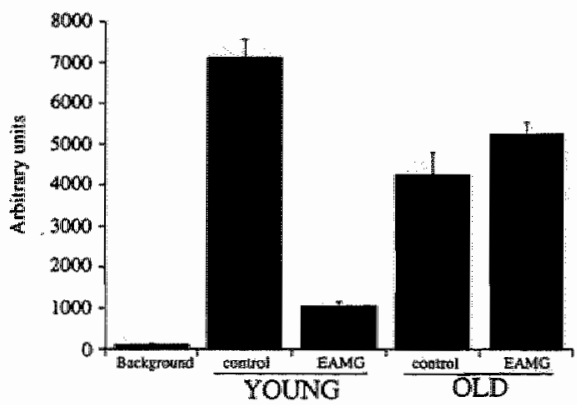

$\mathrm{D}$

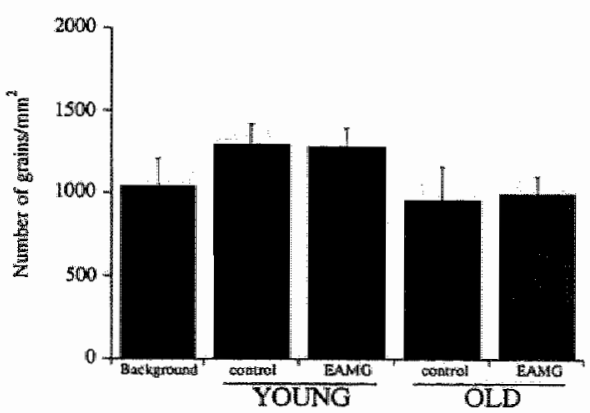

Figure 4: Synaptic expression of AChR $\alpha$ - and $\varepsilon$-subunit mRNA remains unchanged in resistant aged rats, but is strongly reduced in young susceptible rats. A/B. Semiquantitative analysis of synaptic $A C h R(\alpha$-subunit $(A)$ and $\varepsilon$ subunit (B) transcripts in young and aged EAMG and control rats. In aged rats, induction of EAMG induced no apparent changes in size and density of synaptic clusters, whereas in young rats a strong decrease was measured. Levels of synaptic mRNA transcripts are expressed as arbitrary units. Bars represent the mean \pm SEM of at least 40 analyses. CDD. Semiquantitative analysis of extrasynaptic AChR $\alpha$-subunit (C) and $\varepsilon$-subunit (D) transcripts in young and aged EAMG and control rats. Extrasynaptic distribution of AChR $\alpha$ - and E-subunit mRNA did not exceed background levels as determined by hybridization with the respective sense probes. Extrasynaptic expression is expressed as number of autoradiographic grains/mm ${ }^{2}$. Bars represent mean \pm SEM of at least 18 analyses. 
elicited a dramatic reduction of the size and density of the synaptic clusters of grains for both the $\alpha$ - and $\varepsilon$-subunit mRNA transcripts $(P<0.001)$ (Figures 3, 4). The overall extrasynaptic distribution of both $\alpha$ - and $\varepsilon$ - subunit transcripts in mAb 35 injected susceptible young rats remained unaffected and did not exceed background levells (Figures 3, 4), though in some sections, we observed erratic fibers with high levels of $\alpha$-subunit mRNA in extrasynaptic regions (not shown).

\section{Aged rats are resistant to antibody mediated AChR protein degradation}

The AChR protein degradation rates were measured in normal and $\mathrm{mAb} 35$ treated young and aged rats. AChR was labelled in vivo with $125_{\mathbb{I}} \alpha-\mathrm{BT}, 24$ hours prior to induction of passive transfer EAMG. The fraction of AChR labelled at the moment of induction of EAMG was regarded as $100 \%$ (the actual fraction of ${ }^{125} \mathrm{I}-\alpha-\mathrm{BT}$ labelled AChR was $28.7 \pm 1.0 \%$ and $29.6 \pm$ $1.8 \%$ (mean $\pm \mathrm{SD}$ ) in young and aged rats respectively). Twenty-four hours after injection of mAb 35, aged rats showed no significant decrease in the amount of $125 \mathrm{I}-\alpha-\mathrm{BT}$ labelled AChR

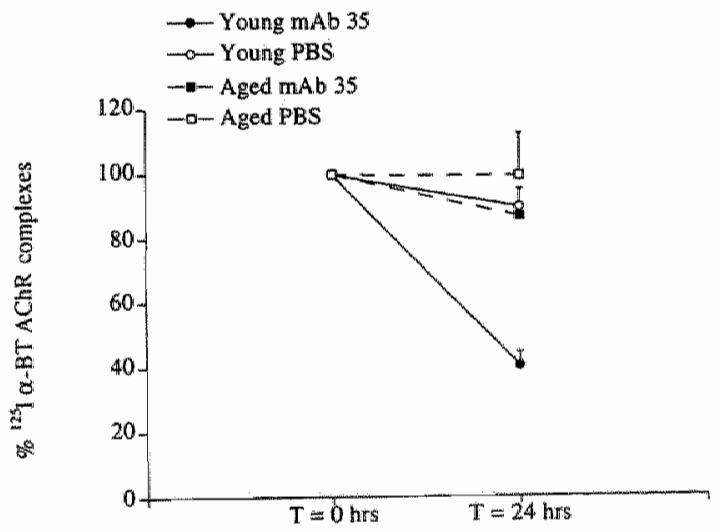

Figure 5: Aged rats are resistant to antibody mediated $\mathrm{AChR}$ degradlation. In vivo AChR degradation rates were measured in young and aged rats after induction of passive transfer EAMG. AChR was labelled with $125 \mathrm{I}-0 \mathrm{-BT} 24$ hours prior to induction of EAMG. At 24 hours after induction of EAMG no significant decrease in amount of 125 I- $\mathrm{C}$-BT labelled $\mathrm{AChR}$ was found in aged rats $(12.8 \pm 8.6 \%$ decrease compared to age matched control rats), whereas young rats showed a significant decrease of $59.5 \pm 4.2 \%$ in the amount of 125 I $\alpha$-BT labelled AChR. Results are expressed as \% loss of $125 \mathrm{I}-\alpha$-BT labelled $\mathrm{AChR}$. The fraction of $\mathrm{AChR}$ labelled at the time point of EAMG induction was considered $100 \%$ (actual fraction of $125 \mathrm{I}-\mathrm{\alpha}-\mathrm{BT}$ labelled AChR was $29.6 \pm 1.8 \%$ and $28.7 \pm$ $1.0 \%$ in young and aged rats respectively). Points represent mean $t$ SD of at least 5 rats per group. 
compared to age matched PBS treated rats $(12.8 \pm 8.6$ and $0.2 \pm 13.0 \%$ decrease respectively)

(Figure 5). MAb 35 injected susceptible young rats, however, showed a significant decrease in 125I- $\alpha$-BT labelled AChR of $59.5 \pm 4.2 \%(\mathrm{P}<0.05)$. No significant decrease in the amount of 125 I- $\alpha$-BT labelled AChR was measured in young PBS treated rats $(9.9 \pm 5.6 \%)$.

A

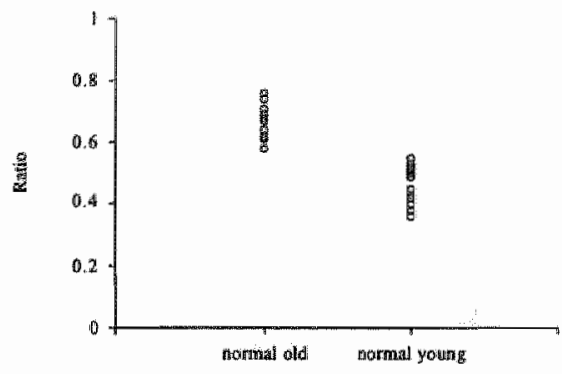

C

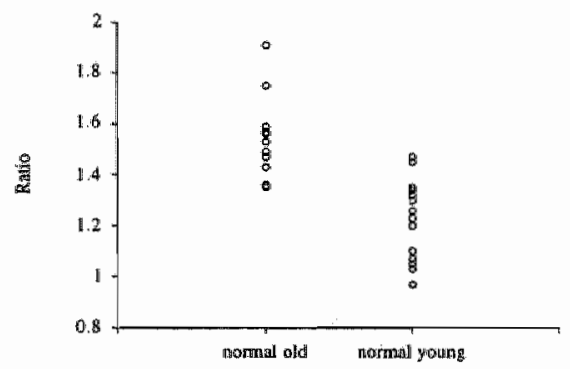

B

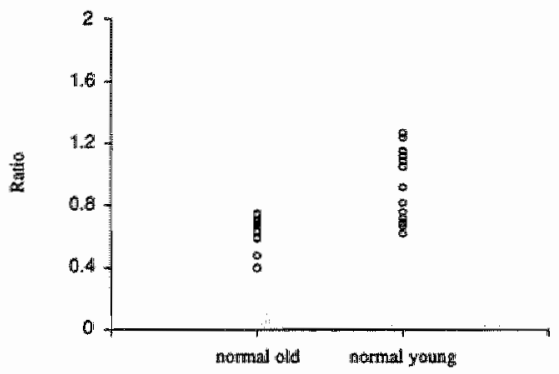

D

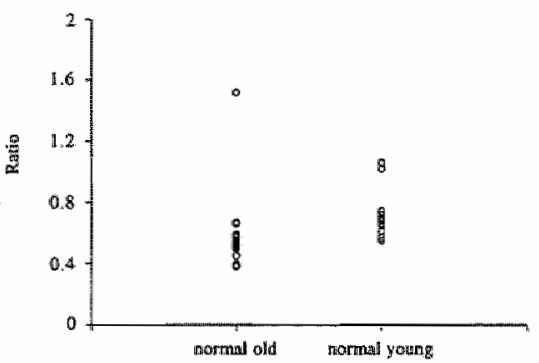

Figure 6: Protein composition of the postsynaptic membrane changes with aging. The relative amounts of s-laminin (A), agrin (B), rapsyn (C) and utrophin (D) were analyzed by confocal laser microscopy. Muscle biopsy cryosections firom young and aged rats were stained by immunofluorescence double staining using rhodaminelabelled $\alpha$-BT to identify endplate regions together with the respective mAb followed by FITC labelled 2 nd step antibodies to stain for postsymaptic membrane proteins. Results are expressed as ratio mean fluorescence intensity FTTC 10 rhodamine staining. A minimum of 10.15 endplates per group was analyzed.

\section{Protein composition of the postsynaptic membrane changes with aging}

Proteins of the basal lamina and the postsynaptic cytoskeleton are known to play an important role in clustering and anchoring of $\mathrm{AChR}$ in the postsynaptic membrane (29). Possible changes in the amounts of s-laminin, agrin, $43 \mathrm{~K}$ and utrophin were analyzed semiquantitatively in muscle biopsies of young and aged rats by confocal laser microscopy. The amount of s-laminin was significantly increased in normal old compared to normal young rats (mean intensity ratio 
$0.66 \pm 0.06$ versus $0.46 \pm 0.06, \mathrm{P}<0.001$ ), (Figure 6A). The amount of agrin significantly decreased with aging from $0.98 \pm 0.22$ in normal young rats to $0.64 \pm 0.10$ in normal aged rats $(\mathrm{P}<0.001)$, (Figure 6B). Similar to s-laminin, the amount of $43 \mathrm{k}$ protein also increased with aging from $1.22 \pm 0.15$ to $1.52 \pm 0.15$ respectively in normal young and aged rats $(P<0.001)$, (Figure 6C). The amount of utrophin was comparable in young and aged rats (Figure 6D).

\section{Discussion}

In this study we examined the role of $A C h R$ in determining susceptibility to EAMG using susceptible young and resistant aged rats. No increase in AChR $\alpha$-subunit mRNA was found upon induction of EAMG in aged rats. In contrast, a 3 - fold increase in $\mathrm{AChR} \alpha$-subunit mRNA was measured in EAMG susceptible young rats by competitive RT-PCR. Nevertheless, upon denervation aged rats were found to be potentially capable of increasing the AChR $\alpha$ subunit mRNA synthesis to the same level as young rats. In situ hybridization showed that the distribution of $\alpha$ - and $\varepsilon$-subunit transcripts was confined to the synapse and was not increased in aged rats after injection of mAb 35. These results suggest that injection of $\mathrm{mAb} 35$ in aged rats does not induce $A C h R$ neosynthesis to compensate for $A C h R$ loss. Measurements of in wivo AChR degradation rates confirmed that in aged rats the AChR protein in the postsynaptic membrane is resistant to antibody mediated degradation. Semiquantitative analysis of several proteins of the postsynaptic membrane revealed that the protein composition of the basal lamina and cytoskeleton changes with aging.

In both $\mathrm{MG}$ and EAMG, the antibody mediated AChR loss results in neuromuscular transmission defects $(19,30,31)$. This impairment of neuromuscular transmission has been reported to cause increased transcription of the AChR $\alpha-, \beta-, \varepsilon_{-}$, and $\delta_{-}$subunit genes in both MG and EAMG $(8,1,12)$. Concomitantly, an increase in MRF4 and myogenin mRNA was observed in EAMG, whereas the levels of MyoD remained unchanged $(13,32)$. In our study, however, induction of EAMG in resistant aged rats did not result in an increase in the amount of AChR $\alpha$-subunit mRNA. In addition, no changes in the levels of MRF4, myogenin or MyoD were detected by Northern blotting (data not shown). Denervation experiments, however, 
indicated that aged rats retain the potential to increase $A C h R$ neosynthesis to a level comparable to that in young rats. Denervation as well as induction of EAMG or injection of a-BT are known to increase the expression of $\mathrm{AChR} \alpha$-subunit and myogenin genes through the impairment of nerve evoked electrical activity $(13,33,34)$. This increase in the levels of AChR $\alpha$-subunit and myogenin mRNA is, however, quantitatively stronger in denervation experiments compared to EAMG or treatment with $\alpha$-BT. This quantitative difference may be related to disruption of the contact between nerve and muscle upon denervation and/or to blocking of the release of neural factors, whereas these processes remain unaffected in EAMG. In situ hybridization experiments indicated that the expression of $\alpha$-and $\varepsilon$-subunit transcripts remains restricted to synaptic areas in aged rats. Furthermore, no increase in synaptic expression of $\alpha$ and $\mathrm{E}$-subunit genes was observed in EAMG resistant aged rats, excluding the possibility of local compensatory $A C h R$ neosynthesis by subsynaptic nuclei. Altogether, these results suggest that in EAMG resistant aged rats, neuromuscular transmission is functional and electrical activity-dependent repression of extrasynaptic $A C h \mathbb{R}$ gene expression is maintained. These findings are supported by data from stimulated single fiber electromyography experiments, showing that neuromuscular transmission is not disturbed in EAMG resistant aged rats compared to age-matched control rats (Hoedemaekers et al, Muscle Nerve in press).

Interestingly, we observed a strong synaptic decrease in $\alpha$ - and $\varepsilon$-subunit mRNA transcripts in EAMG susceptible young rats. These results do not match with those of previous experiments in Lewis rats, which revealed a synaptic increase in $\alpha$-subunit gene expression (13). This difference may have resulted from a lower dose of mAb 35 injected, resulting in less AChR loss (44\% AChR loss in Asher et al, versus $52 \%$ AChR loss in our experiments) and less destruction of the neuromuscular junction. Under normal conditions, motor innervation elicits a compartmentalisation of $\mathrm{AChR}$ gene expression in synaptic domains by two distinct mechanisms. In extrasynaptic regions the electrical activity that spreads along the fiber is mainly responsible for the repression of $\mathrm{AChR}$ gene transcription, while nerve-derived factors and the specialized basal lamina sustain high levels of AChR biosynthesis in the synaptic regions (reviewed in $(2,29)$ ). The maintenance of high numbers of $A C h R$ at the endplate thus requires positive signals. Recently it has been shown that positive signalling by neuregulin in 
required for maintenance of high $A C h R$ density in adult rats (35). Destruction of the endplates in EAMG may interfere with this positive signalling and subsequently decrease the AChR mRNA transcription. Furthermore, the immune attack may interfere with the accessibility of the subsynaptic nuclei for neurotrophic factors such as Neu differentiation factor/ARIA or CGRP. Our experiments suggest that in EAMG susceptible rats the increase in $\alpha$-subunit mRNA, as measured in total muscle by RT-PCR, is mainly extrasynaptic. Since the increase was only approximately 3 -fold, it is very likely that the expression levels remained below the detection threshold of the in situ hybridisation experiments. Alternatively, such an extrasynaptic increase may not be homogeneously distributed over the muscle fibers, as we detected in a few fibers showing a denervation-like morphology.

In vivo AChR degradation experiments showed no loss of in vivo labelled $\mathrm{AChR}$ in EAMG resistant aged rats, whereas significant loss was measured in EAMG susceptible young rats. Loss of 125 I- $\alpha-\mathrm{BT}$ in vivo is not due to displacement by antibody, since the anti-MIR mAb 35 does not interfere with $\alpha-B T$ binding (36). Since the loss of radioactivity with time is an approximation of the rate of $\mathrm{AChR}$ degradation (37), these results indicate that in aged rats the $A C h R$ protein in the postsymaptic membrane is resistant against antibody mediated $A C h R$ degradation.

The postsynaptic membrane is known to change morphologically in aged rats and humans $(38,39)$. Length and degree of branching of the postsynaptic membrane increase with enlargement of the postsynaptic area, and degeneration of junctional folds. Furthermore, it has been shown that membrane rigidity increases with aging (40). Several components of the basal lamina and the postsynaptic cytoskeleton are involved in AChR clustering and anchoring. Agrin and the synapse specific s-laminin are components of the basal lamina. Agrin has been shown to induce AChR clustering in cultured myotubes (41), whereas s-laminin has been shown to affect synapse formation both in witro and in vivo $(42,43)$. 43k protein and utrophin (dystrophin" related protein) are components of the post-synaptic cytoskeleton and play an important role in AChR anchoring by the formation of a crosslinking network. Our data indicate that the concentration of these proteins change with aging. Changes in the concentrations of these or 
other proteins may increase the rigidity of the postsynaptic membrane, which may result in resistance to antigenic modulation and subsequent internalization.

The results of this study show that the age-related resistance to EAMG is determined by resistance of the $\mathrm{AChR}$ to degradation, which may be related to differences in composition of the postsynaptic membrane in aged rats. Furthermore, these results suggest that susceptibility and clinical course of $\mathrm{MG}$ is not only determined by the immune attack towards the neuromuscular junction, but also by the target organ.

\section{Acknowledgements}

We are greatly indebted to Mr. S. Garbai for his help in CCD microscopy and software usage. We wish to thank Dr. B. Schutte for help and advice in confocal laser microsciopy. We also thank Mrs. M. Vroomen for excellent technical assistance, Dr. V. Witzemann for supplying the rat AChR $\varepsilon$-subunit cDNA probe and Dr. S. Tzartos for supplying mAb 35. We thank Prof. S. Fuchs for critical review of the manuscript and helpful discussions. This work was supported by grants from 'Het Prinses Beatrix Fonds", 'I'Association Française contre les Myopathies', Collège de France direction de recherches et études techniques (87/211) and EC Biomed (BMHI-CT93$1100)$.

\section{References}

1 Drachman B. Myasthenia gravis. N Engl J Med 1994; 330: 1797-1810.

2 Duclert A, Changeux J-P. Acetylcholine receptor gene expression at the developing neuromuscular junction. Physiol Rev 1995; 75:339-368.

3 Hall Z, Sanes J. Synaptic structure and development: the neuromuscular junction. Cell $1993 ; 72: 99-121$.

4 Lindstrom J, Seybold M, Lennon V, et al. Antibody to acetylcholine receptor in myasthenia gravis. Prevalence, clinical correlates and diagnostic value. Neurology 1976 ; 26: 1054-1059.

5 Roses A, Olanow W, McAdams M, et al. No direct correlation between serum antiacetylcholine receptor antibody levels and clinical state of individual patients with myasthenia gravis. Neurology 1981; 31:220-224. 
6 Verschuuren $\mathrm{J}$, Graus $\mathrm{Y}$, Theunissen $\mathrm{R}$, et al. Role of acetylcholine receptor antibody complexes in muscle in experimental autoimmune Myasthenia Gravis. J Neuroimmunol 1992; 36:117-125.

7 Garchon H-J, Djabiri F, Viard J-P, et al. Involvement of human muscle acetylcholine receptor $\alpha$-subunit gene (CHRNA) in susceptibility to myasthenia gravis. Proc Natl Acad Sci 1994; 91:4668-4672.

8 Guyon T, Levasseur P, Truffault F, et al. Regulation of acetylcholine receptor $\alpha$ subunit variants RNA in human myasthenia gravis. Quantification of steady-state levels of messenger RNA in muscle biopsy using the polymerase chain reaction. J Clin Invest 1994; 94:16-24.

9 Toyka K, Drachman DB Pestronk A, et al. Myasthenia Gravis: passive transfer from man to mouse. Science $1975 ;$ 190:397-399.

10 Tzartos S, Hochschwender S, Vasquez P, et al. Passive transfer of experimental autoimmune myasthenia gravis by monoclonal antibodies to the main immunogenic region of the acetylcholine receptor. J Neuroimmunol 1987; 15:185-194.

11 Asher $\mathrm{O}$, Neumann $\mathrm{D}$, Witzemenn $\mathrm{V}$, et al. Acetylcholine receptor gene expression in experimental autoimmune myasthenia gravis. FEBS Lett 1990; 267:231-235.

12 Asher O, Neumann D, Fuchs S. Increased levels of acetylcholine receptor $\alpha$-subunit mRNA in experimental autoimmune myasthenia gravis. FEBS Lett 1988; 233:277-281.

13. Asher $\mathrm{O}$, Kues $\mathrm{W}$, Witzemann $\mathrm{V}$, et al. Increased gene expression of acetylcholine receptor and myogenic factors in passively transferred experimental autoimmune myasthenia gravis. J Immunol 1993; 151:6442-6450.

14 Graus Y, Verschuuren J, Spaans F, et al. Age-related resistance to experimental autoimmune Myasthenia Gravis in rats. I Immunol 1993; 150:4093-4103.

15 Hoedemaekers A, Graus Y, van Breda Vriesman P, et al. Age- and sex-related resistance to experimental autoimmune myasthenia gravis in Brown Norway rats. Clin Exp Immunol 1997; 107: 189-197.

16 Hoedemaekers A, Graus $\mathrm{Y}$, Beijleveld $\mathrm{L}$, et al. Macrophage infiltration at the neuromuscular junction does not contribute to $\mathrm{AChR}$ loss and age-related resistance to EAMG. J Neuroimmunol 1997; 75:147-155.

17 Loutrari L, Kokla A, Tzartos S. Passive transfer of experimental myasthenia gravis via antigenic modulation of acetylcholine receptor. Eur J Immunol 1992; 22:2449-2452. Lennon V, Lindstrom $\mathrm{J}$, Seybold M. Experimental autoimmune myasthenia: a model of myasthenia gravis in rats and guinea pigs. J Exp Med 1975; 141:1365-1375.

19 Verschuuren J, Spaans F, De Baets M. Single-fiber electromyography in experimental autoimmune Myasthenia Gravis. Muscle Nerve 1990; 13:485-492. 
Lindstrom J, Lennon V, Seybold M, et al. Experimentail autoimmune Myasthenia Gravis and Myasthenia Gravis; Biochemical and immunochemical aspects. Ann NY Acad Sci $1976 ; 274: 254-274$.

21 Chomczynski $P$, Sacchi N. Single-step method of RNA isolation by acud guanidinium thiocyanate-phenol-chloroform extraction. Anal Biochem 1987; 162:156-159.

22 Klarsfeld $A$, Bessereau J-L, Salmon A-M, et al. An acetylcholine receptor $\alpha$-subunit promotor conferring preferential synaptic expression in muscle of transgenic mice. EMBO Journal 1991; 10:625-632.

23 Fontaine $\mathrm{B}$, Sassoon $\mathrm{D}$, Buckingham $\mathrm{M}$, et al. Detection of the nicotinic acetylcholine receptor $\alpha$-subunit mRNA by in situ hybridization at neuromuscular junctions of 15-dayold chick striulted muscles. EMBO J 1988; 7:603-609.

24 Liu E, Salpeter M. In situ hybridization and cytochemistry: localization of mRNA at stained neuromuscular junctions with 33P-labeled probes. J Histochem Cytochem 1994; 42: $1407-1411$.

25 Konstatinides $\mathrm{K}$, Rasure J. The Khoros software development environment for image and signal processing. IEEE Trans Image Proc 1994; 3:243-252.

Wilson S, Vincent A, Newsom-Davis J. Acetylcholine receptor turover in mice with passively transferred myasthenia gravis. I.Receptor degradation. I Neurol, Neurosurg Psychiatry 1983; 46:377-382.

27 Froehner S. Peripheral proteins of postsynaptic membranes from Torpedo electric organ identified with monoclonal antibodies. J Cell Biol 1984; 99:88-96.

James M, Man N, Wise C, et al. Utrophin-dystroglycan complex in membranes of adherent cultured cells. Cell Motility Cytoskeleton 1996; 33:163-174.

29 Sanes J. The synaptic cleft of the neuromuscular junction. Dev Biol 1995; 6:163-173.

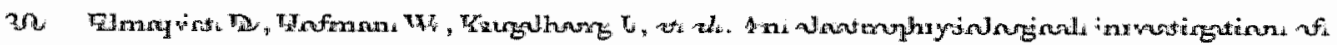
neuromuscular transmission in myasthenia gravis. J Physiol 1964; 174:417-434.

31 Stalberg E, Ekstedt J, Broman A. Neuromuscular transmission in myasthenia grawis studied with single fiber electromyography. J Neurol Neurosurg Psychiatry 1974; 37:540547.

32 Asher $O$, Fuchs $S$, Zuk D, et al. Changes in the expression of mRNAs for myogenic factors and other muscle-specific proteins in experimental autoimmune myasthenia gravis. FEBS 1992; 299:15-18.

33 Duclert A, Piette J, Changeux J-P. Influence of innervation on myogenic factors and acetylcholine receptor $\alpha$-subunit mRNA's. NeuroRepont $1991 ; 2: 25-28$.

34. Asher O, Provenzano C, Fuchs S. Regulation of acetylcholine receptor gene expression in rats treated with $\alpha$-bungarotoxim. FEBS 1991; 282:242-246.

35 Sandrock A, Dryer S, Rosen $\mathrm{K}$, et al. Maintenance of acetylcholine receptor number by neuregulins at the neuromuscular junction in vivo. Science $1997 ; 276: 599-603$. 
36 Tzartos $\mathrm{S}$, Barkas $\mathrm{T}_{*}$ Cung $\mathrm{M}$, et al. The main immunogenic region of the acetylcholine receptor. Structure and role in Myasthenia Gravis. Autoimmunity $1991 ; 8: 259270$.

37 Chang $C$, Huang $M$. Tumover of junctional and extrajunctional acetylcholine receptors of the rat diaphragm. Nature $1975 ; 253: 643-644$.

38 Courtney I, Steinbach J. Age changes in neuromuscular junction morphology and acetylcholine receptor distribution on rat skeletal muscle fibres. J Physiol 1981; 320:435447.

39 Wokke J, Jennekens F, van den Oord C, et al. Morphological changes in the human end plate with age. J Neurol Sci 1990; 95:291-310.

40 Shinitzky M, Barenholz Y. Fluidity parameters of lipid regions determined by fluorescence polarization. Biochim Biophys Acta 1978; 515:367.

41 Reist N, Werle M, McMahan U. Agrin released by motor neurons induces the aggregation of acetylcholine receptors at neuromuscular junctions. Neuron $1992 ; 8: 865-868$.

42 Porter B, Sanes J. Gated migration: neurons migrate on but not onto substrates containing s-laminin. Dev Biol 1995; 167:609-616.

43 Noakes $\mathrm{P}$, Gautam $\mathrm{M}$, Mudd $\mathbf{J}$, et al. Aberrant differentiation of neuromuscular junctions in mice lacking s-laminin/laminin $\beta 2$. Nature 1995; 374:258-262. 


\section{Summary and general discussion}

Experimental autoimmune myasthenia gravis (EAMG) is an animal model for the disease myasthenia gravis (MG). The antibody-mediated immune attack in MG and EAMG results in loss of acetylcholine receptor $(\mathrm{AChR})$ with destruction of the postsynaptic membrane and disturbance of the neuromuscular transmission. The pathogenic mechanisms leading to AChR loss in MG and EAMG include cross-linking of AChR by anti-AChR antibodies, complement-mediated focal lysis of the postsynaptic membrane and direct interference of anti-AChR antibodies with ligand binding.

Susceptibility and course of MG and EAMG are determined by both the immune attack and by the target organ. Clinical severity of disease correlates well with functional activities of anti-AChR antibodies, such as the capacity to reduce AChR function. In addition, a strong correlation between severity of disease and $A C h R$ degradation rates was found, using immunoglobulins from MG patients on cultured myotubes. Furthermore, the blocking of acetylcholine binding by antibodies correlated with the severity of disease. However, total antiAChR antibody titers, the amount of AChR complexed with antibody or AChR loss correllate poorly with the severity of neuromuscular dysfunction.

It has been shown that certain AChR haplotypes and a high frequency of microsatellite variants are associated with a higher susceptibility for MG. Furthermore, analysis of AChR $\alpha$ subunit mRNA concentrations in biopsies from MG patients revealed increased levels of $A C h R$ $\alpha$-subunit mRNA in severely affected patients, whereas no increase was found in moderately ill patients, independently of the anti-AChR antibody titers.

Aged rats are resistant to induction of EAMG. In this study possible factors underlying this age-related resistance were analyzed. The results of this study may elucidate factors determining susceptibility and severity of disease in MG patients. 
In Chapter 1 current facts about the structure and function of the neuromuscular junction (NMJ), MG and EAMG are reviewed. The NMJ plays a central role in the transmission of electrical impulses from nerve to muscle. The presynaptic axonal terminal releases the neurotransmitter acetylcholine which binds to $\mathrm{AChR}$ located at the tops of the postsynaptic junctional folds. The $\mathrm{AChR}$ is a transmembrane glycoprotein composed of 4 different subunits that form a pentameric structure around a central ionchannel. The $\alpha$-subunit contains both the acetylcholine binding site and the main immunogenic region (MIR) towards which the majority of the antibodies in MG and EAMG is directed. During development, the $\mathrm{AChR}$ accumulates at high density at the crests of the postsynaptic junctional folds. The specialized synaptic basal lamina and the postsynaptic membrane contain factors that are involved in clustering and anchoring of the $A C h R$ in the postsynaptic nembrane. The expression of the $A C h R$ genes is highly compartimentalized and restricted to the subsynaptic nuclei. The expression is under control of electrical activity and neural factors and is determined through DNA regulatory sequences in cis and by trans-acting nuclear factors (myogenic regulatory factors). Aging results in gradual changes in structure and function of the NMJ, skeletal muscle fibers and in levels of myogenic regulatory factors.

MG is an autoimmune disease characterized by muscular weakness and excessive fatigue as a result of loss of functional AChR. The loss of AChR is entirely antibody mediated. The antiAChR antibody production by $B$ cells is $T$ cell dependent, and involve Th1, Th2 or Tho subpopulations. Thymic abnormalities, including thymic hyperplasia and thymoma, are found in the majority of the MG patients. The thymus in both normal individuals and MG patients contain all components necessary to induce an autoimmune response including autoreactive $T$ cells, antigen presenting cells and the $A C h R$ protein, suggesting a role for this organ in the pathogenesis of the disease. The antibody mediated immune attack in MG results in loss of $A C h R$, simplification of the postsynaptic membrane and widening of the synaptic space. The diagnosis MG is based on clinical history, physical examination, presence of anti-AChR antibodies, and disturbances in neuromuscular transmission as measured by electromyography. Treatment consists of anticholinesterase drugs, immunosuppression and thymectomy. 
EAMG is a valid model for the disease MG. Chronic EAMG can be induced by active immunization with purified native $\mathrm{AChR}$ or with individual subunits or peptides. Passive transfer EAMG can be induced by passive transfer of polyclonal or monoclonal anti-AChR antibodies. MAbs that are directed against the MIR are very efficient in inducing EAMG. Several species are susceptible to EAMG. Within one species susceptibility has been shown to be determined by genetic factors, the available anti-AChR antibody repertoire and sex hormones. Similar to $M G$, the anti-AChR antibody production in EAMG is $\mathrm{T}$ helper cell dependent. The pathogenic mechanisms leading to AChR loss in MG and EAMG include cross-linking of $A C h R$ by antiAChR antibodies, complement-mediated focal lysis of the postsynaptic membrane, and direct interference of anti-AChR antibodies with ligand binding or donchannel function. Destruction of the postsynaptic membrane in MG and EAMG, and subsequent disturbed neuromuscular signal transmission, results in increased expression of the $\mathrm{AChR}$ subunit genes and increased $\mathrm{AChR}$ protein synthesis. Experimental therapies in EAMG include co-immunization with competitor peptides, induction of mucosal tolerance by nasal or oral AChR administration, manipulation of the idiotype anti-idiotype network and interference with binding of anti-AChR antibodies by high affinity Fab fragments.

In Chapter 2 the influence of age and sex on induction of chronic EAMG was analyzed in $B N$ rats. Aged male $B N$ rats, immunized with $t A C h R$, showed no clinical signs of disease or AChR loss. Immunization of young male $B N$ rats resulted in both clinical signs of disease and AChR loss. In contrast, both young and aged female BN rats showed comparable AChR loss, although aged female rats did not develop clinical signs of disease. In search for an immunologic cause, we analyzed possible differences in anti-AChR antibody titers, isotypes, specificity and complement deposition between susceptible and resistant rats.

Anti-rat AChR antibody titers remained lower in aged than in young female rats. In aged male rats boosted with $\mathrm{ACChR}$, anti-rat $A C h R$ antibody titers were simillar to young male myasthenic animals after a single injection, but they nevertheless failed to develop EAMG. The isotype distribution of the anti-tAChR antibody response proved to be similar in EAMG susceptible and resistant rats and was equally distributed among the $\operatorname{IgG1}, \operatorname{IgG} 2 \mathrm{a}$ and $\operatorname{IgG} 2 \mathrm{~b}$ 
isotypes, which are all capable of complement fixation. Immunohistochemical staining revealed comparable depositions of complement component $\mathrm{C} 3$ and membrane attack complex (MAC) in muscle biopsies, that coincided with the localization of AChR in both EAMG resistant and susceptible rats. Differences in antibody fine specificity between young and aged rats might result in the existence of a particular pathogenic anti-AChR antibody subset in young animals inducing EAMG. However, no differences in the proportion of senum antibodies that were directed against the MIR or $\alpha$-Bungarotoxin binding site were found between susceptible and resistant rats. In vitro antigenic modulation experiments with TE671 cells showed that sera from young susceptible and aged resistant rats were able to induce similar AChR loss.

These results show that resistance to EAMG is age and sex related. Furthermore, these results illustrate that resistance to EAMG is not the result of a deficiency in the immunological effector mechanisms in resistant aged rats.

The contribution of macrophages to the age-related resistance to EAMG was studied in Chapter 3. Induction of passive transfer EAMG in young susceptible rats is characterized by infiltration of the NMJ with macrophages. These macrophages are ED-1 positive and represent newly recruited exudate macrophages. Aged rats, resistant to $\mathrm{AChR}$ loss in passive transfer $\mathrm{EAMG}_{n}$ do not reveal infiltrating macrophages at the endplates. Aging is associated with a general decline in immune function, and macrophage function may be impaired in aged rats. Therefore, aged rats were reconstituted with bone marrow derived from young syngeneic donors prior to induction of passive transfer EAMG. However, this did not restore macrophage infilltration and did not abolish resistance to EAMG in aged rats.

To investigate whether macrophages are a primary cause of antibody mediated AChR loss or attracted to the NMJ secondary to tissue damage, young EAMG susceptible rats were lethally irradiated to deplete them from circulating leukocytes and bone-marrow derived precursor cells. Irradiation of rats, prior to induction of passive transfer EAMG, resulted in absence of ED-1 positive macrophages at the NMJ. However, macrophage depletion did not protect rats from clinical signs of disease or AChR loss. The predominant immune effector response in EAMG is antibody mediated and invollves activation of the lytic phase of the complement cascade. Despite 
the absence of infiltrating macrophages, depositions of MAC were found at all endplates of aged and irradiated young rats, indicating that the immunopathological effector mechanisms were operational and chemotactic factors for the attraction of macrophages were present.

The results of these experiments suggest that the absence of infiltrating macrophages in aged rats in passive transfer EAMG is not due to decreased macrophage function in these rats. More likely, the absence of AChR loss and muscle fiber necrosis, prevents chemotaxis of macrophages towards the NMJ. Furthermore, in susceptible rats macrophages do not contribute to $A C h R$ loss in the effector phase of $E A M G$, but are more likely a phenomenon secondary to AChR loss and tissue damage.

In Chapter 4 differences in susceptibility to EAMG between young and aged Lewis and BN rats were used to analyze factors determining clinical severity of disease. Susceptibility to EAMG was found to decrease with aging in both Lewis and BN rats. Resistance to clinical signs of disease and $\mathrm{AChR}$ loss, developed at an earlier age in BN rats than in Lewis rats. Aged female rats showed no clinical signs of disease despite significant $\mathrm{AChR}$ loss. The incidence and severity of muscular weakness were not proportional to the amount of AChR loss.

Aged rats showed significantly lower anti-rat $A C h R$ antibody titers compared to young rats and developed no, or only mild signs of muscular weakness. Sera from young and aged rats were tested in their ability to interfere with normal $A C h R$ function. Although sera from young susceptible rats inhibited normal AChR function significantly more than those of aged resistant rats, this difference was shown to be due to higher serum anti-AChR antibody titers. These results might suggest that resistance to EAMG in aged rats was related to lower anti-rat AChR antibady titers. This dose dependent effect of antibodies was also supported by the fact that aged rats were more susceptible to AChR loss in chronic EAMG, a condition in which the endplates are exposed to a higher concentration of antibody for a longer period of time, as compared to passive transfer EAMG. However, it has been shown previously that aged rats with similar anti-AChR antibody titers as young rats nevertheless fail to develop clinical signs of disease. Moreover, in individual young or aged rats no correlation was found between the clinical signs of disease and anti-AChR antibody titers. 
Neuromuscular transmission was found to change with aging as measured by single fiber electromyography (SFEMG). In Lewis rats jitters progressively decreased with age, suggesting that neuromuscular transmission is facilitated in aged Lewis rats. Aged female BN rats, however, showed signs of disturbed neuromuscular transmission before immunization. Upon immunization, jitter increased in young and aged Lewis rats and young BN rats; whereas the clinical resistant aged BN rats showed no significant increase in jitter values. Aging may have resulted in a dysfunction of neuromuscular transmission in aged BN rats, which in turn activated mechanisms at the level of the postsynaptic membrane, making the NMJ less susceptible to an antibody mediated attack.

These results indicate that the age-related susceptibility to EAMG is influenced by anti-rat AChR antibody titers. In addition, differences in pre-existing neuromuscular transmission properties may be involved in determining the clinical outcome in EAMG.

Chapter 5 describes the differential susceptibility of young and aged rat muscle to antibody mediated AChR degradation in EAMG. In the previous chapters it was shown that the age-related resistance to EAMG could not be attributed to deficiencies in the immune attack towards the NMJ in aged rats. It is therefore most likely that the resistance to EAMG in aged rats resides at the level of the target organ. Mechanisms that could account for this age-related resistance include a more efficient compensatory $\mathrm{AChR}$ neosynthesis in aged rats or resistance of the AChR protein to antibody mediated AChR degradation.

In MG and EAMG the antibody-mediated AChR degradation results in neuromuscular transmission defects, leading to increased transcription of $A C h R \alpha_{-}, \beta-, \varepsilon-$, and $\delta$-subunit genes. Induction of EAMG in resistant aged rats did not result in an increase in the amount of AChR $\alpha$ subunit mRNA, whereas the levels of AChR $\alpha$-subunit mRNA increased 3-fold in EAMG susceptible young rats, as measured by competitive RT-PCR. Denervation experiments indicated that aged rats retain the potential to increase $A C h R$ neosynthesis to a level comparable to that in young rats. In situ hybridization experiments indicated that the expression of $\alpha$-and $\varepsilon$-subunit genes remained restricted to synaptic areas in aged rats. Furthermore, no increase in synaptic expression of $\alpha$-and $\varepsilon$-subunit genes was observed in EAMG resistant aged rats, excluding the 
possibility of local compensatory $A C h R$ neosynthesis by subsynaptic nuclei. These results indicate that in EAMG resistant aged rats neuromuscular transmission is functional and electrical activity-dependent repression of extrasynaptic $A C h R$ gene expression is maintained.

In vivo AChR degradation experiments showed no loss of in vivo labelled $\mathrm{AChR}$ in EAMG resistant aged rats, whereas significant loss was measured in EAMG susceptible young rats. These results indicate that in aged rats the AChR protein in the postsynaptic membrane is resistant against antibody-mediated $A C h R$ degradation. Several proteins of the basal lamina and cytoskeleton play an important role in clustering and anchoring of AChR in the postsynaptic membrane. The relative amounts of rapsyn, s-laminin and agrin were found to change with aging. Changes in the composition of the postsynaptic membrame may increase the rigidity of the postsynaptic membrane, which may result in resistance to antigenic modulation and subsequent internalization.

The results of our study indicate that resistance to induction of EAMG in aged rats is determined by resistance of the AChR in the postsynaptic membrane to antibody-mediated degradation. Furthermore, induction of EAMG in aged rats is influenced by anti-rat antibody titers. The neuromuscular dysfunction in MG and EAMG is the result of a combination of several factors, including both the immune attack and the target organ. 



\section{Samenvatting en algemene discussie}

Myasthenia gravis (MG) is een autoimmuun ziekte waarbij autoantilichamen gericht zijn tegen acetylcholine receptoren $(\mathrm{AChR})$ die gelegen zijn op de overgang tussen zenuw/uiteinde en spiercelmembraan (neuromusculaire overgang). Verlies van functionele AChR leidt tot een verstoring van de signaaloverdracht tussen zenuwuiteinde en spiercelmembraan waardoor spierzwakte en verlamming ontstaan. Anti-AChR antilichamen veroorzaken dit verlies via tenminste 3 mechanismen: 1 . koppeling van naburige $\mathrm{AChR}$ moleculen door ("crosslinking") waardoor de internalisatie snelheid van de AChR sterk toeneemt; 2 activatie van het complement systeem met als gevolg focale lysis van de postsynaptische membraan; 3 . blokkade van de activatie van de $A C h R$ door anti-AChR antilichamen die de binding van de neurotransmitter acetylcholine verhinderen. Verstoring van de neuromusculaire signaaltransductie activeert ter hoogte van de neuromusculaire overgang een aantal mechanismen die het verlies van AChR compenseren. In het zenuwuiteinde neemt o.a. de hoeveelheid acetylcholine, nodig voor de overdracht van het elektrische signaal van zenuw naar spier, sterk toe. Ter hoogte van de AChR neemt de expressie van de genen die coderen voor de verschillende onderdelen ("subunits") van de $\mathrm{AChR}$ toe, om zo het verlies van $\mathrm{AChR}$ zo goed mogelijk te compenseren.

Experimentele autoimmuun myasthenia gravis (EAMG) is een proefdiermodel woor een aantal aspecten van de ziekte MG. EAMG kan in een groot aantal proefdiersoorten zoals ratten, muizen, konijnen en apen worden opgewekt. Men onderscheidt 2 proefdiermodellen: chronische (actieve) EAMG en passieve EAMG. Het opwekken van chronische EAMG gebeurt door immunisatie met $A C h R$, die gezuiverd zijn uit de elektrische organen van de elektrische rog Torpedo Californica. Ongeveer 4-6 weken na immunisatie onstaat door de gevormde antilichamen een chronische vorm van de ziekte met spierzwakte en verlies van AChR die vergelijkbaar is met de symptomen in MG patiènten. Het opwekken van de passieve vorm van 
EAMG gebeurt middels injectie van anti-AChR antilichamen in proefdieren ("passive transfer $\mathrm{EAMG}^{\prime \prime}$ ) en resulteert reeds bimnen 24-48 uur tot klinische verschijnselen van myasthenie en AChR verlies.

De gevoligheid woor EAMG werschilt zowel tussen verschillende species als ook binnen 1 species en wordt ondermeer door genetische factoren bepaald. Daarnaast blijkt de leeftijd van het proefdier een grote rol te spelen in de gevoeligheid voor het opwekken van EAMG. Het is gebleken dat oude ratten resistent zijn tegen opwekken van EAMG, dit in tegenstelling tot jonge ratten. In dit proefschrift worden de mogelijke mechanismen die aan deze resistentie ten grondslag liggen beschreven. Resultaten van dit proefschrift kunnen meer inzicht bieden in factoren die het verschil in gevoeligheid en ernst van de ziekte bij MG patiënten beînvloeden.

In Hoofdstuk 1 wordt een overzicht gegeven van de meest recente literatuur omtrent de structuur en functie van de neuromusculaire overgang, de autoimmuun ziekte MG en het proefdiermodel EAMG. Voorts wordt de invloed van leeftijd op de structuur en functie van de neuromusculaire overgang en op gewoeligheid en klinische ernst van de ziekte MG beschreven. $\mathrm{Bij}$ het ouder worden ontstaat een aantal morfologische veranderingen ter hoogte van de neuromusculaire overgang. De lengte van de postsynaptische membraan neemt toe, terwijl de postsynaptische plooiing in de membraan afneemt. Daarnaast bestaan er aanwijzingen dat de regulatic van de expressie van $A C h R$ genen verandert.

De incidentie van de ziekte MG vertoont een bimodale verdeling met een le piek tussen 20-29 jaar welke met name vrouwen betreft, en een 2 e piek tussen $70-79$ jaar waarbij mannen en vrouwen ongeveer gelijk zijn betroffen. Jonge vrouwen blijken derhalve gevoeliger voor de ziekte MG te zijn dan jonge mannen, wat een immuun-modulerende rol voor geslachtshormonen suggereert. In de literatuur zijn slechts weinig gegevens beschikbaar met betrekking tot de ernst en het verloop van de ziekte bij oudere MG patiënten. Uit analyse van een gering aantal studies blijkt dat ernst van de ziekte vergelijkbaar is tussen jonge en oude patiènten. Oudere patiënten vertonen echter een betere reactie op therapie dan jongere patiènten en vertonen een lagere mortaliteit. 
In Hoofdstuk 2 wordt de invloed van leeftijd en geslacht op de gevoeligheid voor chronische EAMG in Brown Norway (BN) ratten nader geanalyseerd. Oude mannelijke ratten vertonen geen tekenen van spierzwakte of $A C h R$ verlies na immunisatie met AChR. Jonge mannelijke ratten daarentegen ontwikkelen zowel spierzwakte als ook AChR verlies. Jonge en oude vrouwelijke ratten hebben een vergelijkbaar verlies van $A C h R$ in dit chronische model, echter alleen jonge vrouwelijke ratten vertonen klinische verschijnselen van spierzwakte. Een aantal factoren die aan deze leeftijds-gebonden resistentie ten grondslag kunnen liggen, zijn bestudeerd.

Anti-AChR antilichaam titers gemeten bij oude vrouwelijke ratten zijn lager dan bij jonge vrouwelijke ratten. Oude mannelijke ratten echter ontwikkelen antilichaam titers die vergelijkbaar zijn met die van jonge ratten, maar blijven desondanks ongevoelig voor de ziekte. Er bestaat geen verschil in de immunoglobuline isotype verdeling of in de fijne specificiteit van de anti-AChR antilichamen tussen gevoelige en resistente ratten. Bij histologisch onderzoek worden vergelijkbare afzettingen van de complement componenten C3 en C5-9 gevonden ter hoogte van de zenuwuiteinden van jonge en oude ratten. Antilichamen van jonge en oude ratten hebben voorts een vergelijkbare capaciteit om $\mathrm{AChR}$ te crosslinken en te internaliseren.

De resultaten van deze experimenten tonen aan dat gevoeligheid voor het opwekken van chronische EAMG beïnvloedt wordt door zowel leeftijd als geslacht van de ratten. De resistentie tegen het opwekken van EAMG is derhalve niet het gevolg van ontoerijkende in immunopathogene mechanismen die tot verlies van $A C h R$ leiden.

Hoofdstuk 3 omvat de mogelijke rol van macrofagen in de leeftijdsafhankelijke resistentie tegen EAMG. Opwekken van het passive transfer EAMG model bij jonge ratten gaat histologisch gepaard met infiltratie van de neuromusculaire overgangen door macrofagen. In oude, resistente ratten worden deze macrofaag infiltraten niet aangetroffen. Om uit te sluiten dat macrofagen in oude ratten minder functioneel zijn en zo resistentie tegen EAMG verklaren, zijn oude ratten bestraald met Röntgen straling om zo de circulerende witte bloedcellen (waaruit. macrofagen afkomstig zijn) te vernietigen. Deze witte bloedcellen van oude ratten zijn 
vervolgens vervangen door witte bloedcellen van genetisch identieke jonge ratten. Hiertoe is aan oude ratten een beenmergtransplantatie gegeven met beenmerg afkomstig van jonge donorratten. Ondanks de alanwezigheid van jonge macrofagen, blijven oude ratten resistent tegen het opwekken van passive transfer EAMG en worden er geen infilltrerende macrofagen gewonden ter hoogte van de neuromusculaire overgang in oude ratten.

On vast te stellen of macrofagen een primaire rol spelen bij het veroorzaken van $A C h R$ verlies in EAMG, zijn jonge EAMG gevoelige ratten bestralald met Röntgen straling om zo de circulerende witte bloedcellen te vernietigen. Bestraling van jonge ratten woorafgaand aan inductie van passive transfer EAMG resulteert in afwezigheid van macrofagen ter hoogte van de neuromusculaire overgang. Echter deze bestraalde ratten vertonen evenveel $A C h R$ verlies als niet bestraalde ratten.

Deze experimenten tonen aan dat afwezigheid van macrofagen niet de oorzaak is van de resistentie tegen passive transfer EAMG in oude ratten. Verder spelen macrofagen geen primaire rol bij het antilichaam-gemedieerde AChR verlies, maar zij worden waarschijnlijk secundair naar de neuromusculaire overgang aangetrokken om de ontstane weefselschade op te ruimen.

In Hoofdstuk 4 worden bestaande verschillen in gevoeligheid voor EAMG tussen jonge en oude ratten van 2 verschillende stammen gebruikt om factoren te analyseren die de ernst van de ziekte kunnen beinvloeden. Zowel bij Lewis als bij BN ratten neemt de gevoeligheid voor EAMG at met de leeftijd. Resistentie tegen EAMG onstaat in BN ratten op jongere leeftijd dan in Lewis ratten. Er bestaat geen directe correlatie tussen ernst van de klimische verschijnselen en mate van AChR verlies. Oude ratten hebben significant lagere anti-AChR antilichaam titers dan jonge ratten en ontwikkelen geen of slechts milde klinische verschijnselen. De capaciteit van deze antilichamen om rechtstreeks de AChR functie te blokkeren is hoger in jonge dan in oude ratten, maar dit verschil kan volledig worden toegeschreven aan verschillen in antilichaam titers. Deze resultaten suggereren dat anti-AChR antilichaam titers aan het verschil in gevoeligheid tussen jonge en oude ratten ten grondslag kunnen liggen. Echter, ook bij vergelijkbare anti-AChR antilichaam titers tussen jonge en oude ratten blijven oude ratten 
resistent tegen inductie van EAMG. Bovendien bestatat er geen relatie tussen emst van de spierzwakte en anti-AChR antilichaam titers.

De kwaliteit van de neuromusculaire signaal overdracht kan met single-fiber electromyografisch onderzoek (SFEMG) worden gemeten; de z.g. jitter is een maat voor de variatie van deze signaal overdracht. In Lewis ratten neemt de jitter progressief af met het toenemen van de leeftijd, wat een verbeterde neuromusculaire overdracht suggereert. In oude $\mathrm{BN}$ ratten daarentegen worden hogere jitter waarden gevonden dan in jonge ratten. Na immunisatie met AChR neemt in oude Lewis ratten de jitter toe, terwijl bij oude BN ratten geen verschil in neuromusculaire overdracht wordt gemeten. Mogelijk is er bij het ouder worden in BN ratten een compensatie mechanisme ontstaan ter hoogte van de zenuw-spier overgang dat beschermt tegen verder functieverlies.

Deze resultaten tonen aan dat de leeftijds-afhankelijke resistentie tegen EAMG wordt beïnvloedt door verschillen in anti-AChR antilichaam titers . Daarbij lijken verschillen in preexistente neuromusculaire overdracht kwaliteiten de klinische ernst van de ziekte mede te bepalen.

Hoofdstuk 5 omvat het verschil in gevoeligheid van het doelwitorgaan voor het opwekken van EAMG. Uit de voorgaande hoofdstukken is gebleken dat verschillen in het immunusysteen de resistentie tegen het opwekken van EAMG in oude ratten niet geheel kunnen verklaren. Het is thet meest waarschijilijk dat de resistentie door de $A C h R$ in de postsynaptische membraan wordt bepaald. Opwekken van EAMG in gevoelige ratten leidt tot toename van het. AChR boodschapper RNA (mRNA) welke een verhoogde synthese var AChR reflecteert. Meting van de totale AChR mRNA concentraties in spieren van oude ratten laat daarentegen geen toename zien. In spiercoupes van jonge en oude ratten is het mogelijk de AChR mRNA concentratie lokaal ter hoogte van de neuromusculaire overgang te meten. In oude ratten blijft de hoeveellheid mRNA gelijk na induceren van EAMG, terwijl in jonge ratten de hoeveelheid mRNA afneemt. Omdat er geen initieel verlies van AChR optreedt in oude ratten, betekent dit dat in oude ratten waarschijnlijk geen $A C h R$ neo-synthese plaatsvindt om eventueel verlies van AChR te compenseren. 
Om te bestuderen of de AChR zelf resistenter is tegen aforaak in oude ratten dan in jonge ratten, zün beide groepen geïnjecteerd met radioactief $\alpha$-Bungarotoxine. Dit slangegif bindt irreversibel aan de AChR om te worden gelabeld. Nadat het slangegif irreversibel gebonden heeft aan de AChR, wordt het passive transfer EAMG model in jonge en oude ratten opgewekt. In jonge ratten is een verlies van radioactief gelabelde AChR gemeten, terwijl in oude ratten geen verlies van gelabelde $A C h R$ plaatsvindt. Dit bewijst dat resistentie tegen EAMG in oude ratten veroorzaakt wordt door resistentie van de $A C h R$ op zïch, tegen antilichaam gemedieerde destructie. Met histologisch onderzoek zijn verschillen aangetoond in de eiwitsamenstelling van de postsynaptische membraan. Veranderingen in deze samenstelling kunnen mogelijk de verankering van de $\mathrm{AChR}$ of de rigiditeit van de membraan veranderen waardoor deze resistent wordt tegen internallisatie en degradatie.

Samengevat tonen de resultaten van deze studie aan dat resistentie tegen het opwekken van EAMG wordt bepaald door resistentie van de AChR in de postsynaptische membraan tegen antilichaam gemedieerde destructie. Daamaast wordt het verschil in gevoeligheid voor het opwekken van EAMG tussen jonge en oude ratten beïnvloedt door verschillen in anti-AChR antilichaam titers. Hieruit blijkt dat de neuromusculaire dysfunctie in MG en EAMG een resultante is van de combinatie van factoren die wordt bepaald door zowell het immunsysteem als ook door gevoeligheid van het doelwitorgan. 


\section{Publications}

Hoedemaekers A, Graus Y, van Breda Vriesman P, De Baets M. Age- and sex-related resistance to experimental autoimmune myasthenia gravis (EAMG) in Brown Norway rats. Clin Exp Immunol 1997; 107: 189-197.

Hoedemaekers A, Graus Y, Beijleveld L, van Breda Vriesman P, De Baets M. Macrophage infiltration at the neuromuscular junction does not contribute to AChR loss and age-related resistance to EAMG. J Neuroimmunol 1997; 75: 147-155.

Hoedemaekers A, Verschuuren J, Spaans F, Graus Y, Riemersma S, van Breda Vriesman P, De Baets M. Age-related resistance to experimental autoimmune myasthenia gravis: immunological and electrophysiological aspects. Muscle Nerve, in press.

Hoedemaekers A, van Breda Vriesman P, De Baets M. Myasthenia gravis as a prototype autoimmune receptor disease. Immunol Res, in press.

Hoedemaekers A, Bessereau J-L, Graus Y, Guyon T, Changeux J-P, Berrih-Aknin S, van Breda Vriesman P, De Baets M. Role of the target organ in determining susceptibility to experimental autoimmune myasthenia gravis. Ann Neurol, submitted.

Wauben M, Hoedemaekers A, Graus Y, van Breda Vriesman P, van Eden W, De Baets M. Inhibition of experimental autoimmune myasthenia gravis by major histocompatibility complex class II competitor peptides results not only in a suppressed but also in an altered immune response. Eur J Immunol 1996; 26: 2866-2875. 
Dankwoord

One oarsman on his own cannot win the Oxford and Cambridge boat race

Richard Dawkins, The selfish gene

Grape will ill, sander nomen te nomen. all menses heel harketigh be dam ken die. elk op hun ripen mize, en bojdrage hebben gelevend an de tot stand homing van dit profschift!

Astrid

147 


\section{Curriculum vitae}

Astrid Hoedemaekers werd geboren op 20 februari 1968 in Maastricht. In 1986 behaalde zij het Gymnasium $\beta$ diploma aan de scholengemeenschap Stella Maris te Meerssen. In datzelfde jaar startte zij met de studie geneeskunde aan de Rijksuniversiteit Limburg, alwaar zij in 1990 het doctoraal examen en in 1992 het artsexamen behaalde. Van november 1992 tot mei 1997 was zij werkzaam als assistent in opleiding in dienst van de Universiteit van Maastricht bij de vakgroep Immunologie. Onder leiding van Prof. Dr. P. vam Breda Vriesman en Dr. M. De Baets werd gedurende deze periode het onderzoek verricht beschreven in dit proefschrift. Tijdens deze periode werd een deel van het onderzoek uitgevoerd in het Institut Pasteur, Départment de Neurobiologie Moleculaire te Parijs (hoofd: Prof. Dr. J-P Changeux). Vanaf juli 1997 is zij werkzaam als arts-assistent in opleiding interne geneeskunde in het St. Joseph ziekenhuis te Veldhoven. 